\author{
UNIVERSIDADE DE SÃO PAULO \\ INSTITUTO DE QUÍMICA DE SÃO CARLOS \\ GRUPO DE FÍSICO-QUÍMICA ORGÂNICA
}

ELLEN RAPHAEL

ESTUDO DE ELETRÓLITOS POLIMÉRICOS À BASE DE AGAR PARA APLICAÇÃO EM DISPOSITIVOS

ELETROCRÔMICOS

SÃO CARLOS

2010 
ELLEN RAPHAEL

\section{ESTUDO DE ELETRÓLITOS POLIMÉRICOS À BASE DE AGAR PARA APLICAÇÃO EM DISPOSITIVOS ELETROCRÔMICOS.}

Tese apresentada ao Programa de PósGraduação em Química da Universidade de São Paulo, para a obtenção do título de doutor em Ciências, área de concentração: Físico-Química.

Orientadora: Prof $^{\mathrm{a}} \mathrm{Dr}^{\mathrm{a}}$ Agnieszka Joanna Pawlicka Maule 
A REPRODUÇÃO E DIVULGAÇÃO TOTAL OU PARCIAL DESTE TRABALHO, POR QUALQUER MEIO CONVENCIONAL OU ELETRÔNICO, PARA FINS DE ESTUDO E PESQUISA, DESDE QUE CITADA A FONTE.

Este exemplar foi revisado e alterado em
relação à versão original, sob a exclusiva
responsabilidade do autor.
São Carlos, 08 de fevereiro de 2011
Ellen Raphael


Dedico esta tese aos meus familiares, em especial ao meu avô Hermindo Rossi, símbolo de sabedoria, carinho e dedicação por todos da família. Um grande homem que me auxiliou muito em minha formação e representa parte do que sou.

In Memorian 


\section{AGRADECIMENTOS}

Durante o desenvolvimento desta tese, tive a oportunidade de contar com a colaboração e incentivo de muitas pessoas, que me auxiliaram das mais variadas formas, seja com a atenção em momentos que necessitei, ou com conhecimento sobre vários assuntos estudados, ou com seu trabalho técnico na operação de alguns equipamentos para a aquisição de dados, ou até mesmo com um ombro amigo nos momentos de dificuldade.

Primeiramente gostaria de agradecer a Deus que me deu o dom da vida, saúde e força para vencer mais esta etapa, que sempre esteve ao meu lado nos momentos difíceis e nos dias mais tranqüilos, que colocou em meu caminho pessoas tão maravilhosas que certamente fizeram parte em tudo que conquistei, além de ter me proporcionado momentos especiais e oportunidades, que certamente incluem a realização deste trabalho.

Agradeço de todo coração a Prof $^{a}$. Dra ${ }^{a}$ Agnieszka Pawlicka, por ter acreditado em mim ao confiar o desenvolvimento deste trabalho, por sua orientação tão importante desde o desenvolvimento do meu trabalho de mestrado até a conclusão desta tese de doutorado.

À CAPES pelo apoio financeiro que viabilizou esta tese.

Aos meus pais José Romeu Raphael e Roseli Rossi Raphael, por serem as pessoas mais importantes da minha vida e simplesmente por me apoiarem e me incentivarem a seguir meus objetivos desde meus quinze anos quando fui morar sozinha para dar início ao estudo da química, cursando o ensino técnico.

Aos grandes colegas de laboratório: Aline, Alessandra, Bruno, Cesar, Denise, Diogo, Éder, Franciani, Franciele, Gilmara, Marins, Lucas, Pamela, Ritarama, Rodrigo e Sarah, Pela ajuda que sempre me prestaram, pela amizade e companheirismo que neles encontrei.

Aos assistentes de pesquisa: Augusto, Luiz, Márcia, Mauro, Silvana, Vânia pela realização das análises instrumentais e pelas explicações.

E por último e não menos importante, gostaria de agradecer a todos meus amigos, a toda paciência que tiveram comigo, principalmente nos momentos difíceis e por muitas vezes compreenderem a dificuldade de assumir compromissos com eles nesses últimos anos. 
"A adversidade desperta em nós capacidades que, em circunstâncias favoráveis, teriam ficado adormecidas." 


\section{RESUMO}

Esta tese apresenta os resultados de estudo de eletrólitos poliméricos obtidos a partir de agar com o propósito de serem aplicados em dispositivos eletrocrômicos (ECDs). Modificações físico-químicas foram efetuadas no agar através da adição do plastificante glicerol, bem como de formaldeído, além da adição de uma fonte de prótons, a partir de ácido acético, ou uma fonte de íons, utilizando-se $\mathrm{LiClO}_{4}$, para promover a condutividade iônica dos filmes. Foram também preparadas blendas a partir de agar com gelatina, com quitosana e com poli(etileno dióxido de tiofeno):poli(estireno) (PEDOT:PSS) com o objetivo de se obter novos materiais alternativos, para serem utilizados como eletrólitos poliméricos. O estudo revelou que todas as membranas apresentaram-se homogêneas, com estabilidade térmica até $200^{\circ} \mathrm{C}$ e com a estrutura predominantemente amorfa, com valores de temperatura vítrea em torno de $-70{ }^{\circ} \mathrm{C}$ e transparência no visível de $90 \%$. $\mathrm{O}$ manuseio das amostras obtidas revelou boa maleabilidade e aderência ao vidro. Os valores de condutividade iônica das membranas variaram entre $1 \times 10^{-6} \mathrm{~S} / \mathrm{cm}$ e $1,1 \times 10^{-4} \mathrm{~S} / \mathrm{cm}$ dependendo da composição e quantidade de ácido ou sal de lítio adicionado. No caso das amostras onde foi adicionado PEDOT:PSS, os resultados de condutividade obtidos foram na ordem de $10^{-4} \mathrm{~S} / \mathrm{cm}$, no entanto as amostras apresentaram a transparência somente de $17 \%$. Foi feito um estudo preliminar, de aplicação dos melhores eletrólitos em ECDs revelando mudança de coloração entre o estado colorido e transparente de 25\%, reversível inserção de carga entre 11 e 5,0 $\mathrm{mC} / \mathrm{cm}^{2}$ e tempo de coloração de 15 segundos e de descoloração de $2 \mathrm{~s}$. 
Palavras-chave: Agar, Eletrólitos Poliméricos, Condutividade lônica, Dispositivos Eletrocrômicos. 


\section{ABSTRACT}

With the aim to develop new electrochromic devices (ECDs), we present a study on polymer electrolytes obtained from agar. Agar was submitted to physicochemical modifications by adding glycerol as plasticizer and formaldehyde; besides, to promote ionic conductivity of the films, a proton source such as acetic acid, or an ion source, $\mathrm{LiClO}_{4}$, were also added. Moreover new alternative materials to be used as polymer electrolytes composed by blends of agar with gelatin, chitosan and poly (ethylene dioxide thiophene):poly(styrene sulfonate) (PEDOT:PSS) were also prepared and characterized. The study revealed that the membranes were homogeneous, with thermal stability up to $200^{\circ} \mathrm{C}$ and predominantly amorphous. The glass transition values were found to be around $-70{ }^{\circ} \mathrm{C}$ and the transparency in the visible region of $90 \%$. The ionic conductivity values were in the range of $1 \times 10^{-6} \mathrm{~S} / \mathrm{cm}$ to $1.1 \times 10^{-4} \mathrm{~S} / \mathrm{cm}$, depending on composition and amount of added acid or salt. The ionic conductivity of the samples containing PEDOT:PSS were of the order of $10^{-4}$ S/cm, however, the corresponding transparencies were found to be about $17 \%$, only. A preliminary study to qualify the performance of our best electrolytes in ECDs have shown a color change of $25 \%$, reversible inserted charge of 5 to $11 \mathrm{mC} / \mathrm{cm}^{2}$ and coloring/bleaching times of 15 and 2 seconds, respectively.

Keywords: Agar, Polymer Electrolytes, Ionic Conductivity, Electrochromic Devices. 


\section{LISTA DE FIGURAS}

Figura 1 - Modos de solvatação dos cátions $\left(\mathrm{Li}^{+}\right)$pelos átomos de oxigênio de uma cadeia polimérica de PEO: (a) solvatação por uma única cadeia; (b) solvatação por duas cadeias ${ }^{12}$.

Figura 2 - Unidade repetitiva presente no $\operatorname{agar}^{48}$.

Figura 3- llustração da forma de coordenação do lítio com o oxigênio presente no agar.

Figura 4 - Esquema de uma janela eletrocrômica ${ }^{65}$.

Figura 5 - Célula utilizada na realização da análise de espectroscopia de impedância eletroquímica.

Figura 6 - Célula de medida dentro do forno - sistema utilizado na realização da análise de espectroscopia de impedância eletroquímica.

Figura 7 - Células fechadas utilizadas na realização da análise de espectroscopia de impedância, com umidade controlada.

Figura 8: Gráfico de viscosidade reduzida versus concentração das diferentes soluções de agar utilizadas na análise viscosimétrica.

Figura 9: Espectro de FT-IR do agar.

Figura 10 - Difratograma de raios-X para o agar.

Figura 11 - Curvas de TGA dos filmes contendo diferentes quantidades de ácido acético (\% em massa).

Figura 12 - Curva de DSC dos filmes contendo diferentes quantidades de ácido acético (\% em massa)..

Figura 13 - Log $\sigma$ em função da concentração de ácido acético.

Figura 14 - Impedância complexa para o eletrólito com 50\% de ácido acético a diferentes temperaturas.

Figura 15 - Log da condutividade em função da temperatura para filmes com diferentes quantidades de ácido acético (\% em massa).

Figura 16 - Energia de ativação versus concentração de ácido acético.

Figura 17: Janela de estabilidade eletroquímica do filme de agar com $50 \%$ de ácido acético a temperatura de $32,8^{\circ} \mathrm{C}$.

Figura 18 - Condutividade iônica dos filmes com 33\% de umidade relativa.

Figura 19 - Espectros de UV-vis para eletrólitos com diferentes concentrações de ácido acético(\%).

Figura 20 - Difração de raios- $X$ de filmes contendo diferentes quantidades de ácido acético.

Figura 21 - Micrografias dos filmes de agar com diferentes quantidades de ácido acético, ampliadas 1000x.

Figura 22: Transmitância dos DECs para o filme de agar com ácido acético $50 \%$ em massa. 
Figura 23: Densidade de carga para o DEC com eletrólito a base de agar com ácido acético $50 \%$ em massa.

Figura 24: Voltamograma para o DEC com eletrólito a base de agar com ácido acético $50 \%$ em massa.

Figura 25 - Curvas de TGA dos filmes contendo diferentes quantidades de $\mathrm{LiClO}_{4}$ (\% em massa).

Figura 26 - Curva de DSC dos filmes contendo diferentes quantidades de $\mathrm{LiClO}_{4}$.

Figura 27 - Gráfico de impedância complexa para os filmes com diferentes concentrações de perclorato de lítio (\% em massa)

Figura 28 - Log $\sigma$ em função da concentração de $\mathrm{LiClO}_{4}$.

Figura 29 - Log da condutividade em função da temperatura para filmes com diferentes quantidades de sal de lítio (\% em massa)

Figura 30 - Ajuste do modelo VTF para determinação das energias de ativação aparentes.

Figura 31 - Energia de ativação aparente versus concentração de perclorato de lítio.

Figura 32 - Janela de estabilidade eletroquímica do filme de agar com 17\% $\mathrm{LiClO}_{4}$ a temperatura de $30,2{ }^{\circ} \mathrm{C}$.

Figura 33 - Espectros de UV-vis para filmes preparados com diferentes concentrações de sal de lítio (\% em massa)

Figura 34 - Difração de raios- $X$ de filmes contendo diferentes quantidades de ácido acético - (a) filmes amorfos (b) filmes com cristalização do $\mathrm{LiClO}_{4}$.

Figura 35 - Micrografias dos filmes de agar com diferentes quantidades de $\mathrm{LiClO}_{4}$, ampliadas 1000x.

Figura 36: Transmitância dos DECs para o filme de agar com $\mathrm{LiClO}_{4}$ 17\% em massa.

Figura 37: Densidade de carga para o DEC com eletrólito a base de agar com $\mathrm{LiClO}_{4}$ 17\% em massa.

Figura 38: Voltamograma para o DEC com eletrólito a base de agar com $\mathrm{LiClO}_{4} 17 \%$ em massa.

Figura 39 - Curvas de TGA dos eletrólitos a base de blendas de agar.

Figura 40. - Curvas de DSC dos filmes preparados das duas blendas.

Figura 41. Representação da interração de agarose e agaropectina com as cadeias de quitosana.

Figura 42 - Representação da interação da agarose e agaropectina com o fragmento da macromolécula de gelatina.

Figura 43 - Log da condutividade em função da temperatura para filmes com diferentes blendas.

Figura 44 - Log da condutividade em função da temperatura para eletrólito a base de agar e de blendas de agar.

Figura 45 - Espectros de UV-vis para filmes a base de blendas de agar. 
Figura 46 - Difração de raios- $X$ dos filmes a base de blendas de agar.

Figura 47 - Micrografias dos filmes a base de blendas de agar: (a) agarquitosana e (b) agar-gelatina, ampliadas 1000x.

Figura 48: Transmitância dos DECs para o filme de blenda de agar com quitosana.

Figura 49: Densidade de carga para o DEC com eletrólito a base blenda de agar com quitosana.

Figura 50: Voltamograma para o DEC com eletrólito a base de blenda de agar com quitosana.

Figura 51: Transmitância dos DECs para o filme de blenda de agar com gelatina.

Figura 52: Densidade de carga para o DEC com eletrólito a base blenda de agar com gelatina.

Figura 53: Voltamograma para o DEC com eletrólito a base de blenda de agar com quitosana.

Figura 54 - Representação química do sistema PEDOT:PSS.

Figura 55 - Log $\sigma$ para os eletrólitos a base de agar com PEDOT:PSS com diferentes quantidades de $\mathrm{LiClO}_{4}$.

Figura 56 - Log $\sigma$ para os eletrólitos a base de agar com PEDOT:PSS e com quantidade fixa de $\mathrm{LiClO}_{4}$.

Figura 57 - Log $\sigma$ para os eletrólitos a base de agar com PEDOT:PSS e ácido acético.

Figura 58 - Log da condutividade em função da temperatura para o eletrólito a base de agar, com e sem adição de PEDOT:PSS, ambos contendo 0,2g de $\mathrm{LiClO}_{4}$.

Figura 59 - Log da condutividade em função da temperatura para o eletrólito a base de agar, com e sem adição de PEDOT:PSS, ambos contendo $1,5 \mathrm{~g}$ de ácido acético.

Figura 60 - Curvas de TGA dos filmes contendo $\mathrm{LiClO}_{4}$ e diferentes quantidades de glicerol e PEDOT :PSS.

Figura 61 - Curvas de TGA dos filmes contendo ácido acético e diferentes quantidades de glicerol e PEDOT (\% em massa).

Figura 62 - Difração de raios-X de filmes contendo diferentes quantidades de ácido acético.

Figura 63 - Difração de raios- $X$ de filmes contendo diferentes quantidades de ácido acético.

Figura 64 - Curva de DSC do eletrólito a base de agar com $\mathrm{LiClO}_{4}$ e PEDOT:PSS.

Figura 65 - Micrografias dos filmes de agar com diferentes quantidades de ácido acético, ou $\mathrm{LiClO}_{4}$, ampliadas 1000x.

Figura 66 - Espectros de UV-vis para eletrólitos a base de agar com adição de PEDOT:PSS 


\section{LISTA DE TABELAS}

Tabela 1 - Propriedades físico-químicas de alguns sais e ácido acético

Tabela 2: Composição química do agar utilizado no preparo das membranas

Tabela 3: Valores de condutividades e energia de ativação para os eletrólitos a base de agar e a base de blendas de agar Tabela 4: Valores de condutividades e energia de ativação para os eletrólitos a base de agar e a base de blendas de agar com quitosana e com gelatina.

Tabela 5: Composição dos diferentes eletrólitos a base de agar com PEDOT preparados

Tabela 6: Valores de condutividades e energia de ativação para os

eletrólitos a base de agar e a base de agar com PEDOT:PSS, ambos contendo 2,0g de $\mathrm{LiClO}_{4}$.

Tabela 7: Valores de condutividades e energia de ativação para os

eletrólitos a base de agar e a base de agar com PEDOT:PSS, ambos contendo $1,5 \mathrm{~g}$ de ácido acético. 


\section{LISTA DE ABREVIATURAS E SIGLAS}

PEO : poli(óxido de etileno)

MEEP-(LiX)n: poli[bis-(dimetiletoxi)fosfazeno)]

ESPs: Eletrólitos Sólidos Poliméricos

PEGDME: poli(etilenoglicol) dimetil éter

VTF: Vogel-Tammam-Fulcher

WLF: Willians-Landel-Ferry

PTMG: poli(tetrametileno glicol)

PEG: poli(etileno glicol)

GPTS: glicidopropiltrimetóxisilano

GLYMO: glicidilpropiltrimetóxisilano

HEC: hidroxietilcelulose

HPC: hidroxipropilcelulose

PMMA: poli(metacrilato de metila)

IUPAC: União Internacional de Química Pura e Aplicada

TG: análise termogravimétria 
$T_{g}$ : temperatura de transição vítrea

DSC: calorimetria diferencial de varredura

PVC: poli(cloreto de vinila)

CT: um condutor transparente

ITO: óxido de estanho dopado com índio

FTO: óxido de estanho dopado com flúor

CE: filme eletrocrômico (eletrodo de trabalho constituído por filme fino de $\mathrm{WO}_{3}$ )

Cl: condutor iônico

RI: filme reservatório dos íons ou contra-eletrodo

PEDOT: poli(3,4-etileno dioxitiofeno)

PSS: poli(estireno sulfonato)

DECs: dispositivos eletrocrômicos

EPGs: eletrólitos poliméricos géis 


\section{SUMÁRIO}

CAPÍTULO 1 - INTRODUÇÃO 20

1.1-Polímeros condutores $\quad 20$

1.2 - Eletrólitos poliméricos $\quad 21$

1.3 - Polímeros Naturais $\quad 27$

1.4 - Eletrólitos poliméricos a base de polímeros naturais 28

1.5 - Agar 34

1.6 - Plastificantes 35

1.7 - Sais e Ácidos 38

1.8- Dispositivos eletrocrômicos 39

CAPÍTULO 2 - OBJETIVOS 50

CAPÍTULO 3 - MATERIAIS E MÉTODOS 51

3.1 - Caracterização do Agar 51

3.1.1 - Análise Elementar 51

3.1 .2 - Análise Viscosimétrica 51

3.1.3 - Espectroscopia no Infravermelho - FT-IR 51

3.2 - Preparo dos Eletrólitos 52

3.2.1 - Preparos dos Eletrólitos de Agar 52

3.2.2 - Preparos dos Eletrólitos de Blendas de Agar com Gelatina 52

3.2.3 - Preparos dos Eletrólitos de Blendas de Agar com Quitosana 53

3.2.4 - Preparos dos Eletrólitos de Agar com PEDOT:PSS 53

3.3 - Caracterização dos Filmes 54

3.3.1 - Análise Termogravimétrica (TG) 54

3.3.2 - Calorimetria Diferencial de Varredura (DSC) 54

3.3.3 - Espectroscopia de Impedância Eletroquímica (EIE) 55

3.3.4 - Espectroscopia de Impedância Eletroquímica (EIE) com 57

Umidade Controlada.
3.3.5 - Espectroscopia no Ultravioleta-Visível (UV-vis)

3.3.6 - Difração de Raios-X 58

3.3.7 - Microscopia Eletrônica de Varredura (MEV) 58

3.4 - Dispositivos Eletrocrômicos 58

3.4.1 - Montagem dos Dispositivos Eletrocrômicos 58

3.4.2 - Voltametria Cíclica e Cronoamperometria 60 
CAPÍTULO 4 - CARACTERIZAÇÃO DO AGAR: RESULTADOS E 61 DISCUSSÕES

4.1 - Análise Elementar $\quad 61$

4.2 - Determinação de Massa Molar do Agar por Técnica 62

Viscosimétrica

4.1.3 - Análise Espectroscópica - FT-IR 64

4.1.4 - Difração de Raios-X 65

CAPÍTULO 5 - CARACTERIZAÇÃO DOS ELETRÓLITOS DE ÁGAR 68

COM ÁCIDO ACÉTICO - RESULTADOS E DISCUSSÕES.

5.1 - Análise Termogravimétrica (TG) 68

5.2 - Calorimetria Diferencial de Varredura (DSC) 70

5.3 - Espectroscopia de Impedância Eletroquímica (EIE) 71

5.4 - Espectroscopia de Impedância Eletroquímica (EIE) com Umidade 76 Controlada.

5.5 - Espectroscopia no Ultravioleta-Visível (UV-vis) 77

5.6 - Difração de Raios-X 78

5.7 - Microscopia Eletrônica de Varredura (MEV) 79

5.8 -Dispositivos Eletrocrômicos $\quad 80$

5.9 - Conclusões do Capítulo 83

CAPÍTULO 6 - CARACTERIZAÇÃO DOS ELETRÓLITOS DE ÁGAR 87

COM LiClO ${ }_{4}$ - RESULTADOS E DISCUSSÕES.

6.1 - Análise Termogravimétrica (TG) 87

6.2 - Calorimetria Diferencial de Varredura (DSC) 89

6.3 - Espectroscopia de Impedância Eletroquímica (EIE) 90

6.4 - Espectroscopia no Ultravioleta-Visível (UV-vis) 96

6.5 - Difração de Raios-X $\quad 97$

6.6 - Microscopia Eletrônica de Varredura (MEV) 98

6.7 - Dispositivos Eletrocrômicos $\quad 99$

6.8 - Conclusões do Capítulo 102

CAPÍTULO 7 - CARACTERIZAÇÃO DOS ELETRÓLITOS A BASE DE 106

BLENDAS DE POLÍMEROS NATURAIS: AGAR-GELATINA E AGAR-

QUITOSANA - RESULTADOS E DISCUSSÕES.

$\begin{array}{ll}7.1 \text { - Análise Termogravimétrica (TG) } & 107\end{array}$

7.2 - Calorimetria Diferencial de Varredura (DSC) 108

7.3 - Espectroscopia de Impedância Eletroquímica (EIE) 111

7.4 - Espectroscopia no Ultravioleta-Visível (UV-vis) 114

7.5 - Difração de raios-X 116 
7.6 - Microscopia Eletrônica de Varredura (MEV)

7.7 - Dispositivos Eletrocrômicos

7.8 - Conclusões do Capítulo

CAPÍTULO 8 - CARACTERIZAÇÃO DOS ELETRÓLITOS DE ÁGAR 128 COM PEDOT:PSS - RESULTADOS E DISCUSSÕES.

8.1 - Espectroscopia de Impedância Eletroquímica (EIE) 130

8.2 - Análise Termogravimétrica (TG) 135

8.3 - Difração de Raios-X 136

8.4 - Calorimetria Diferencial de Varredura (DSC) 138

8.5 - Microscopia Eletrônica de Varredura (MEV) 139

8.6 - Espectroscopia no Ultravioleta-Visível (UV-vis) 140

8.7 - Conclusões do Capítulo 142

CAPÍTULO 9 - CONCLUSÕES FINAIS 146 


\section{CAPÍTULO 1 - INTRODUÇÃO}

\section{1- Polímeros condutores}

Os polímeros têm sido extensivamente utilizados na indústria devido à facilidade de processamento e a versatilidade de suas aplicações. São também materiais que apresentam vantagens na resistência à corrosão, leveza, tenacidade, durabilidade, dentre outros fatores. Outro ponto determinante na opção pelo uso dos polímeros é seu custo reduzido em relação aos demais materiais, fator que reflete no custo do produto final ${ }^{1}$.

Desde a descoberta dos polímeros no começo do século XX, sua utilização levou em conta a propriedade isolante. É consenso assumir que os materiais inorgânicos e os semicondutores se adaptam melhor para aplicações que requerem elevados valores de condutividade elétrica; os polímeros, entretanto, são mais explorados em aplicações que demandam propriedades isolantes ${ }^{2}$. Já em anos setenta do século passado, as diferentes necessidades industriais, ligadas a produção e estocagem de energia, incentivaram pesquisas que demonstraram que os polímeros são capazes de conduzir elétrons ou íons. As novas descobertas de Allan MacDiarmid, Allan Heeger e T.Shirakawa ${ }^{4-6}$, agraciados pelo prêmio Nobel em 2000 projetaram seu uso em aplicações modernas, substituindo metais e cerâmicas. Desta forma, a visão quanto às aplicações dos polímeros na indústria sofre rápida ampliação. As novas pesquisas nesta área despertam atenção tanto de indústrias quanto de instituições de ensino e pesquisa, em consideração aos avanços alcançados nas últimas décadas, propondo novas rotas de síntese e de processamento. Recentes pesquisas têm descoberto novos materiais poliméricos 
com grande variedade de propriedades elétricas e ópticas, antes observadas apenas em sistemas inorgânicos ${ }^{2-4}$.

Existem várias classes de polímeros condutores. A classe dos polímeros condutores eletrônicos é bastante distinta e caracterizada pela presença de ligações duplas conjugadas e de substâncias dopantes tais como sais inorgânicos $\mathrm{FeCl}_{3}$, $\mathrm{AlCl}_{3}$ ou $\mathrm{I}_{2}$ permitindo a condução elétrica. Outra classe de polímeros com propriedades não isolantes são polímeros condutores iônicos descobertos pelo Peter Wright $^{5}$ em 1973 e pesquisados pelo Michel Armand ${ }^{6}$ a partir de 1978. Estes polímeros se caracterizam pelo fato de ter na sua estrutura átomos com pares de elétrons livres, no caso oxigênio, que possibilitam a interação com alguns sais inorgânicos mono ou divalentes como $\mathrm{LiClO}_{4}$ ou $\mathrm{Ca}\left(\mathrm{CF}_{3} \mathrm{SO}_{3}\right)_{2}$, entre outros. O principal exemplo desta categoria é o poli(óxido de etileno), $\mathrm{PEO}^{3-5}$, que da mesma maneira como líquido consegue dissolver os sais mencionados. Estes polímeros também, podem apresentar comportamento elétrico, óptico e magnético semelhante aos metais e semicondutores inorgânicos, em combinação com as propriedades mecânicas e a processabilidade dos polímeros convencionais ${ }^{2,5}$.

\section{2 - Eletrólitos poliméricos}

Recentemente, muita atenção tem sido demonstrada aos estudos de eletrólitos poliméricos. Esses eletrólitos consistem de um ácido ou sal disperso numa matriz polimérica a qual pode conduzir elétrons ou íons e são uma alternativa eficiente para substituir os eletrólitos líquidos e cristais inorgânicos ${ }^{3,4}$.

A aplicação desses materiais está em diversas áreas como, desenvolvimento espacial, novos tipos de memória e arquitetura de computadores, baterias, células solares, sensores, janelas eletrocrômicas e fotocrômicas. Para sua utilização no 
eletrólito, o polímero deve possuir características como: caráter amorfo, capacidade de solvatar íons, baixa temperatura de transição vítrea, estabilidade eletroquímica e dimensional, resistência mecânica e possibilidade de formar filmes finos ou pastilhas $^{7,8}$

O sucesso no preparo dos eletrólitos poliméricos com ótimos valores de condutividade está amplamente relacionado com o uso de estruturas que melhorem a mobilidade e a concentração dos portadores de carga. Para promover a mobilidade de elétrons ou íons nesses eletrólitos é necessária a introdução de substâncias tais como sais inorgânicos $\left(\mathrm{LiClO}_{4}, \mathrm{NaClO}_{4}, \mathrm{LiCF}_{3} \mathrm{SO}_{3}, \mathrm{LiBF}_{4}\right.$, por exemplo) ou a adição de ácidos, fornecedores de prótons $\left(\mathrm{H}^{+}\right)^{8}$.

Era de se esperar que o aumento da quantidade de sal ou ácido na matriz polimérica levasse ao aumento na condutividade iônica, porém estudos já realizados mostraram que os valores de condutividade iônica para os eletrólitos a base de polímeros aumentam até um valor limite conforme ocorre à inserção de íons. Após o máximo formam-se agregados iônicos os quais diminuem a condutividade devido ao aumento da viscosidade e da temperatura de transição vítrea do polímero ${ }^{9}$.

A natureza do sal também influência na condutividade iônica dos eletrólitos, geralmente, os sais de lítio com ânions de grande volume e com baixas energias reticulares, como $\mathrm{LiClO}_{4}, \mathrm{LiBF}_{4}, \mathrm{LiCF}_{3} \mathrm{SO}_{3}$ e $\mathrm{LiN}\left(\mathrm{SO}_{2} \mathrm{CF}_{2}\right)_{2}$ (LISCN) levam a altas condutividades quando comparados com os sais de haletos $\mathrm{LiCl}$ e $\mathrm{LiBr}$ que possuem maior energia reticular ${ }^{10-11}$.

No caso do MEEP-(LiX)n poly[bis-(dimetiletoxi)fosfazeno)] Shriver e colaboradores $^{12}$ constataram que a condutividade aumenta com a diminuição da energia reticular do sal. Por exemplo, $\mathrm{LiBF}_{4}$ que apresenta uma energia reticular de $699 \mathrm{~kJ} / \mathrm{mol}$, possui uma alta condutividade comparada com o LiSCN com uma 
energia reticular de $807 \mathrm{~kJ} / \mathrm{mol}$. Entretanto, como o $\mathrm{LiClO}_{4}$ possui uma energia reticular de $723 \mathrm{~kJ} / \mathrm{mol}$, o valor da condutividade não apresenta uma grande diferença entre $\mathrm{LiBF}_{4}$ e $\mathrm{LiClO}_{4}$, pois as energias reticulares são próximas.

A explicação mais aceita para a solvatação dos sais por matrizes poliméricas é demonstrada na Figura 1 onde os cátions $\mathrm{Li}^{+}$, formados na dissociação do sal, coordenam-se com as espécies capazes de solvatá-los, i.e., átomos doadores de elétrons como, por exemplo, os oxigênios presentes na cadeia polimérica do PEO. Também estes átomos demonstram-se como os melhores candidatos, pois solvatam adequadamente as espécies responsáveis pela condução.

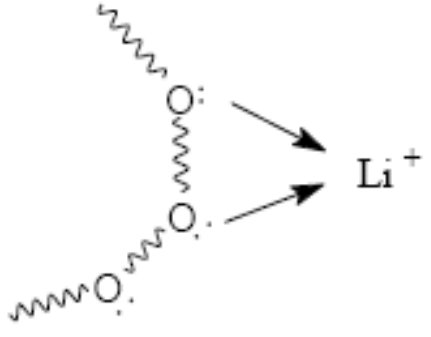

(a)

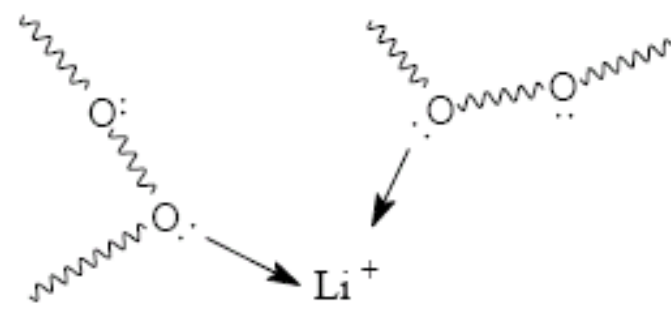

(b)

Figura 1 - Modos de solvatação dos cátions ( $\mathrm{Li}+)$ pelos átomos de oxigênio de uma cadeia polimérica de PEO: (a) solvatação por uma única cadeia; (b) solvatação por duas cadeias ${ }^{12}$.

Outra maneira de melhorar a condutividade nos ESPs é a utilização de plastificantes como o glicerol, sorbitol, etileno glicol, etc, já que estes aumentam a mobilidade dos portadores de carga no polímero, diminuindo a temperatura de transição vítrea $\left(\mathrm{T}_{\mathrm{g}}\right)$. $\mathrm{O}$ plastificante também permite maior flexibilidade e movimentação das cadeias do polímero e ainda possui capacidade de separação de cargas, diminuindo a chance de formação de pares iônicos que pode prejudicar a condutividade iônica do eletrólito. Essa capacidade está relacionada com a constante dielétrica do plastificante, assim quanto maior ela for, maior será a habilidade deste em separar cargas $^{8}$. 
O trabalho de Kelly e colaboradores ${ }^{10}$, demonstram que a condutividade do PEO- $\left(\mathrm{LiCF}_{3} \mathrm{SO}_{3}\right.$ ) pode ser aumentada para $10^{-4} \mathrm{~S} / \mathrm{cm}$ a $40^{\circ} \mathrm{C}$, com a adição de $20 \%$ de poli(etilenoglicol) dimetil éter (PEGDME). Como o PEGDME é um éter de baixa constante dielétrica $(\varepsilon=7)$, ou seja, da mesma magnitude do PEO, não se espera um ganho significativo nos portadores de cargas. Assim, o aumento da condutividade pode ser atribuído ao aumento da mobilidade dos portadores de carga provocados pelo plastificante. Já o plastificante carbonato de propileno (PC) tem uma constante dielétrica de 64,4, muito maior do que o PEO. Desta maneira, a sua adição no poli(óxido de etileno) pode favorecer, além de aumento da mobilidade iônica, também um aumento nos portadores de cargas $^{8,9}$.

Uma das propriedades mais citadas para eletrólitos sólidos poliméricos é o comportamento da condutividade iônica das amostras em função da temperatura. Essa dependência fornece as informações sobre os mecanismos que governam a condutividade iônica. Quando a movimentação dos íons não resulta do compartilhamento da movimentação do polímero (matriz), ou seja, os íons "saltam" de um sítio de solvatação para outro, há um comportamento da condutividade em função da temperatura do tipo Arrehenius. O modelo de Arrhenius pode ser expresso através da equação (1):

$$
\sigma=A \exp (-E a / R T)
$$

onde Ea é a energia de ativação, A um fator pré-exponencial e $R$ é a constante dos gases ideais $(8,31441 \mathrm{~J} / \mathrm{mol} \mathrm{K})$. Tendo os valores de condutividade para diferentes temperaturas é possível obter a energia de ativação do sistema estudado.

Entretanto, quando o transporte dos íons ocorre com o auxílio dos movimentos da cadeia polimérica da matriz onde o sal é dissolvido, há um comportamento do tipo VTF (Vogel-Tammam-Fulcher) ${ }^{13,14}$ ou WLF (Willians-Landel- 
Ferry $)^{15}$. Nesses modelos a temperatura de transição vítrea está intimamente relacionada com a mobilidade conformacional das cadeias poliméricas que, por sua vez, estão relacionadas à mobilidade iônica. Abaixo da temperatura de transição vítrea a mobilidade da cadeia é comprometida e várias propriedades macroscópicas do material mudam drasticamente. A dedução da equação VTF consta de três parâmetros, $\sigma, T_{0}$ e A. Para sistemas com diferentes concentrações, reticulados ou não e com diferentes sais é descrita pela equação $(2)^{16}$ :

$$
\sigma=\mathrm{A} / \mathrm{T}^{1 / 2} \exp \left[-\Delta \mathrm{E} /\left(\mathrm{T}-\mathrm{T}_{0}\right)\right]
$$

onde, $\mathrm{A}$ - é o fator pré-exponencial referente ao número de transporte iônico a dada temperatura $\mathrm{T} ; \Delta \mathrm{E}$ - pseudo energia de ativação e $\mathrm{T}_{0}$ é um valor característico do condutor iônico, ou seja, $T_{0}=T_{g}-50 K$, onde $T_{g}$ é a temperatura de transição vítrea, determinada pela técnica de análise térmica. A partir do gráfico $\ln \left(\sigma \times T^{1 / 2}\right)$ versus 1/(T- $\left.T_{0}\right)$ determina-se os parâmetros $A$ e $\Delta E$ a partir dos coeficientes liner e angular da reta obtida.

A equação do tipo Vogel-Tamman-Fulcher (VTF; equação 2), foi originalmente proposta para descrever a viscosidade de líquidos super resfriados ${ }^{17}$. As adaptações ao modelo foram feitas a fim de relacionar a viscosidade e, portanto, o coeficiente de difusão e a condutividade. Elas baseiam-se em duas considerações ${ }^{17,18}$. A primeira assume que os movimentos moleculares em um líquido não são termicamente ativados, mas ocorrem como resultado da redistribuição do "volume livre" do sistema, desta forma, $T_{0}$ é a temperatura na qual o volume livre desaparece, ou seja, quando cessam os movimentos translacionais ${ }^{17}$. Segundo ela, as partículas dissolvidas na matriz possuem taxa de difusão igual à dos segmentos poliméricos, movendo-se livremente (sem energia de ativação) enquanto houver volume livre disponível. 
A segunda consideração baseia-se no modelo de entropia configuracional, onde o transporte é visualizado como conseqüência dos rearranjos cooperativos entre as cadeias ${ }^{18}$. Se os íons estiverem fortemente associados ao polímero, os movimentos iônicos podem ser correlacionados aos dos segmentos poliméricos.

Os pesquisadores da área de eletrólitos sólidos buscam um eletrólito sólido polimérico (ESP), que combine uma ótima condutividade com boa estabilidade eletroquímica. Procurando estas qualidades, foi desenvolvido um eletrólito a base de PEO-LiPF 6 com característica de condutividade acima de $10^{-4} \mathrm{Sc} / \mathrm{m}$, para baixas concentrações de sal. Outro eletrólito a base de PMMA-(PC - carbonato de propileno e EC - carbonato de etileno) com $\mathrm{LiN}\left(\mathrm{CF}_{3} \mathrm{SO}_{2}\right)_{2}$, apresentou uma condutividade de $3 \times 10^{-3} \mathrm{~S} / \mathrm{cm}$, ou seja, um ótimo valor à temperatura ambiente, o qual pode ser utilizado em janelas eletrocrômicas ${ }^{19}$.

Entre inúmeros trabalhos sobre ESPs pode ser citado artigo do Furtado e colaboradores ${ }^{20}$, em que investigaram um eletrólito sólido polimérico a base de um copolímero de poli (tetrametileno glicol) (PTMG) de baixa massa molar com poli (etileno glicol) (PEG), obtendo valores de condutividade abaixo de $10^{-4} \mathrm{~S} / \mathrm{cm}$ à temperatura ambiente. Gazotti e colaboradores ${ }^{21}$, também estudaram a condutividade iônica de copolímeros de óxido de etileno/epicloridrina, contendo $\mathrm{LiClO}_{4}$. Estes pesquisadores obtiveram altos valores de condutividade, em torno de $4,1 \times 10^{-5} \mathrm{~S} / \mathrm{cm}$ à $30^{\circ} \mathrm{C}$ além de uma boa estabilidade eletroquímica.

Além dos ESPs também estão sendo intensivamente pesquisados sistemas híbridos, chamados de eletrólitos organicamente modificados (ORMOLITAS). Munro e colaboradores ${ }^{22}$ e Orel e colaboradores ${ }^{23}$ descreveram dispositivos eletrocrômicos com eletrólitos obtidos da hidrólise de silanos organicamente modificados como glicidopropiltrimetóxisilano (GPTS) ou glicidilpropiltrimetóxisilano (GLYMO). Esses 
condutores iônicos são constituídos por uma mistura de fases orgânicas e inorgânicas em escalas nonométricas e eles exibem além de boa condutividade também elevada transparência. Nestes sistemas, ambas as fases contribuem para estas boas propriedades. Assim, a condução iônica e a flexibilidade são induzidas pela fase polimérica e as propriedades mecânicas deste eletrólito são melhoradas devido à presença da rede inorgânica.

\section{3 - Polímeros Naturais}

As tendências mundiais para o avanço científico no desenvolvimento de novos materiais destacam a importância da utilização de fontes renováveis, como matéria-prima, além dos resíduos industriais e agro-industriais nos processos de produção. A utilização de resíduos minimiza os problemas ambientais ligados ao seu acúmulo. A utilização de fontes renováveis é de grande interesse, principalmente aquelas obtidas de plantas de rápido crescimento ${ }^{23}$.

Atualmente as indústrias buscam se adequar à exigência das novas políticas ambientais, ou seja, poluir o menos possível. Um grande problema enfrentado é a questão dos plásticos, pois demoram muitos anos para se degradarem no meio ambiente, deste modo, procuram-se produtos biodegradáveis e/ou principalmente reutilizáveis para outros fins. Uma idéia bastante viável, e que despertou um grande interesse em pesquisadores de várias partes do mundo, é a utilização da biomassa vegetal como matéria-prima para substituição dos polímeros sintéticos.

A biomassa vegetal (fonte renovável) é muito rica em polissacarídeos que atualmente são aproveitados principalmente para a produção de papel, alimentos e na indústria farmaceútica. 
Alguns polissacarídeos e seus derivados são muito interessantes do ponto de vista industrial para obtenção tanto de materiais tradicionais como no desenvolvimento de novos materiais com propriedades específicas. Assim, a celulose é utilizada para obtenção de fibras têxteis e seus derivados na indústria cosmética e de tintas devido a elevadas viscosidades das suas soluções e propriedades filmógenas. O amido e a quitosana também estão ganhando cada vez mais atenção no desenvolvimento de novos materiais além das suas aplicações tradicionais na indústria alimentícia e farmacêutica, respectivamente ${ }^{8,24}$.

A produção de materiais biodegradáveis oferece uma solução interessante para os materiais plásticos. Como para os resíduos orgânicos, tais como os alimentos, a eliminação dos materiais biodegradáveis não é automática e é considerada pelos especialistas como uma reciclagem. Os materiais biodegradáveis passam por um processo de compostagem, com a obtenção de um composto estável, considerado como o produto final da reciclagem.

Desta maneira, parece bastante interessante substituir os materiais poliméricos não degradáveis e pouco recicláveis por modernos materiais biodegradáveis obtidos a partir de macromoléculas naturais.

\section{4 - Eletrólitos poliméricos a base de polímeros naturais}

Nos últimos anos tem sido dada considerável atenção ao desenvolvimento de novos materiais poliméricos baseados em polissacarídeos e proteínas, não somente visando suas aplicações na indústria alimentícia e farmaceútica, mas também para a indústria eletrônica. Entre diversos estudos envolvendo essas macromoléculas naturais também são encontrados trabalhos no campo de eletrólitos poliméricos ${ }^{25}$. Estão sendo estudadas as alterações das propriedades físicas e químicas dos 
polímeros naturais e melhoria das suas características funcionais seja por processos físicos, como a plastificação ou por meio de reações químicas, tais como eterificação, esterificação, enxertia e reações de reticulação ${ }^{26}$. O objetivo é encontrar composições que proporcionem a obtenção de membranas com boas propriedades óticas, mecânicas, bem como a adesão às superfícies de vidro e metal. Além das modificações por reações químicas também têm sido feitas pesquisas sobre 0 preparo de blendas à base de polissacarídeos, tais como, celulose e seus derivados $^{19,27-30}$, quitosana ${ }^{27-29}$, amido ${ }^{26}$, ou gelatina ${ }^{30-32}$.

Os recentes trabalhos destacam que os processos de plastificação, i.e., a inserção de substâncias de baixo peso molecular, aumentam os valores de condutividade iônica destes materias, o que proporciona o desenvolvimento de uma nova classe de eletrólitos poliméricos géis a base de polímeros naturais ${ }^{8,26,33}$. Com o objetivo de otimizar a elaboração destes eletrólitos poliméricos, estudos sobre a estabilidade eletroquímica, propriedades condutoras e o preparo de filmes tem sido realizados ${ }^{25}$. Neste campo, a celulose, o amido e seus derivados são polímeros naturais que se mostraram muito atrativos devido à sua boa formação de filmes com ótimas propriedades mecânicas e sua variedade na natureza ${ }^{8,34}$. Outro polissacarídeo muito estudado é a quitosana, devido às suas propriedades específicas, tais como biocompatibilidade e bioatividade ${ }^{27-29}$. Como alguns outros derivados de polissacarídeos, a quitosana é biodegradável e pode ser facilmente moldada em filmes finos. Devido a seus grupos de amina distribuídos regularmente ao longo da cadeia polimérica, em solução ácida torna-se um polieletrólito catiônico ${ }^{35}$.

Como comentado acima há duas rotas de obtenção de eletrólitos poliméricos, (i) via enxertia, levando a formação de redes ou (i) via plastificação que leva a 
formação de blendas. Em 1994 LeNest et al. ${ }^{38}$ reportaram a possibilidade da obtenção de eletrólitos sólidos poliméricos através de formação de redes de hidroxietilcelulose (HEC) e hidroxipropilcelulose (HPC) por enxertia destes polímeros com diisocianatos de poli(óxidos de etileno). Em 1995 Schönenberger et al. ${ }^{39}$ propôs um novo tipo de eletrólito sólido polimérico baseado em HEC enxertada com poli(óxido de etileno) (PEO) através da reação de condensação de hidroxila $(\mathrm{OH})$ da HEC com diisocianatos de oligômeros de PEO . Regiani et al. ${ }^{33}$, estudou amostras de filmes transparentes obtidas de hidroxietilcelulose enxertadas com diisocianatos de poli(óxido de etileno) (Jeffamine). Após a adição de sal de lítio $\left(\mathrm{LiClO}_{4}\right)$ a estas redes foram obtidos eletrólitos sólidos poliméricos com valores de condutividade iônica de $2,1 \times 10^{-5} \mathrm{~S} / \mathrm{cm}$ a $40{ }^{\circ} \mathrm{C}$ e $8,8 \times 10^{-4} \mathrm{~S} / \mathrm{cm}$ a $60 \stackrel{\circ}{\circ}$. Machado et al ${ }^{35}$ apresentaram um novo tipo de síntese, via reação a base de Shiff, onde a hidroxipropilcelulose oxidada foi enxertada com diamina de poli(óxido de etileno) (Jeffamina). Essas redes apresentaram melhores resultados de condutividade iônica de $5,9 \times 10^{-6}$ a $23^{\circ} \mathrm{C}$ e $5 \times 10^{-4} \mathrm{~S} / \mathrm{cm}$ a $84^{\circ} \mathrm{C}$ para as amostras com concentração de sal de lítio de $[\mathrm{O}] /[\mathrm{Li}]=6$.

Poucos trabalhos com amido enxertado foram relatados. Dragunski et al. ${ }^{40}$ apresentou resultados com amostras de amido de milho rico em amilopectina enxertado com tolueno diisocianato de poli (óxido de propileno), obtendo filmes com boas propriedades mecânicas, formação de ligações uretana, diminuição da fase cristalina e temperatura de transição vítrea $\left(T_{g}\right)$ de $-11^{\circ} \mathrm{C}$. Esses filmes exibiram condutividade iônica de $3,5 \times 10^{-5} \mathrm{~S} / \mathrm{cm}$ a $1,5 \times 10^{-3} \mathrm{~S} / \mathrm{cm}$. Em 1998, Velásquez Morales et al. ${ }^{41}$ descreveram a síntese da quitosana oxipropilada enxertada e reticulada com oligo-éter baseado em mono e di-isocianatos, como no caso dos éteres de celulose. As membranas condutoras iônicas foram obtidas através da 
introdução de bis (trifluorometil sulfonil) imida de lítio $\left(\mathrm{LIN}\left(\mathrm{CF}_{3} \mathrm{SO}_{2}\right)_{2}\right.$ - LiTFSI) por difusão a partir de uma solução de acetonitrila, obtendo-se valores semelhantes aos obtidos para as redes de derivados de celulose descritos acima.

Em relação aos trabalhos empregando processos de plastificação para modificação de polímeros em 2002, Dragunski et al. ${ }^{26}$ apresentou os primeiros resultados de novos eletrólitos sólidos poliméricos baseados em amido de milho rico em amilopectina plastificados com glicerol e contendo $\mathrm{LiClO}_{4}$. Foram obtidos filmes transparentes, com baixa temperatura de transição vítrea $\left(T_{g}\right)$ e estrutura predominantemente amorfa. Foram obtidos os valores das condutividades iônicas de $5,1 \times 10^{-5} \mathrm{~S} / \mathrm{cm}$ em $30^{\circ} \mathrm{C}$ a $7,2 \times 10^{-3} \mathrm{~S} / \mathrm{cm}$ em $80^{\circ} \mathrm{C}$. Com o objetivo de verificar a influência da fonte de amido na modificação das propriedades dos eletrólitos poliméricos, foram preparados e caracterizados diferentes ESPs à base de amido de mandioca modificados, como acetilado, catiónico, oxidado e oxidado e acetilado ${ }^{35}$. Neste estudo, foi afirmado que os valores de condutividade iônica de todas as amostras a base de amido de mandioca modificados variaram na faixa de $10^{-6}$ a $10^{-4}$ $\mathrm{S} / \mathrm{cm}$, e os melhores valores de condutividade iônica foram obtidos para as amostras de amidos oxidados $\left(1,8 \times 10^{-4} \mathrm{~S} / \mathrm{cm}\right.$ a $32{ }^{\circ} \mathrm{C}$ e $1,2 \times 10^{-3} \mathrm{~S} / \mathrm{cm}$ a $\left.85^{\circ} \mathrm{C}\right)$ e acetilados $\left(4,5 \times 10^{-4} \mathrm{~S} / \mathrm{cm}\right.$ à temperatura ambiente e $2,4 \times 10^{-3} \mathrm{~S} / \mathrm{cm}$ a $\left.80^{\circ} \mathrm{C}\right)$ plastificados com glicerol e contendo $\mathrm{LiClO}_{4}$.

Eletrólitos sólidos poliméricos baseados em hidroxietilcelulose (HEC) plastificados com glicerol e contendo sal $\mathrm{LiCF}_{3} \mathrm{SO}_{3}$ foram estudados por Machado et al. ${ }^{36}$. Foram obtidos filmes transparentes, com boas propriedades de aderência, estrutura predominantemente amorfa e ótimos valores de condutividade iônica de

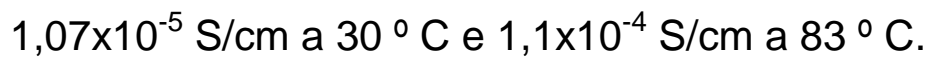


O primeiro relato sobre eletrólitos poliméricos baseados em quitosana foi feito por Morni et al. ${ }^{42}$, que apresentou condutividade iônica de 2,6 $\times 10^{-5} \mathrm{~S} / \mathrm{cm}$, para amostras contendo $\mathrm{AgNO}_{3}$. Osman et al. ${ }^{43}$ e Arof et al. ${ }^{44}$ apresentaram os resultados de quitosana plastificada com carbonato de etileno, com valores de condutividade de cerca de $10^{-5} \mathrm{~S} / \mathrm{cm}$, sendo obtidas membranas transparentes, com baixa temperatura de transição vítrea $\left(-87^{\circ} \mathrm{C}\right)$ e baixa cristalinidade

Um sistema de condução iônica à base de borracha natural modificada e plastificada foi descrito por Idris et al. ${ }^{45}$. Nesse trabalho os autores prepararam e caracterizaram amostras de epóxido de borracha natural (NR) e poli(metacrilato de metila) (PMMA) enxertadas, não plastificadas e plastificadas com carbonato de propileno e carbonato de etileno e contendo $\mathrm{LiCF}_{3} \mathrm{SO}_{3}$. Eles mostraram que as amostras não plastificadas apresentaram valores de condutividade iônica de cerca de $10^{-6}-10^{-5} \mathrm{~S} / \mathrm{cm}$, e que esses valores aumentam para até $10^{-4}-10^{-3} \mathrm{~S} / \mathrm{cm}$ para as amostras plastificadas.

A capacidade das proteínas para formar filmes ou membranas é conhecida há muitos anos. A gelatina também foi um dos primeiros materiais a serem utilizados na produção de filmes. Como outros polímeros naturais, essa proteína é muito promissora no desenvolvimento de novos materiais, uma vez que é abundante e biodegradável, tem baixo custo, não é tóxica e forma soluções transparentes com elevada viscosidade. Filmes de gelatina são obtidos por solubilização a quente, e desidratação de colágeno, que leva a uma distorção parcial da tripla hélice desta macromolécula. No entanto, para melhorar suas propriedades funcionais, agentes de reticulação como formaldeído, glutaraldeído ou glioxal são utilizados ${ }^{46,47}$.

Três diferentes eletrólitos de polímero à base de gelatina reticulados com formaldeído, plastificados com glicerol e contendo ácido acético ${ }^{30}, \mathrm{LiClO}_{4}{ }^{31}$ e $\mathrm{LiBF}_{4}{ }^{32}$ 
foram obtidos e caracterizados por Vieira et al. No primeiro trabalho verificou-se que a quantidade de ácido acético nas amostras condutoras protônicas exerce influência sobre a condução de prótons sendo obtidos altos valores de condução iônica de 4,5 $\times 10^{-5} \mathrm{~S} / \mathrm{cm}$ à temperatura ambiente e $3,6 \times 10^{-4} \mathrm{~S} / \mathrm{cm}$ a $80 \stackrel{\circ}{\circ} \mathrm{C}$, com $26,3 \%$ em peso de ácido acético. No caso das amostras com $\mathrm{LiClO}_{4}$, a quantidade de lítio também influencia a condutividade, até um máximo de $7,9 \%$ de sal de lítio, onde a condutividade iônica aumenta de $1,5 \times 10^{-5} \mathrm{~S} / \mathrm{cm}$ à temperatura ambiente a $4,9 \times 10^{-4}$

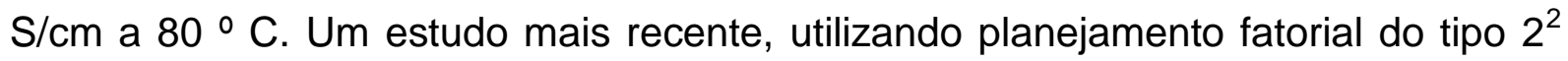
com duas variáveis: glicerol e $\mathrm{LiBF}_{4}$, sobre os eletrólitos de polímero à base de gelatina e $\mathrm{LiBF}_{4}$ revelou que o efeito do plastificante sobre os resultados de condutividade iônica é muito mais importante do que o efeito do sal de lítio ou o efeito de a interação de ambas as variáveis. Também neste caso os valores de condutividade iônica à temperatura ambiente foram obtidos na faixa de $10^{-5} \mathrm{~S} / \mathrm{cm}$.

Como demonstrado acima, são poucos estudos envolvendo macromoléculas naturais como matrizes para obtenção de eletrólitos sólidos ou géis com intuíto de aplicação em dispositivos eletroquímicos. Entretatno, através dessa pequena revisão observa-se, que tanto os valores de condutividade iônica quanto as propriedades físico-químicas (transparência principalmente) são bastante promissoras. Essa revisão revelou também diferenças entre amostras enxertadas e plastificadas, assim como, marcantes diferenças nos valores de condutividade ionica dos eletrólitos com diferentes cargas iônicas. Isso levou também a propor estudos sobre o agar como matriz polímerica condutora iônica. 


\section{5 - Agar}

O agar-agar é um hidrocolóide extraído de algas marinhas largamente utilizado na indústria alimentícia. Entre as suas principais propriedades destacam-se seu alto poder gelificante a baixas concentrações, baixa viscosidade em solução, alta transparência, gel termo-reversível e temperaturas de fusão/gelificação bem definidas. $\mathrm{O}$ agar-agar é também utilizado em diversas aplicações em outros setores industriais, tais como, farmacéutico.

Em seu estado natural, o agar ocorre como carboidrato estrutural da parede celular das algas agarófitas, existindo na forma de sais de cálcio ou uma mistura de sais de cálcio e magnésio. É uma complexa mistura de polissacarídeos composto por duas frações principais: a agarose, um polímero neutro, e a agaropectina, um polímero com carga sulfatada (Figura 2$)^{48}$.

A agarose, fração gelificante, é uma molécula linear neutra, essencialmente livre de sulfatos, que consiste de cadeias repetidas de unidades alternadas $\beta-1,3 D$ galactose e a-1,4 3,6-anidro-L-galactose. A agaropectina, fração não-gelificante, é um polissacarídeo sulfatado ( 3 a $10 \%$ de sulfato) contendo a agarose e porcentagens variadas de éster sulfato, ácido D-glucurônico e pequenas quantidades de ácido pirúvico. A proporção destes dois polímeros varia de acordo com a espécie da alga sendo que a agarose compreende normalmente ao menos dois terços do agar natural| ${ }^{49,50}$.

Estima-se que o peso molecular do agar é de aproximadamente 3.000 a 160.000 dependendo do tipo de colóide. 


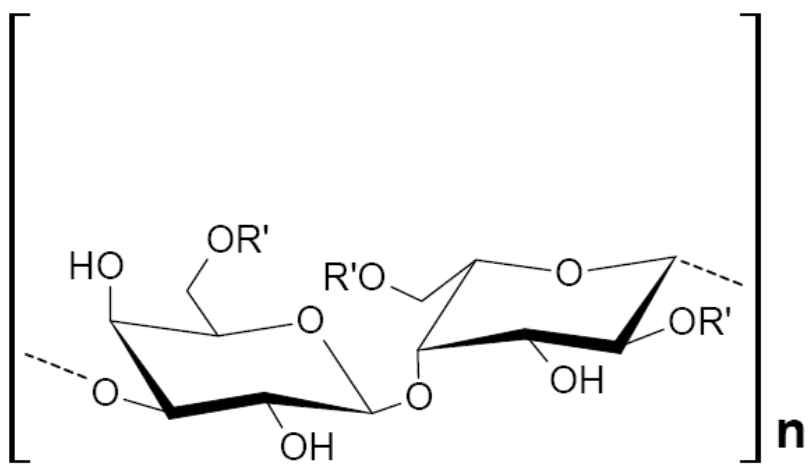

$\mathrm{R}^{\prime}=\mathrm{H}, \mathrm{CH}_{3}$ Ou $\mathrm{SO}_{3}^{-}$

Figura 2 - Unidade repetitiva presente no $\operatorname{agar}^{48}$.

O agar é insolúvel em água fria porém expande-se consideravelmente e absorve uma quantidade de água de até vinte vezes o seu próprio peso. A dissolução em água quente é rápida e pode-se observar a formação de um gel firme a concentrações tão baixas quanto $0,50 \%$. O agar em pó seco é solúvel em água, soluções aquosas e outros solventes, por exemplo: dimetilsulfóxido (DMSO), a temperaturas de $95^{\circ}$ a $100^{\circ}$ C. O agar em pó umedecido por imersão em etanol, 2propanol, acetona ou salinizado por altas concentrações de eletrólito é solúvel em uma variedade de solventes à temperatura ambiente.

Devido às suas propriedades, o agar é utilizado amplamente nos casos em que se necessita de um agente de suspensão, estabilização, espessamento ou gelificação, assim é aplicado amplamente na indústria de alimentos, farmacologia e microbiologia, entre outros ${ }^{51-54}$.

\section{6 - Plastificantes}

Os plastificantes são aditivos largamente empregados em alguns tipos de materiais poliméricos, com o objetivo de melhorar a processabilidade deles e 
aumentar sua flexibilidade. Em muitas circunstâncias, eles são adicionados para obtenção de ampla escala de propriedades físicas em um único polímero ${ }^{55}$.

Um plastificante é definido pela União Internacional de Química Pura e Aplicada (IUPAC) como sendo uma substância incorporada em um material para aumentar sua flexibilidade e manuseio. Desta maneira um plastificante pode diminuir o ponto de fusão, abaixar a temperatura de transição vítrea $\left(\mathrm{T}_{\mathrm{g}}\right)$ e diminuir a cristalinidade do material ao qual foi incorporado. Os plastificantes, em sua maioria, são líquidos de baixa volatilidade e viscosidade.

Em termos práticos, a plastificação (ou plasticização) consiste em adicionar o plastificante através de mistura física com as moléculas do polímero para alterar a viscosidade do sistema, aumentando a mobilidade das macromoléculas. Os plastificantes podem ser sólidos ou, como na maioria dos casos, líquidos de baixa volatilidade (alto ponto de ebulição). Tem sido postulado que a adição do plastificante reduz as forças intermoleculares dos polímeros e aumenta o volume livre. As principais considerações para a seleção de um plastificante com a finalidade de modificar as propriedades de um sistema polimérico são: compatibilidade, permanência e envelhecimento, além de outros. O plastificante deve permanecer na mistura durante o tempo de vida útil do produto. Um plastificante deve ser capaz de se misturar uniformemente e homogeneamente e permanecer no polímero mesmo quando resfriado ou aquecido moderadamente assim como, em temperatura ambiente. O plastificante não pode migrar do material devido à volatilidade, extração ou outras influências do ambiente. Desta maneira para escolher um plastificante deve-se considerar a sua eficiência para modificar as propriedades desejáveis, tão bem como aperfeiçoar os efeitos em outras propriedades. 
Devido ao papel e o propósito de um plastificante em um sistema polimérico serem bem definidos, é fácil entender quais são os materiais poliméricos que utilizam plastificantes para modificar suas propriedades físicas, para as suas aplicações desejadas. O poli(cloreto de vinila) (PVC) e seus copolímeros são os que mais utilizam plastificantes para ampliar suas propriedades físicas e de aplicação. Derivados de celulose dependem dos plastificantes com a finalidade de diminuir a temperatura de fusão para temperaturas bem abaixo da sua degradação, tornando assim o material processável ${ }^{56}$.

Os plastificantes podem ser classificados pela massa molar, estrutura molecular, compatibilidade, eficiência ou propósito de aplicação. De um ponto de vista analítico, os plastificantes podem ser classificados pelas suas estruturas moleculares porque a estrutura molecular está diretamente relacionada com a polaridade e flexibilidade molecular. Na escolha do plastificante é preciso considerar sua eficiência em modificar as propriedades desejadas, tanto quanto a sua influência sobre outras propriedades físico-químicas.

Desta forma, as transições que podem ocorrer nos materiais poliméricos são importante fator a ser conhecido quando se trabalha com plastificantes, pois seu desempenho está intimamente ligado a essa variável.

Há um grande interesse comercial em obter eletrólitos poliméricos com altos valores de condutividade $\left(10^{-5} \mathrm{~S} / \mathrm{cm}\right)$, com a finalidade de utilizá-los em baterias de lítio ou em dispositivos eletroquimicos. Dessa forma, foi descoberto em recentes estudos, que a adição de plastificantes polares capazes de formar um complexo com o íon lítio, favorece um aumento na condutividade iônica dos eletrólitos ${ }^{57-59}$. Além de plastificar o polímero, o plastificante, geralmente uma substância de baixa massa molar, tem como principal função separar as cargas (íons) que estão complexadas 
com o polímero e promover uma dissociação do sal, contribuindo assim, para a condutividade iônica do eletrólito.

\section{7 - Sais e Ácidos}

Apesar de existirem polímeros com propriedades condutoras tanto iônicas quanto eletrônicas a maioria das moléculas poliméricas possui valores de condutividade relativamente baixos, i.e., na faixa de $10^{-12}$ a $10^{-10} \mathrm{Scm}^{-1}$. Porém, ao adicionar ao PEO uma pequena quantidade de sal inorgânico, como por exemplo, $\mathrm{LiClO}_{4}$, ou mesmo um ácido, como por exemplo, $\mathrm{CH}_{3} \mathrm{COOH}$, ocorre a dissociação dos íons metálicos ou prótons através da coordenação do íon com um dos pares de elétrons livres do átomo de oxigênio presente na estrutura do polímero (Figura 3). Em comparação a eletrólitos com sais de metais alcalinos, os condutores protônicos possuem melhor dinâmica de transporte iônico e na maioria dos casos os eletrólitos na forma de gel possuem uma matriz polimérica "inchada" com uma solução do próton doador em um solvente polar e sítios redox ${ }^{4,56-60}$.

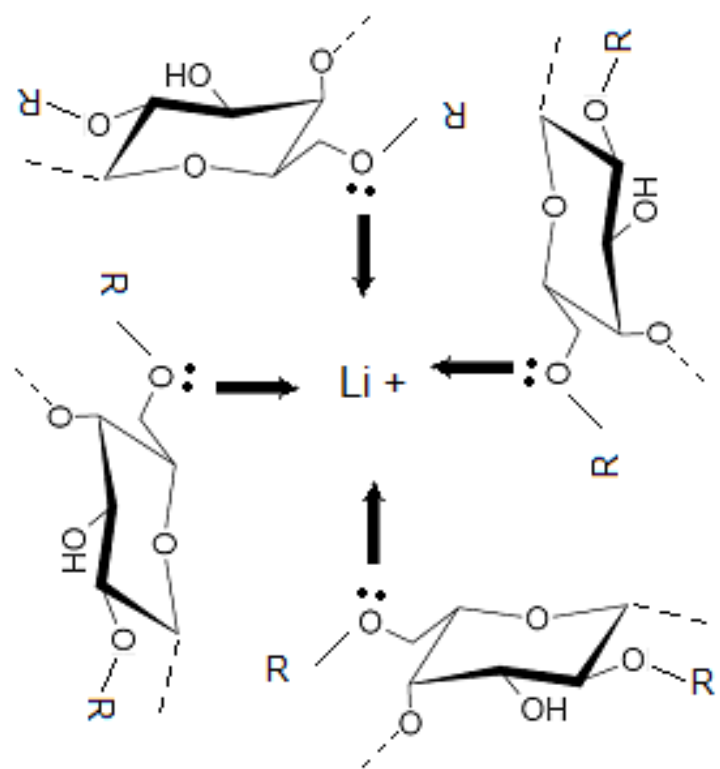

Figura 3- llustração da forma de coordenação do lítio com os oxigênios presentes no agar. 
Também segundo os trabalhos anteriores ${ }^{45,47}$, a utilização de $\mathrm{LiBF}_{4}$ em eletrólitos sólidos poliméricos (ESP) à base de gelatina comercial promoveu uma condutividade iônica de $1,45 \times 10^{-5}{\mathrm{~S} . \mathrm{cm}^{-1}}^{-}$em temperatura ambiente. Contudo, observa-se que a adição dos sais confere um aumento de condutividade até certo limite de concentração do sal após o qual ocorre uma diminuição da mesma. Por causa disso, fatores como grau de dissociação do sal, constante dielétrica do polímero, grau de agregação iônica e a mobilidade das cadeias poliméricas alteram o grau de transporte iônico dentro da matriz polimérica ${ }^{45,47,60}$.

Compostos orgânicos também podem contribuir na condutividade dos ESPs, como no caso do ácido acético, que por ser um ácido de base fraca, libera um próton $\left(\mathrm{H}^{+}\right)$, que fica livre para se coordenar com o oxigênio presente. A Tabela 1 mostra algumas características físico-químicas de substâncias que promovem a condutividade iônica.

Tabela 1 - Propriedades físico-químicas de alguns sais e ácido acético ${ }^{61}$

\begin{tabular}{|c|c|c|c|c|}
\hline $\begin{array}{l}\text { Agentes } \\
\text { lonizantes }\end{array}$ & $\begin{array}{c}\text { Massa Molar } \\
(\text { g.mol }\end{array}$ & $\begin{array}{c}\text { Massa } \\
\text { Específica } \\
\left(\mathrm{g} \cdot \mathrm{cm}^{3}\right)\end{array}$ & $\begin{array}{l}\text { Ponto de } \\
\text { Fusão (ํㅡ) }\end{array}$ & $\begin{array}{l}\text { Solubilidade } \\
\text { em } \mathrm{H}_{2} \mathrm{O} \text { a } 25^{\circ} \mathrm{C}\end{array}$ \\
\hline $\mathrm{LiBF}_{4}$ & 93.75 & 0.852 & 275 & Muito Solúvel \\
\hline Lil & 133.85 & 3.494 & 459 & $151 \mathrm{~g} / 100 \mathrm{~mL}$ \\
\hline $\mathrm{LiClO}_{4}$ & 106.39 & 2.43 & 236 & $60 \mathrm{~g} / 100 \mathrm{~mL}$ \\
\hline $\mathrm{HCl}$ & 36.46 & 1,19 & -114.2 & $72 \mathrm{~g} / 100 \mathrm{~mL}$ \\
\hline $\mathrm{CH}_{3} \mathrm{COOH}$ & 60.05 & 1.049 & 16.5 & Muito Solúvel \\
\hline
\end{tabular}

\section{8- Dispositivos eletrocrômicos}

Dispositivos eletrocrômicos são as aplicações práticas do fenômeno de eletrocromismo. Este fenômeno é definido como mudança reversível de coloração 
de material, no caso do óxido de tungstênio de transparente para o azul escuro, causada pela aplicação de corrente ou potencial elétrico ${ }^{62}$.

Os dispositivos eletrocrômicos vêm sendo muito estudados por apresentarem várias vantagens em relação às janelas ou visores de cristais líquidos. Estas vantagens seriam: alto contraste óptico com contínua variação de transmitância e independência em relação ao ângulo de visão, memória óptica, estabilidade aos raios ultravioleta, além de ampla operação nas mais variadas faixas de temperatura 62

As quatro principais aplicações na área de dispositivos eletrocrômicos são:

- janelas eletrocrômicas: para controle da transmissão, aos ambientes internos, de comprimentos de ondas que variam desde o ultravioleta ao infravermelho próximo ${ }^{63}$,

- displays,

- retrovisores com reflexão variável para aplicação em veículos como exemplo do modelo Vectra e Omega $\mathrm{GM}^{64}$ e

- superfícies com emissão térmica variável para refletir no infravermelho.

Os dispositivos eletrocrômicos típicos geralmente são constituídos por cinco camadas denominadas na seqüência: vidro/CT/CE/Cl/RI/CT/vidro, como mostrado na Figura 4. As abreviações significam: CT - um condutor transparente, geralmente filmes finos de ITO (óxido de estanho dopado com índio) ou FTO (óxido de estanho dopado com flúor), CE - filme eletrocrômico (eletrodo de trabalho constituído por filme fino de $\left.\mathrm{WO}_{3}\right), \mathrm{Cl}$ - condutor iônico e Rl- filme reservatório dos íons ou contraeletrodo. A montagem destes dispositivos é feita geralmente através da deposição separada das camadas CE e RI sobre os substratos que são constituídos de vidro recoberto com CT. No final as duas partes são unidas através de um condutor 
iônico, objetivo deste trabalho, e seladas a fim de isolar do ambiente e umidade externas. A mudança de coloração do dispositivo ocorre quando é aplicada a diferença do potencial ao mesmo. Assim, a camada eletrocrômica muda de coloração de transparente para geralmente azul devido à dupla injeção no seu interior de íons de lítio e elétrons ${ }^{61}$.

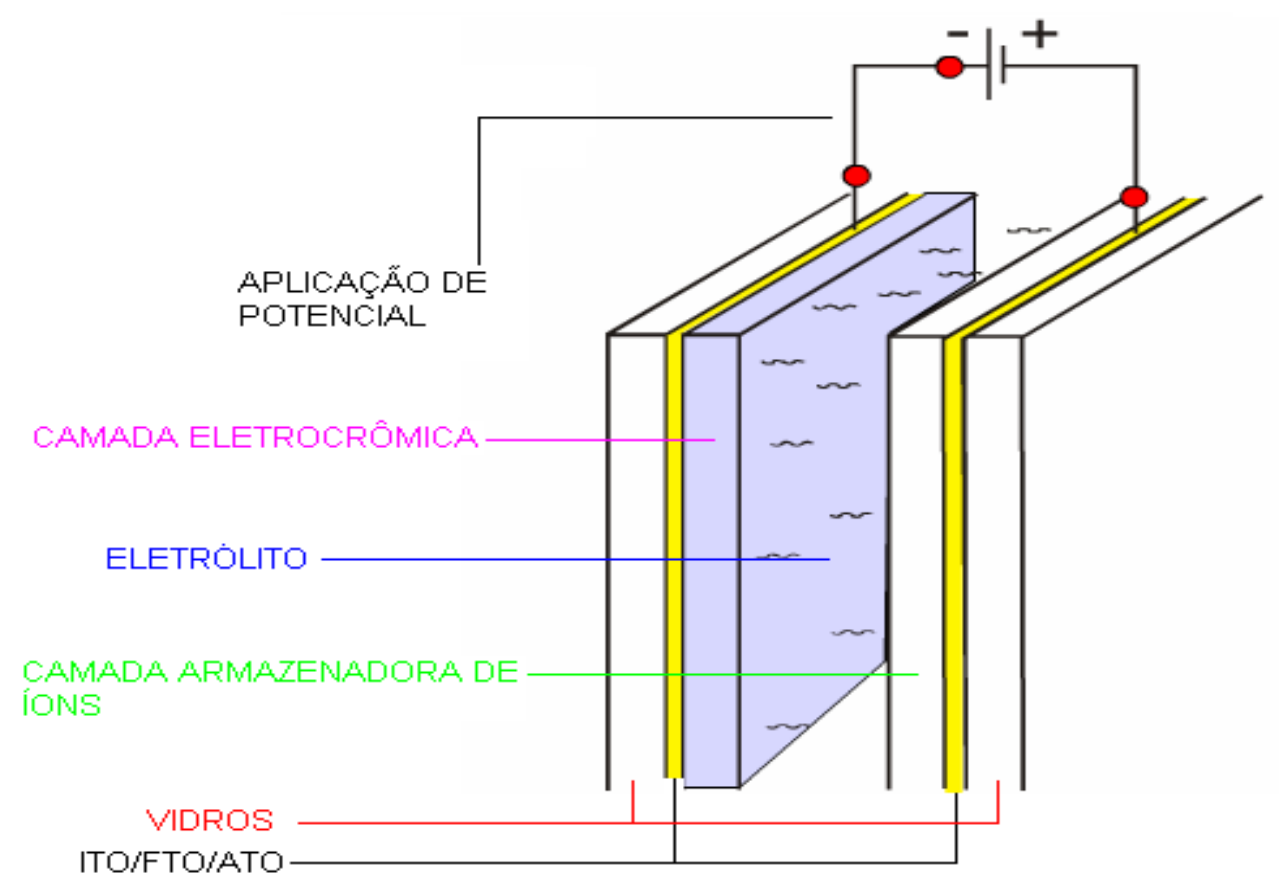

Figura 4 - Esquema de uma janela eletrocrômica ${ }^{65}$.

Dependendo dos materiais utilizados os dispositivos eletrocrômicos podem trabalhar no modo de reflexão, como no caso de displays ou espelhos retrovisores ou no modo de transmissão como as janelas, o que é assunto de pesquisa de vários laboratórios tanto industriais como científicos ${ }^{66,67}$. Como exemplo, pode ser citado o trabalho de Munro e colaboradores ${ }^{23}$ que desenvolveram uma interessante janela eletrocrômica constituída por $\mathrm{ITO} / \mathrm{WO}_{3} / \mathrm{Li}^{+}$-eletrólito/ $/ \mathrm{CeO}_{2}-\mathrm{TiO}_{2} / \mathrm{ITO}$. Esta janela apresentou uma ótima variação na transmitância, de $60 \%$, entre o estado colorido e transparente. 
As janelas eletrocrômicas, também chamadas de "janelas inteligentes", por permitirem alterações da transmissão e reflexão da luz, têm ampla variedade de aplicações. O mercado potencial para dispositivos inteligentes é enorme. Os primeiros produtos comercializados foram espelhos retrovisores eletrocrômicos para automóveis, os quais automaticamente diminuem a reflexão da luz quando uma luz de alta intensidade incide sobre os olhos do motorista. Indústrias japonesas estão produzindo óculos eletrocrômicos que atuam tanto em ambientes claros como em escuros, graças a um sistema de baterias embutido na haste dos óculos ${ }^{68}$.

No campo da arquitetura, há possibilidade da aplicação das janelas eletrocrômicas para regulagem da luminosidade e calor em ambientes fechados, diminuindo assim, o consumo de energia gasto por lâmpadas e aparelhos de arcondicionados. Nos meses de verão, a janela eletrocrômica pode minimizar a passagem dos raios ultravioleta e infravermelho diminuindo assim, o aquecimento dos ambientes internos e no inverno atuar do modo inverso. Isso demonstra que a pesquisa no campo de desenvolvimento de eletrólitos sólidos poliméricos para aplicação em dispositivos eletrocrômicos além de ser interessante do ponto de vista científico, também, pode ser benéfica à população.

\section{Referências Bibliográficas}

[1] MOYA, L. M. Efeitos da radiação sobre propriedades eletroquímicas da polianilina. 2006. 92f. Dissertação (Mestrado) - Universidade Tecnológica Federal do Paraná. Programa de Pós-Graduação em Engenharia Mecânica, Curitiba, 2006.

[2] SILVA, V. P. R.; CALIMAN, V.; SILVA, G. G. Polymers with ionic conductivity: fundamental challenges and technological potential. Polímeros, v. 15, n. 4, p. 249255, 2005. 
[3] GREGG, B. A. Photoelectrochromic cells and their applications. Endeavour, v. 2, n. 2, p. 52, 1997.

[4] MACDONALD, J. R. Impedance spectroscopy. New York: John Wiley, 1987. $346 p$.

[5] WRIGHT, P. V. Electrical conductivity in ionic complexes of poly (ethylene oxide). British Polymer Journal, v. 7, p. 319 - 327, 1975.

[6] MAGISTIS, A.; SINGH, K. PEO-based polymer electrolytes. Polymer International, v. 28, p. 277-280, 1992.

[7] WARD, I. M.; BODEN, N.; CRUICKSHANK, J.; LENG, S. A. NMR studies of ionic mobility'and molecular mobility in polymer electrolytes. Electrochimica Acta, v. 40, n. 13-14, p. 2071- 2076, 1995.

[8] DRAGUNSKI, D. C. Preparação de eletrólitos sólidos poliméricos a partir do amido. 2003. 163f. Tese (Doutorado) - Instituto de Química de São Carlos, Universidade de São Paulo, São Carlos, 2003.

[9] HIRANKUMAR, G.; SELVASEKARAPANDIAN, S.; BHUVANESWARI, M. S.; BASKARAN, R.; VIJAYAKUMAR, M. Ag+ ion transport studies in a polyvinyl alcoholbased polymer electrolyte system. Journal of Solid State Electrochemistry, v. 10, n. 4, p. 193-197, 2006.

[10] KELLY I. E.; OWEN, J. R.; STEEL, B. C. H. Poly(ethyleneoxide) electrolytes for operation at near room-temperature. Journal of Power Sources, v. 14, n. 13, p. 13 $-21,1985$.

[11] THE MERCK Index: an encyclopedia of chemicals, drugs, and biologicals. 13.ed. Whitehouse Station: Merck Research Laboratories, 2001. p. 3832.

[12] BLONSKY P. M.; SHRIVER, D. F., AUSTIN; P.; ALLCOCK, H. R. Complexformation and ionic-conductivity of polyphosphazene solid electrolytes. Solid State Ionics, v. 18 - 19, p. 258, 1986.

[13] NEYERTZ, S.; BROWN, D. Local structure and mobility of ions in polymer electrolytes: a molecular dynamic simulation study of the amorphous PEOxNal system. Journal of Chemical Physics, v. 104, n. 10, p. 3797-3809, 1996. 
[12] MAGISTRIS, A.; MUSTARELLI, P.; QUARTARONE, E.; TOMASI, C. Transport and thermal properties of (PEO)(n)-LiPF6 electrolytes for super-ambient applications. Solid State Ionics, v. 136-137, p. 1241-1247, 2000.

[13] COHEN, M. H.; TURNBULL, D. Molecular transport in liquids and glasses. Journal of Chemical Physics, v. 31, p. $1164-1169,1959$.

[14] LEMES, N. H. T.; SILVA, G. G. Análise de ajustes de curvas de condutividade iônica em função da temperatura em eletrólitos poliméricos In: REUNIÃO ANUAL DA SOCIEDADE BRASILEIRA DE QUÍMICA, 18., 1995. Caxambu. Livro de resumos... São Paulo: Sociedade Brasileira de Química, 1995, p.65.

[15] ADAM, G.; GIBBS, J. H. On the temperature dependence of cooperative relaxation properties in glass-forming liquids. Journal of Chemical Physics, v. 43, p. 139-146, 1965.

[16] GOULART, G.; LEMES, N. H. T.; PAOLI, M. A. Solid State polymeric electrolytes based on poly(epychlorhydrin). Solid State lonics, v. 93, n. 1 - 2, p. 105 -116, 1996.

[17] RATNER, M. A. Aspects on theoretical treatmente of polymer solid electrolytes: transport theory and models. In: MACCALLUM, J. R.; VINCENT, C. A. Polymer electrolytes reviews. London: Elsevier Applied Science, 1987. p. 173-236.

[18] VINCENT, C. A. Progress in solid state chemistry. Polymer Electrolytes, v. 17, n. 3, p. 145-261, 1987.

[19] REGIANI, A. M. Eletrólitos Sólidos Poliméricos à base de polissacarídeos: Síntese e caracterização. 2000. 161f. Tese (Doutorado) - Instituto de Química de São Carlos, Universidade de São Paulo, São Carlos, 2000.

[20] OREL, B.; KRASOVEC, U. O.; STANGAR, U. L.; JUDEINSTEIN, P. All sol-gel electrochromic devices with $\mathrm{Li}+$ ionic conductor, WO3 electrochromic films and $\mathrm{SnO} 2$ counterelectrode films. Journal of Sol-Gel Science and Technology, v. 11, n. 1, p. 87-104, 1998.

[21] FURTADO, C. A.; SILVA, G. G.; PIMENTA, M. A.; MACHADO, J. C. Conductivities, thermal properties and Raman estudies of poly(tetramethylene glycol) based polymer electrolytes. Electrochimica Acta, v. 43, n. 10-11, p. 1477-1480, 1998. 
[22] GAZOTTI, W. A.; SPINACE, M. A. S.; GIROTTO, E. M.; DE PAOLI, M. A. Polymer electrolytes based on ethylene oxide-epichlorohydrin copolymers. Solid State lonics, v. 130, n. 3 - 4, p. 281-291, 2000.

[23] MUNRO, B.; CONRAD, P.; KRAMER, S.; SCHMIDT, H.; ZAPP, P. Development of electrochromic cells by the sol-gel process. Solar Energy Material and Solar Cells, v. 54, n. 1 - 4, p. 131-137, 1998.

[24] JANE, J.; LIM, S.; PAETAU, I.; SPENCE, K.; WANG, S. Biodegradable plastics made from agricultural biopolymers. Washington: ACS, 1994. cap. 6, p. 92-100. (ACS Symposium Series, 575).

[25] PAWLICKA, A.; DONOSO, J. P. Polymer electrolytes based on natural polymers. In: POLYMER electrolytes: properties and applications. Cambridge: Woodhead Publishing, 2010. 632 p.

[26] DRAGUNSKI, D. C.; PAWLICKA, A. Starch based solid polymeric electrolytes. Molecular Crystals and Liquid Crystals Science and Technology. Section A, Molecular Crystals and Liquid Crystals, v. 374, p. 561 - 568, 2002.

[27] PAWLICKA, A. ; DANCZUK, M. ; WIECZOREK, W. ; ZYGADLO-

MONIKOWSKA, E. . influence of plasticizer type on the properties of polymer electrolytes based on chitosan. Journal of Physical Chemistry. A, Molecules, Spectroscopy, Kinetics, Environment, \& General Theory, v. 112, p. 8888 - 8895, 2008.

[28] DANCZUK, M. Eletrólitos sólidos poliméricos a base de quitosana. 2007. 126f. Dissertação (Mestrado) - Instituto de Química de São Carlos, Universidade de São Paulo, São Carlos, 2007.

[29] FUENTES, S.; RETUERT P.J.; GONZÁLEZ, G. Lithium ion conductivity of molecularly compatibilized chitosan-poly (aminopropyltriethoxysilane)-poly(ethylene oxide) nanocomposites. Electrochimica Acta. v. 53, p. 1417- 1421, 2007.

[30] VIEIRA, D.; AVELLANEDA, C.; PAWLICKA, A. Conductivity study of a gelatinbased polymer electrolyte. Electrochimica Acta, v. 53, n. 4, p. 1404-1408, 2007.

[31] VIEIRA, D. F.; AVELLANEDA, C. O.; PAWLICKA, A. AC Impedance, X-ray Diffraction and DSC Investigation on Gelatin Based-Electrolyte with LiClO4. Molecular Crystals and Liquid Crystals (Philadelphia), Molecular Crystals Liquid Crystals, v. 485, p. 843 - 852, 2008. 
[32] VIEIRA, D. F.; PAWLICKA, A. Optimization of performances of gelatin/libf4 based polymer electrolytes. Electrochimica Acta, v. 55, p. 251489 - 1494, 2010.

[33] REGIANI, A. M; PAWLICKA, A.; CURVELO, A. A. S.; GANDINI, A.; LE NEST, J. F. Celulose enxertada com poliéters. Polímeros: Ciência e Tecnologia, v. 3, p. $45-$ 50, 1999.

[34] MACHADO, G. O. Preparação e caracterização de eletrólitos sólidos poliméricos a partir dos derivados de hidroxipropilcelulose e

hidroxietilcelulose. 2004. 127f. Tese (Doutorado) - Interunidades Ciência e Engenharia de Materiais, Universidade de São Paulo, São Carlos, 2004.

[35] PAWLICKA, A., SABADINI, A., RAPHAEL, E.; DRAGUNSKI, D. Ionic conductivity thermogravimetry measurements of starch-based polymeric electrolytes. Molecular Crystals and Liquid Crystals, v. 485, p. 804, 2008.

[36] MACHADO G.; PAWLICKA A.; YONASHIRO, M. Solid polymeric electrolytes networks of hydroxycellulose with jeffamine. Nonlinear Optics Quantum Optics, v. 32, p. 141-148, 2004.

[37] MACHADO, G.; FERREIRA, H.; PAWLICKA, A. Influence of plasticizer contents on the properties of HEC-based solid polymeric electrolytes. Electrochimica Acta, v. 50 , p. $3827-3831,2005$.

[38] LeNEST, J. F.; GANDINI, A.; SCHOENENBERGER, C. Elastomeric polymer electrolytes base on crosslinked polyethers: state of the art. Trends in Polymer Scienci, v. 2, p. 432 - 437, 1994.

[39] SCHOENENBERGER, C.; LE NEST, J. F.; GANDINI A. Polymer electrolytes based on modified polysaccharides. 2. Polyeter-modified cellulosics. Electrochimica Acta,v. 40, n. 13-14, p. 2281-2284, 1995.

[40] DRAGUNSKI, D.C.; PAWLICKA, A. Preparation and characterization of starch grafted with toluene poly(propylene oxide) diisocyanate. Materials Research, v. 4, p. 77-81, 2001.

[41] VELAZQUEZ-MORALES, P.; LeNEST, J. F.; GANDINI, A. Polymer electrolytes dirived from chitosan/polyether networks. Electrochimica Acta, v. 43, n. 10-11, p. 1275 - 1279, 1998. 
[42] MORNI N. M.; MOHAMED N. S.; AROF A. K. Silver nitrate doped chitosan acetate films and electrochemical cell performance. Materials Science and Engineering B-solid state materials for advanced technology, v. 45, p. 140 - 146, 1997.

[43] OSMAN Z.; AROF A. K. FTIR studies of chitosan acetate based polymer electrolytes. Electrochimica Acta, v. 48, n. 8, p. 993-999, 2003.

[44] AROF, A. K.; OSMAN, Z.; MORNIN, N. M.; KAMARULZAMAN, N.; IBRAHIM, Z. A. MUHAMAD, M. R. Chitosan-based electrolyte for secondary litthium cells. Journal of Materials Science, v. 36, p. 791, 2001.

[45] IDRIS, R.; GLASSE, M. D.; LATHAM, R. J.; LINFORD, R. G.; SCHLINDWEIN, W. S. J. Polymer electrolytes based on modified natural rubber for use in rechargeable lithium batteries. Power Sources, v. 94, p. 206 - 211, 2001.

[46] BERGO, P.; SOBRAL, P. J. A. Effects of plasticizer on physical properties of pigskin gelatin films. Food Hydrocolloids, v. 21, p. 1285 - 1289, 2007.

[47] CARVALHO, R.A.; GROSSO, C. R. F. Characterization of gelatin based films modified with transglutaminase, glyoxal and formaldehyde. Food Hydrocolloids, v. 18, p. 717 - 726, 2004.

[48] BASTIOLE, C. Global status of the production of biobased packagin materials. In: THE FOOD BIOPACK CONFERENCE, 2000, Copenhagen.

Proceedings...Copenhagen: VCH, 2000, p. 2-7.

[49] CARDOSO, M. A., Determinação da estrutura química de xilomanas e galactanas sulfatadas isoladas de macroalgas marinhas(Ceramiales, Rhodophyta). 2007, 108p. Tese (Doutorado). Curso de Pós- Graduação em Bioquímica, Universidade Federal do Paraná, Curitiba, 2007.

[50] Retamales, C. A.; MARTínEZ, A.; BUSCHMANN, A. H. Mantención interanual de los niveles productivos y del rendimiento de agar de Gracilaria chilensis cultivada en estanques en el sur de Chile, Revista de biología marina y oceanografía, v. 29, n. 2, p. 251 - 261, 1994.

[51] ETCHEVERRY, H. Algas marinas chilenas productoras de ficocoloides, Revista de Bioogia Marina, v. 8, n. 1, 2 e 3, p. 153-174, 1958. 
[52] LLAÑA, A. H. Algas industriales de Chile, Revista de biología marina y oceanografía, v. 1, n.2, p.124 - 131,1948.

[53] TAKANO, R.; YOSHIKAWA, S.; UEDA, T.; HAYASHI, K.; HIRASE, S.; HARA, S. Journal of Carbohydrate Chemistry, v. 15, p. 449, 1996.

[54] CUBILLOS, R. El agar-agar chileno. Revista de biología marina y oceanografía, v. 3, n. 1 - 2, p. 70 - 88, 1951.

[55] WANG, F. C. Y. Polymer additive analysis by pyrolysis-gas chromatography I. Plasticizers. Journal of Chromatography A, v. 883, n. 1 - 2, p. 199 - 210, 2000.

[56] LORCKS, J. Properties and applications of compostable starch-based plastic material. Polymer Degradation and Stabability, v. 59, n. 1 - 3, p. $245-249,1998$.

[57] MATHEW, A. P.; DUFRESNE, A. Plasticized waxy maize starch: effect of polyols and relative humidity on material properties, Biomacromolecules, v. 3, n. 5, p. 1101 $-1108,2002$.

[58] OLIVEIRA, S. C.; TORRESI, R. M. Uma visão das tendências e perspectivas em eletrocromismo: a busca de novo materiais e desenhos mais simples. Química Nova, v. 23, n. 1, p. $79-87,2000$.

[59] ZOPPI, R. A.; NUNES S. P. Uso do processo sol-gel na obtenção de materiais híbridos organo-inorgânicos: preparação, caracterização e aplicação em eletrólitos de estado sólido. Polímeros: Ciência e Tecnologia, v. 7, p. 27, 1997.

[60] MATTOS, R. I.; PAWLICKA, A.; LIMA, J. F.; TAMBELLI, C. E.; MAGON, C. J.; DONOSO, J. P. Magnetic resonance and conductivity study of gelatin-based proton conductor polymer electrolytes. Electrochimica Acta, v. 55, p. 1396 -1400, 2010.

[61]LIDE, D. R. (Ed.) $C R C$ handbook of chemistry and physics: a ready-reference book of chemical and physical data. 83. ed. Boca Raton: CRC Press, 2002. 2664p.

[62] MACEDO, M. A. Preparação e caracterização de filmes finos sol-gel para dispositivos eletrocrômicos. 1994. 93p. Tese (Doutorado) - Instituto de Física de São Carlos, Universidade de São Paulo, São Carlos, 1994. 
[63] AVELLANEDA, C. Desenvolvimento de janelas eletrocrômicas preparadas pelo processo sol-gel. 1999. 102p. Tese (Doutorado) - Instituto de Física de São Carlos, Universidade de São Paulo, São Carlos, 1999.

[64] OLIVEIRA, S.C. Estudo espectroeletroquímico da decomposição de bismuto em meio geleificado: construção de dispositivo eletrocrômico de transmitância variável, 2003. 107p. Tese (Doutorado) - Instituto de Química de São Carlos, Universidade de São Paulo, São Carlos, 2003.

[65] MELO, L. O. Preparação e caracterização de filmes finos sol-gel de $\mathrm{Nb}_{2} \mathrm{O}_{5}$ dopados com $\mathrm{Li}^{+}$visando possível aplicação em arquitetura. 2001. 81f. Dissertação (Mestrado) Programa de Pós Graduação em Ciências e Engenharia de Materiais - Universidade de São Paulo. São Carlos, 2001.

[66] MESSIAS, R. R. Uma contribuição para a caracterização elétrica e ótica de filmes finos de $\mathrm{SnO}_{2}$ preparados a partir de soluções coloidais. 1998. 78p. Dissertação (Mestrado) - Escola de Engenharia de São Carlos, Instituto de Química de São Carlos, Instituto de Física de São Carlos, Universidade de São Paulo, São Carlos, 1998.

[67] KROEZE, J. E.; HIRATA, N.; SCHMIDT-MENDE, L.; ORIZU, C.; OGIER, S. D.; CARR, K.; GRATZEL, M.; DURRANT J. R. Parameters influencing charge separation in solid-state dye-sensitized solar cells using novel hole conductors Advanced Functional Materials, v. 16. n. 14, p. 1832 - 1838, 2006.

[68] BENEDETTI, J. E.; DE PAOLI, M. A.; NOGUEIRA, A. F. Enhancement of photocurrent generation and open circuit voltage in dyesensitized solar cells using $\mathrm{Li}+$ trapping species in the gel electrolyte. Chemical Communications, v. 7, n. 9, p. 1121 - 1123, 2008. 


\section{CAPÍTULO 2 - OBJETIVOS}

Os principais objetivos deste trabalho foram o preparo e estudo de eletrólitos poliméricos géis a base de agar com a finalidade de se obter novos sistemas de condução iônica para aplicação em dispositivos eletrocrômicos. Os trabalhos anteriores desenvolvendo eletrólitos a base de polissacarídeos se demonstraram muito promissores devido aos seus ótimos valores das condutividades iônicas, baixo custo, boa estabilidade eletroquímica, boa transparência na região do UV-Vis e fácil preparação. Além disso, o objetivo foi estudar a possibilidade de adição de ácido como fonte de prótons, assim como possibilidade de obtenção de blendas com outros polímeros, tanto naturais quanto sintéticos.

Para obter os melhores valores de condutividade iônica das amostras preparadas, o objetivo foi o estudo da influência da concentração de sal (íons) ou ácido (prótons) sobre a condutividade iônica, além de preparar blendas entre agar e outros polímeros, tais como, gelatina e quitosana, bem como estudar a adição de materiais que auxiliem na condução iônica e/ou proporcionam propriedades eletrocrômicas, como foi o caso do PEDOT:PSS. 


\section{CAPÍTULO 3 - MATERIAIS E MÉTODOS}

\section{1 - Caracterização do Agar}

Para o desenvolvimento deste trabalho foi utilizado agar adquirido da SigmaAldrich.

\subsection{1 - Análise Elementar}

Para determinação da composição elementar do agar empregado para o preparo dos eletrólitos, foi utilizado equipamento da marca CE (Carlo Erba) Instruments, modelo EA 1110 CHNS-O. Os padrões foram, L-cistina $\left(\mathrm{C}_{6} \mathrm{H}_{12} \mathrm{~N}_{2} \mathrm{O}_{4} \mathrm{~S}_{2}\right)$, DL-metionina $\left(\mathrm{C}_{5} \mathrm{H}_{11} \mathrm{NO}_{2} \mathrm{~S}\right)$, sulfanilamida $\left(\mathrm{C}_{6} \mathrm{H}_{8} \mathrm{~N}_{2} \mathrm{O}_{2} \mathrm{~S}\right)$ e BBOT $\left(\mathrm{C}_{26} \mathrm{H}_{26} \mathrm{~N}_{2} \mathrm{O}_{2} \mathrm{~S}\right)$.

\subsection{2 - Análise Viscosimétrica}

A massa molar viscosimétrica do agar utilizado foi determinada através de medida de viscosidade de soluções do polissacarídeo a cinco concentrações: 0,1865 $\mathrm{g} / \mathrm{L} ; 0,2167 \mathrm{~g} / \mathrm{L} ; 0,3626 \mathrm{~g} / \mathrm{L} ; 0,4087 \mathrm{~g} / \mathrm{L}$ e $0,5088 \mathrm{~g} / \mathrm{L}$. As soluções de agar foram preparadas por dissolução de amostras de polissacarídeo em solução $0,1 \mathrm{M}$ de $\mathrm{NaCl}$, com agitação a temperatura de $100^{\circ} \mathrm{C}$, para completa dissolução dos grânulos de agar, e as medidas de viscosidade foram realizadas em um viscosímetro capilar do tipo Ubbelohde modelo $0 \mathrm{C}$ submerso em banho termostático a $45^{\circ} \mathrm{C}$.

\subsection{3 - Espectroscopia no Infravermelho - FT-IR}

A análise foi realizada em aparelho BOMEM modelo MB-102 com transformada de Fourier. A amostra foi solubilizada em água MilliQ, dispersa sobre um cristal de silício e seca com ar quente. 


\section{2 - Preparo dos Eletrólitos}

\subsection{1 - Preparos dos Eletrólitos de Agar}

Preparou-se os eletrólitos com $0,5 \mathrm{~g}$ de agar (Sigma-Aldrich) disperso em 25 $\mathrm{mL}$ de água Millipore Milli-Q com a resistividade controlada de $18,2 \mathrm{~m} \Omega^{-1} \mathrm{~cm}^{-1}$ à $25^{\circ} \mathrm{C}$. A dissolução foi feita sob agitação magnética constante e aquecimento $\left(100^{\circ} \mathrm{C}\right)$.

Posteriormente, adicionou-se $0,5 \mathrm{~g}$ de glicerol, $0,5 \mathrm{~g}$ de formaldeído (para promover a reticulação do agar e permitir a formação dos filmes) e uma fonte de prótons, a partir da introdução de ácido acético glacial, em diferentes concentrações (0,1-2,0 g). Em um segundo momento, utilizou-se como fonte de íons um sal de lítio, em diferentes concentrações $(0,05-0,7 \mathrm{~g})$, no caso o $\mathrm{LiClO}_{4}$.

A solução viscosa foi dispersa em uma placa de Petri e seca durante 48 horas na estufa a $50^{\circ} \mathrm{C}$. Os filmes obtidos foram estocados em um dessecador até a realização das análises de caracterização.

\subsection{2 - Preparos dos Eletrólitos de Blendas de Agar com Gelatina}

Sob agitação magnética e uma temperatura de $50^{\circ} \mathrm{C}, 2,0 \mathrm{~g}$ de gelatina comercial incolor e sem sabor (Dr. Oetker ${ }^{\circledR}$ ) foi misturada com água Millipore Milli-Q com resistividade controlada de $18 \mathrm{~m}^{-1} \mathrm{~cm}^{-1}$ à $25^{\circ} \mathrm{C}$, até a completa dissolução. Em seguida adicionou-se 2,5 g de glicerol retornando a agitação por mais alguns minutos. Por fim, adicionou-se $0,25 \mathrm{~g}$ de formaldeído.

Simultaneamente foi preparada a solução de agar, conforme descrito no item 3.2.1, mas utilizando-se a quantidade de $0,5 \mathrm{~g}$ de agar, $0,5 \mathrm{~g}$ de glicerol, $0,5 \mathrm{~g}$ de formaldeído e 1,5 g de ácido acético. 
Após o término do preparo da solução de gelatina e do agar, misturou-se as duas soluções, agitou-se por 10 minutos e colocou-se as misturas em Placas de Petri que foram secas em estufa a $50{ }^{\circ} \mathrm{C}$ por 48 horas. Após secagem as amostras foram mantidas em dessecador até a realização das análises de caracterização.

\subsection{3 - Preparos dos Eletrólitos de Blendas de Agar com Quitosana}

Deixou-se sob agitação magnética $0,55 \mathrm{~g}$ de chitosana (Sigma-Aldrich, com massa molecular de $3 \times 10^{4}-6 \times 10^{4}$, viscosidade de 200-800 cpx com $1 \%$ $\mathrm{CH}_{3} \mathrm{COOH}$ e grau de desacetilação de $70 \%$ ) em $55 \mathrm{~mL}$ de solução de ácido acético em água (10\% em peso) por 12 horas, então a solução foi filtrada à vácuo e adicionou-se $0,8 \mathrm{~g}$ de glicerol ao filtrado, deixou-se sob agitação magnética por 10 minutos para completa homogeneização.

Simultaneamente foi preparada a solução de agar, conforme descrito no item 3.2.1, mas utilizando-se a quantidade de $0,5 \mathrm{~g}$ de agar, $0,5 \mathrm{~g}$ de glicerol, $0,5 \mathrm{~g}$ de formaldeído e 1,5 g de ácido acético.

Após o término do preparo da solução de quitosana e do agar, misturou-se as duas soluções, agitou-se por 10 minutos e colocou-se as misturas em Placas de Petri que foram secas em estufa a $50^{\circ} \mathrm{C}$ por 48 horas. Após secagem as amostras foram mantidas em dessecador até a realização das análises de caracterização.

\subsection{4 - Preparos dos Eletrólitos de Agar com PEDOT:PSS}

Preparou-se os eletrólitos com $0,5 \mathrm{~g}$ de agar (Sigma-Aldrich) disperso em 25

$\mathrm{mL}$ de água Millipore Milli-Q com a resistividade controlada de $18,2 \mathrm{~m}^{-1} \mathrm{~cm}^{-1}$ à $25^{\circ} \mathrm{C}$. A dissolução foi feita sob agitação magnética constante e aquecimento a $100^{\circ} \mathrm{C}$ 
Posteriormente, adicionou-se diferentes quantidades de glicerol $(0,2-0,5 \mathrm{~g})$, diferentes quantidades de PEDOT:PSS $(0,2-0,5 \mathrm{~g}), 0,5 \mathrm{~g}$ de formaldeído (para promover a reticulação do agar e permitir a formação dos filmes) e uma fonte de prótons, a partir da introdução de ácido acético glacial, em diferentes concentrações (1,0 - 1,5 g). Em um segundo momento, utilizou-se como fonte de íons um sal de lítio, em diferentes concentrações $(0,2-0,5 \mathrm{~g})$, no caso o $\mathrm{LiClO}_{4}$. Foi utilizado o sistema PEDOT:PSS = 0,5 \% : 0,8 \% em massa (Sigma-Aldrich - 1,3 \% em peso disperso em $\mathrm{H}_{2} \mathrm{O}$ ).

A solução viscosa foi dispersa em uma placa de Petri e seca durante 48 horas na estufa a $50^{\circ} \mathrm{C}$. Os filmes obtidos foram estocados em um dessecador até a realização das análises de caracterização.

\section{3 - Caracterização dos Filmes}

\subsection{1 - Análise Termogravimétrica (TG)}

As análises termogravimétricas foram feitas em equipamento da marca SHIMADZU modelo TGA-50, utilizando-se aproximadamente $3 \mathrm{mg}$ de amostra, a qual foi aquecida de temperatura ambiente a $800^{\circ} \mathrm{C}$, com taxa de aquecimento de 10 @C/min sob atmosfera dinâmica de $\mathrm{N}_{2}$ e fluxo de $50 \mathrm{~mL} / \mathrm{min}$.

\subsection{2 - Calorimetria Diferencial de Varredura (DSC)}

Nas análises de calorimetria exploratória diferencial (DSC) foram realizadas duas corridas para cada amostra, com o objetivo principal de verificar a temperatura de transição vítrea do material $\left(\mathrm{T}_{\mathrm{g}}\right)$. A primeira corrida foi realizada da temperatura ambiente até $120^{\circ} \mathrm{C}$, corrida esta realizada com o objetivo de ambientar 
termicamente a amostra e eliminar a umidade, se ainda presente, foi utilizado para esta corrida uma taxa de aquecimento de $20^{\circ} \mathrm{C} / \mathrm{min}$. A segunda corrida foi realizada

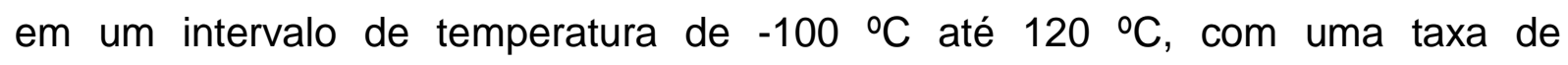
aquecimento de $10 \stackrel{\circ}{\circ} / \mathrm{min}$. A quantidade de amostra utilizada foi de aproximadamente $20 \mathrm{mg}$.

Para esta análise foi utilizado um equipamento SHIMADZU DSC-50, portaamostra de alumínio tampado, atmosfera dinâmica de $\mathrm{N}_{2}$ com fluxo de $100 \mathrm{~mL} / \mathrm{min}$.

\subsection{3 - Espectroscopia de Impedância Eletroquímica (EIE)}

O sistema utilizado para determinação da condutividade está representado nas Figuras 5 e 6 . A amostra foi prensada entre dois eletrodos de aço inoxidável polidos que estão contidos dentro de um cilindro de teflon ${ }^{\circledR}$. O contato elétrico inferior possui uma haste de aço inox onde está soldado um fio. O contato elétrico superior possui uma haste de aço inoxidável vazada. Ambos os contatos elétricos e a amostra ficam num compartimento isolado do ambiente, sob vácuo. Um termopar foi colocado dentro da haste superior (próximo da amostra), no interior do cilindro, permitindo a leitura direta da temperatura do sistema. Os eletrodos possuem um diâmetro de $15 \mathrm{~mm}$. O aquecimento da célula (da temperatura ambiente até $80^{\circ} \mathrm{C}$ ) foi realizado com auxílio de um forno EDG 5P. 


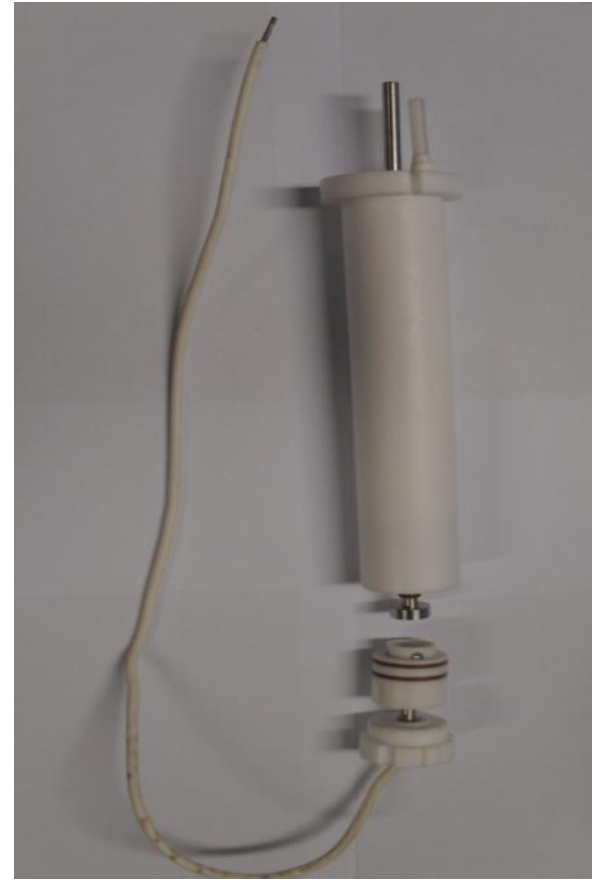

Figura 5 - Célula utilizada na realização da análise de espectroscopia de impedância eletroquímica.

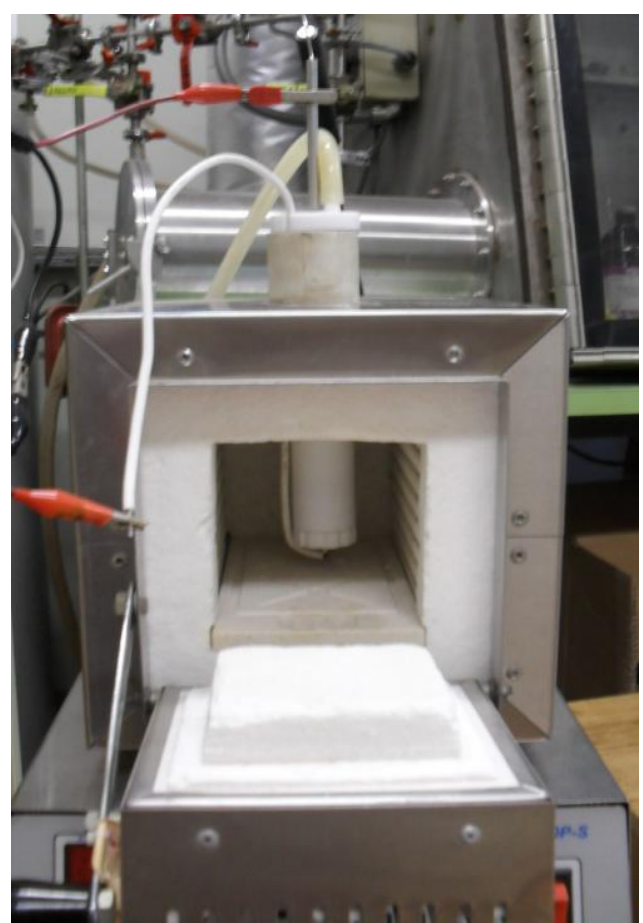

Figura 6 - Célula de medida dentro do forno sistema utilizado na realização da análise de espectroscopia de impedância eletroquímica.

O diagrama de impedância é obtido através do equipamento Solartron modelo SI 1260, em um intervalo de freqüência de $0,1 \mathrm{~Hz}$ a $10^{7} \mathrm{~Hz}$, com voltagens aplicadas em amplitude de $5 \mathrm{mV}$. As medidas foram realizadas sob vácuo, para evitar a influência da umidade e uma melhora na fixação do filme nos eletrodos de aço.

Para efetuar-se o cálculo da resistência do eletrólito foi feita uma extrapolação das duas partes do semicírculo do gráfico de impedâncias até o eixo x. Considera-se um circuito equivalente do tipo $\mathrm{RC} / /$ e, para a extrapolação foi utilizado o ajuste efetuado pelo programa do equipamento Solartron modelo 1260.

Obtendo o valor da resistência da amostra (R), é possível calcular a condutividade iônica da mesma, através da equação 3 :

$\sigma=I /(R \cdot s)$

sendo l é a espessura do filme e s a área superficial. 
O aumento da temperatura provoca uma mudança significativa no espectro de impedância. Ocorre o desaparecimento do semicírculo referente à parte resistiva, desta forma o cálculo da resistência é feito pela extrapolação da parte capacitiva no eixo $x$.

\subsection{4 - Espectroscopia de Impedância Eletroquímica (EIE) com Umidade}

\section{Controlada.}

A influência da água sobre a condutividade iônica foi verificada através de medidas de condutividade para amostras acondicionadas em ambientes com determinadas e constantes umidades relativas do ar. Este ensaio foi realizado acondicionando-se as amostras por 24 horas em células fechadas hermeticamente (Figura 7) contendo solução saturada de $\mathrm{NaNO}_{3}$, a qual satura o ambiente interno das células com umidade controlada em $33 \%$. Logo em seguida, foram realizadas as medidas de condutividade iônica do filme a temperatura ambiente.

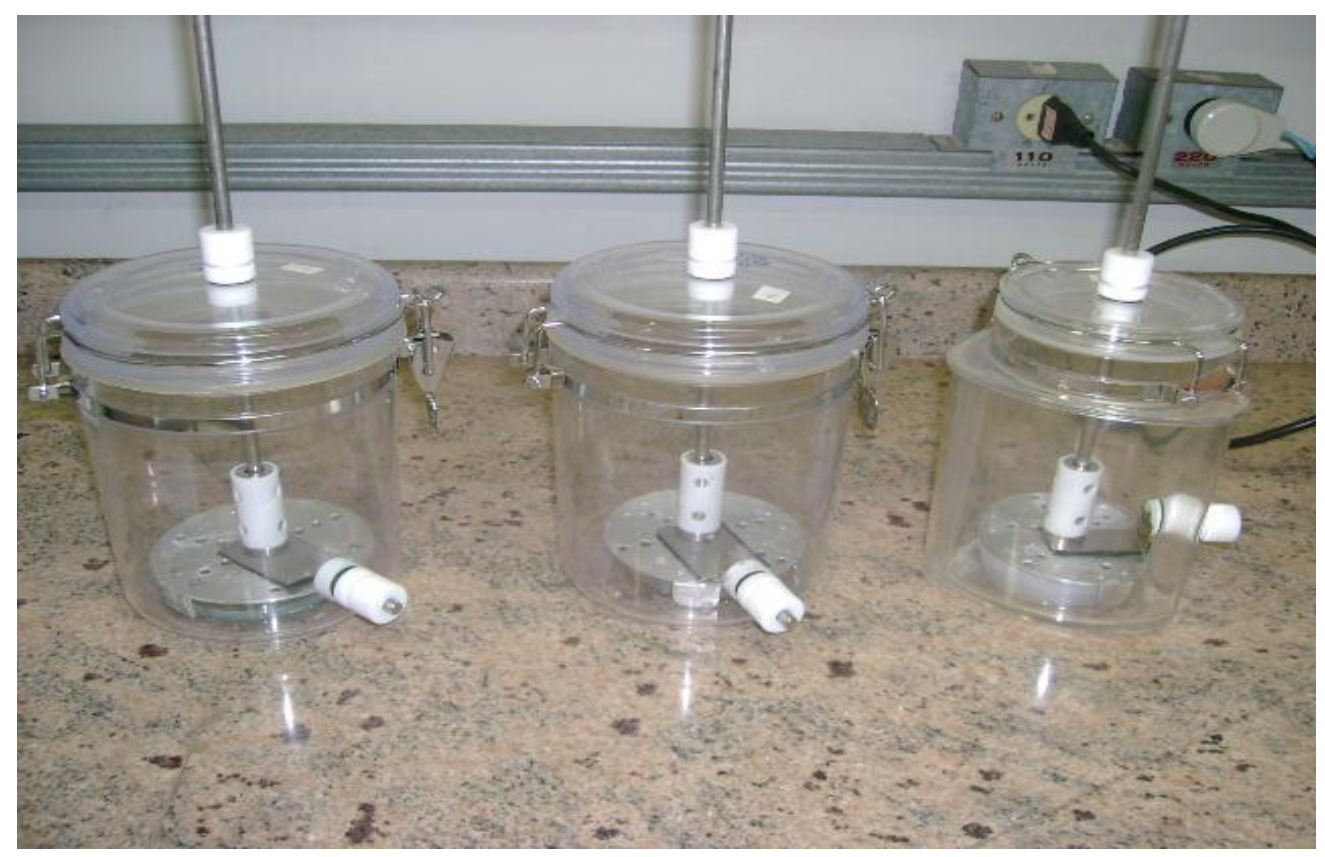

Figura 7 - Células fechadas utilizadas na realização da análise de espectroscopia de impedância, com umidade controlada. 


\subsection{5 - Espectroscopia no Ultravioleta-Visível (UV-vis)}

A técnica de espectroscopia de UV/VIS opera em duas faixas de luz, no ultravioleta de 190 à 400 nm, no visível de 400 a 800 nm e no infravermelho próximo de 800 a $2000 \mathrm{~nm}$. Os espectros foram obtidos dos filmes de espessura média de 0,20 mm - empregando-se o espectrômetro da marca Hewlett Packard e HITACHI modelo U-3501, Agilent Instruments ou Varian 5G.

\subsection{6 - Difração de Raios-X}

Os difratogramas foram obtidos com Difratômetro Universal de Raios-X URD6, CARL ZEISS JENA, a potência $m=40 K V / 100 \mathrm{~mA}$ e $\mathrm{I}(\mathrm{CuK} \alpha)=1540 \AA$, em um intervalo de ângulo de $5-40^{\circ}(2 \theta)$ sobre os filmes à temperatura ambiente.

\subsection{7 - Microscopia Eletrônica de Varredura (MEV)}

A morfologia dos diferentes filmes preparados foi analisada em um microscópio eletrônico de varredura digital, marca LEO, modelo 440. Os filmes foram colocados sobre uma fita adesiva de carbono, no porta-amostra de alumínio e recobertas com ouro, com espessura de recobrimento de $20 \mathrm{~nm}$. A corrente do feixe utilizado foi de $1 \mathrm{pA}$ e a potência do feixe de $15 \mathrm{KV}$. Os filmes foram previamente secos em estufa a $40^{\circ} \mathrm{C}$ antes de serem fixados no porta-amostra.

\section{4 - Dispositivos Eletrocrômicos}

\subsection{1 - Montagem dos Dispositivos Eletrocrômicos}

Foram montados dispositivos eletrocrômicos (DECs) com a configuração vidro/ITO $\mathrm{WO}_{3} /$ eletrólito/CEO $2-\mathrm{TiO}_{2} / \mathrm{TTO} /$ idro e com área de $2 \mathrm{~cm}^{2}$, sendo o 
vidro/ITO um substrato condutor transparente comercial (Delta Technologies) e os filmes de $\mathrm{WO}_{3}$ e $\mathrm{CeO}_{2}-\mathrm{TiO}_{2}$, obtidos a partir de soluções coloidais (obtidas pelo processo sol-gel) espalhadas pelo método dip coating. Os DECs foram obtidos de duas maneiras, (i) com eletrólito injetado e (ii) eletrólitos depositados na forma de membranas. No caso de DECs com eletrólito injetado as duas camadas de vidro/ITO/ $\mathrm{WO}_{3}$ e vidro/ITO/CeO $-\mathrm{TiO}_{2}$ foram unidas usando fita adesiva (Scoth Magic Tape 3M) de espessura de $50 \mu \mathrm{m}$ como espaçador. Foi deixado $5 \mathrm{~mm}$ de espaço livre para o contato elétrico. Então, foi colada uma fita condutora de cobre nesse espaço livre de cada substrato para a conecção elétrica. A solução viscosa de eletrólito foi finalmente injetada com uma seringa entre as duas camadas de vidro, com o cuidado de evitar qualquer formação de bolhas de ar durante a injeção da amostra. Após secagem foram feitas as caracterizações dos dispositivos.

A montagem do dispositivo com eletrólito na forma de membrana foi feita depositando a membrana condutora iônica a base de agar sobre os filmes eletrocrômicos $\mathrm{WO}_{3}$, e prensando o contra-eletrodo $\mathrm{CeO}_{2}-\mathrm{TiO}_{2}$, sobre o eletrólito formando uma estrutura de camadas (sandwich).

Foram montadas janelas com os filmes de $\mathrm{WO}_{3}, \mathrm{CeO}_{2}-\mathrm{TiO}_{2}$ e com os seguintes eletrólitos contendo:

1. Agar e ácido acetico.

2. Agar e $\mathrm{LiClO}_{4}$.

3. Blenda de agar com gelatina.

4. Blenda de agar com quitosana. 


\subsection{2 - Voltametria Cíclica e Cronoamperometria}

As medidas eletroquímicas das janelas eletrocrômicas foram obtidas com um potenciostato/galvanostato Autolab PGSTAT 302N. No caso de medidas voltamétricas foram aplicados potenciais entre $-3,5$ e $3 \mathrm{~V}$ nos dois ciclos inciais e depois usando potenciais de $-2,5$ e $2 \mathrm{~V}$. No caso das medidas cronoamperométricas foram utilizados mesmos potenciais com tempos de $15 \mathrm{~s} / 15 \mathrm{~s}$.

\subsection{3 - Medidas Ótico-eletroquimicas}

As medidas ótico-eletroquímicas foram feitas para estudar as diferenças na transmitância das janelas entre o estado colorido e transparente em função do comprimento de onda $(\lambda)$, desde a região do ultravioleta $(250 \mathrm{~nm})$ ao infravermelho próximo $(2200 \mathrm{~nm})$ do espectro eletromagnético. Para isso, conectou-se a célula eletroquímica com as janelas ao potenciostato/galvanostato Autolab PGSTAT 302N, e polarizou-se as janelas com o potencial de $-3,5 \mathrm{~V}$ (estado colorido), desconectou-a ou não adaptou-a ao espectrofotômetro Varian 5G ou Agilent Instruments e mediuse a transmissão ótica. O mesmo procedimento foi feito para o estado descolorido $(+3,0 \mathrm{~V})$ 


\section{CAPÍTULO 4 - CARACTERIZAÇÃO DO AGAR: RESULTADOS E DISCUSSÕES}

Os eletrólitos poliméricos géis (EPGs) estudados neste trabalho, foram preparados utilizando-se agar (Sigma - Aldrich) como material base. Para um melhor entendimento deste material, propôs-se a caracterização do mesmo, utilizando as técnicas de análise elementar, análise viscosimétrica e espectroscopia no infravermelho.

\section{1 - Análise Elementar}

Com o objetivo de analisar a composição química dos polímeros naturais utilizados como material de partida para obtenção de eletrólitos foram realizadas medidas de análise elementar. Por meio dessa técnica foram quantificados os teores de carbono, oxigênio, nitrogênio e enxofre nas amostras utilizadas. Os resultados estão dispostos na Tabela 1.

Tabela 2: Composição química do agar utilizado no preparo das membranas

\begin{tabular}{|c|c|c|c|c|c|}
\hline & $\begin{array}{c}(\%) \\
\text { Nitrogênio }\end{array}$ & $(\%)$ Carbono & $\begin{array}{c}(\%) \\
\text { Hidrogênio }\end{array}$ & $(\%)$ Oxigênio & $(\%)$ Enxofre \\
\hline Teórico & 0 & 49,31 & 6,86 & 43,83 & 0 \\
\hline Experimental & 0,17 & 40,44 & 7,35 & 51,1 & 0,94 \\
\hline
\end{tabular}

De acordo com os resultados obtidos pode-se verificar a presença de uma pequena porcentagem de enxofre, característico da formação estrutural da agaropectina. Os cálculos teóricos foram feitos baseados em uma estrutura do agar 
não sulfatado e totalmente metoxilado. A partir dos resultados experimentais obtidos foram simuladas as substituições da unidade repetitiva do agar, desta forma pode-se dizer que o agar utilizado foi $5 \%$ sulfatado, referente as frações correspondentes à agaropectina $^{1-3}$.

\section{2 - Determinação de Massa Molar do Agar por Técnica Viscosimétrica}

A viscosidade de soluções poliméricas é basicamente uma medida do volume hidrodinâmico (tamanho ou extensão no espaço) do polímero em solução, estando empiricamente relacionada à massa molar de polímeros lineares ${ }^{4}$. A simplicidade desta técnica permite sua ampla utilização na caracterização de macromoléculas. A medida de viscosidade de soluções poliméricas é resultado da comparação entre o tempo de escoamento do solvente num capilar calibrado ( $\left.t_{0}\right)$ e o da solução a determinada concentração $\left(t_{s}\right)$. A partir destas medidas físicas são definidos vários parâmetros $^{4-5}$ :

- Viscosidade relativa ( $\left.\eta_{\text {rel }}\right)$; parâmetro adimensional:

$\eta_{\text {rel }} \approx t / t_{0}$

- Viscosidade específica $\left(\eta_{\mathrm{sp}}\right)$; parâmetro adimensional:

$\eta_{\mathrm{sp}}=\eta_{\mathrm{rel}}-1$

- Viscosidade reduzida $\left(\eta_{\text {red }}\right)$; tem como dimensão o inverso da concentração:

$\eta_{\text {red }}=\eta_{\text {sp }} / C$

- Viscosidade intrínseca ([ๆ]); tem como dimensão o inverso da concentração:

$$
[\eta]=\lim _{c \rightarrow 0}\left[\eta_{s p} / C\right]
$$

A viscosidade intrínseca é independente da concentração, entretanto depende do solvente utilizado para a realização das medidas. Este parâmetro reflete as propriedades da macromolécula individual, ou seja, reflete as propriedades de 
uma única molécula em solução. A medida de viscosidade intrínseca é feita pela extrapolação do gráfico de viscosidade reduzida versus concentração à diluição infinita. Esta extrapolação é realizada com base na equação de Huggins ${ }^{4}$,

$\eta_{\text {red }}=[\eta]=k[\eta]^{2} \mathrm{C}$

Sendo k é uma constante característica do polímero e de sua massa molar.

A Figura 8 abaixo apresenta o gráfico da viscosidade reduzida para as soluções de agar em solução aquosa de $\mathrm{NaCl} 0,1 \mathrm{M}$ versus cinco diferentes concentrações destas soluções. A partir deste gráfico foi obtido o valor de viscosidade intrínseca $[\eta]=595,01 \mathrm{~mL} \cdot \mathrm{g}^{-1}$ para o agar utilizado .

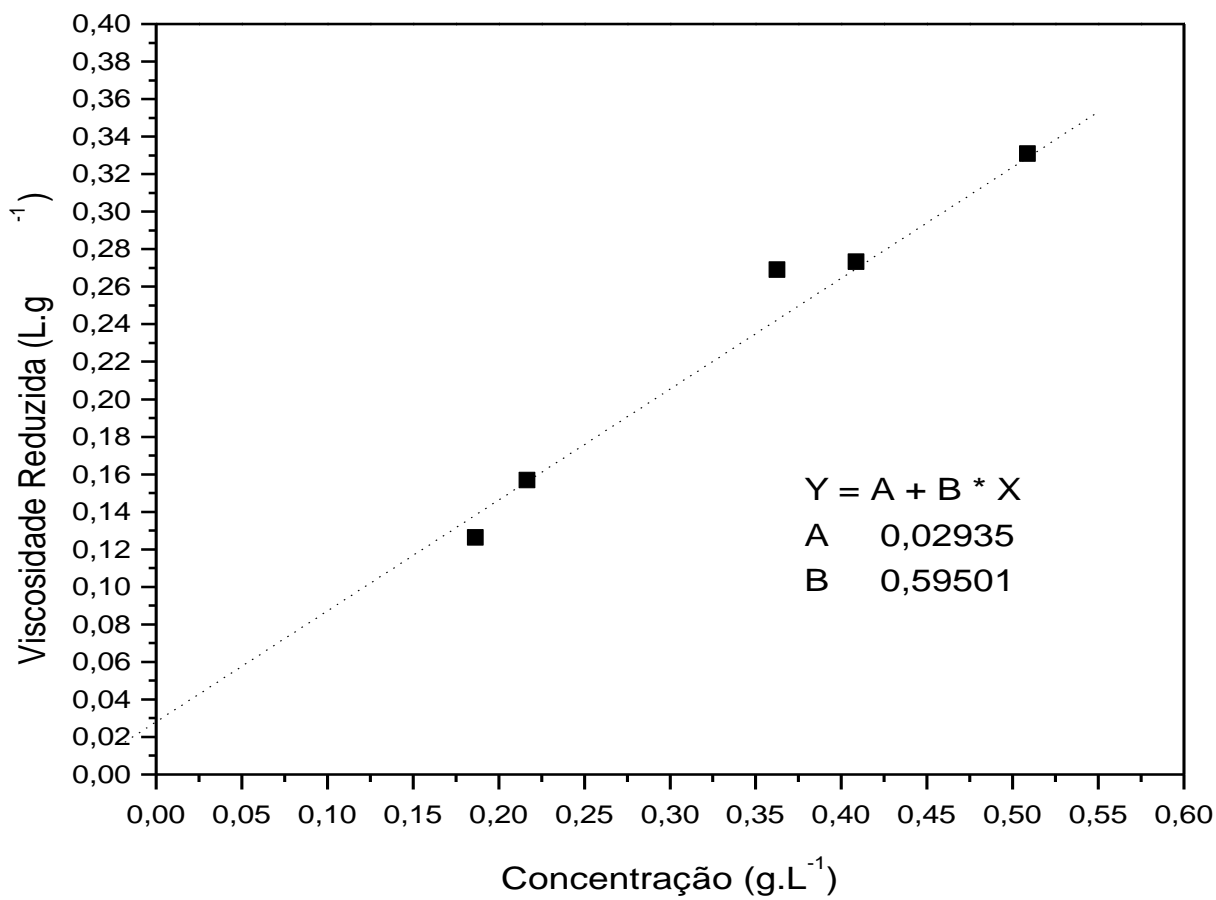

Figura 8: Gráfico de viscosidade reduzida versus concentração das diferentes soluções de agar utilizadas na análise viscosimétrica.

A dependência da viscosidade intrínseca com a massa molar é dada pela expressão geral (equação de Mark-Houvink) ${ }^{4}$

$[\eta]=\mathrm{KM}^{\mathrm{a}}$ 
Sendo a constante a está relacionada ao volume hidrodinâmico do polímero em solução como descrito na teoria de Flory e Fox 6 . Para soluções aquosas de agar a relação entre o parâmetro viscosimétrico aqui discutido e a massa molar do polímero é dada por (unidade de dL.g $\left.{ }^{-1}\right)^{6}$

$[\eta]=0,07 \mathrm{M}^{0,72}$

Logo a massa molecular determinada para o agar utilizado foi de $\mathrm{M} \sim 120.000 \mathrm{~g} / \mathrm{mol}$.

\subsection{3 - Análise Espectroscópica - FT-IR}

Embora o espectro de infravermelho seja característico da molécula como um toda, certos grupos de átomos dão origem a bandas que ocorrem mais ou menos na mesma freqüência, independentemente da estrutura da molécula. É justamente a presença destas bandas características de grupos que permite ao químico a obtenção, através de simples exame do espectro e consulta a tabelas, de informações estruturais úteis e é neste fato que foi feita a identificação de estruturas ${ }^{7}$

O espectro de infravermelho para o agar $^{7-9}$ está apresentado na Figura 9, em que se pode observar uma banda larga em $3397 \mathrm{~cm}^{-1}$ atribuída ao estiramento dos grupos hidroxila $\mathrm{O}-\mathrm{H}$, que participam de formação de ligações de hidrogênio inter e intramoleculares. As bandas em 2934 e $2887 \mathrm{~cm}^{-1}$ são referentes ao estiramento assimétrico de $\mathrm{C}-\mathrm{H}$, em $1653 \mathrm{~cm}^{-1}$ a água adsorvida e em 1438 e $1360 \mathrm{~cm}^{-1}$ a deformação angular da ligação C-H. O estiramento da ligação C-O de éter aparece em $1164 \mathrm{~cm}^{-1}$ e o estiramento da ligação C-O de álcool em $1087 \mathrm{~cm}^{-1}$. 


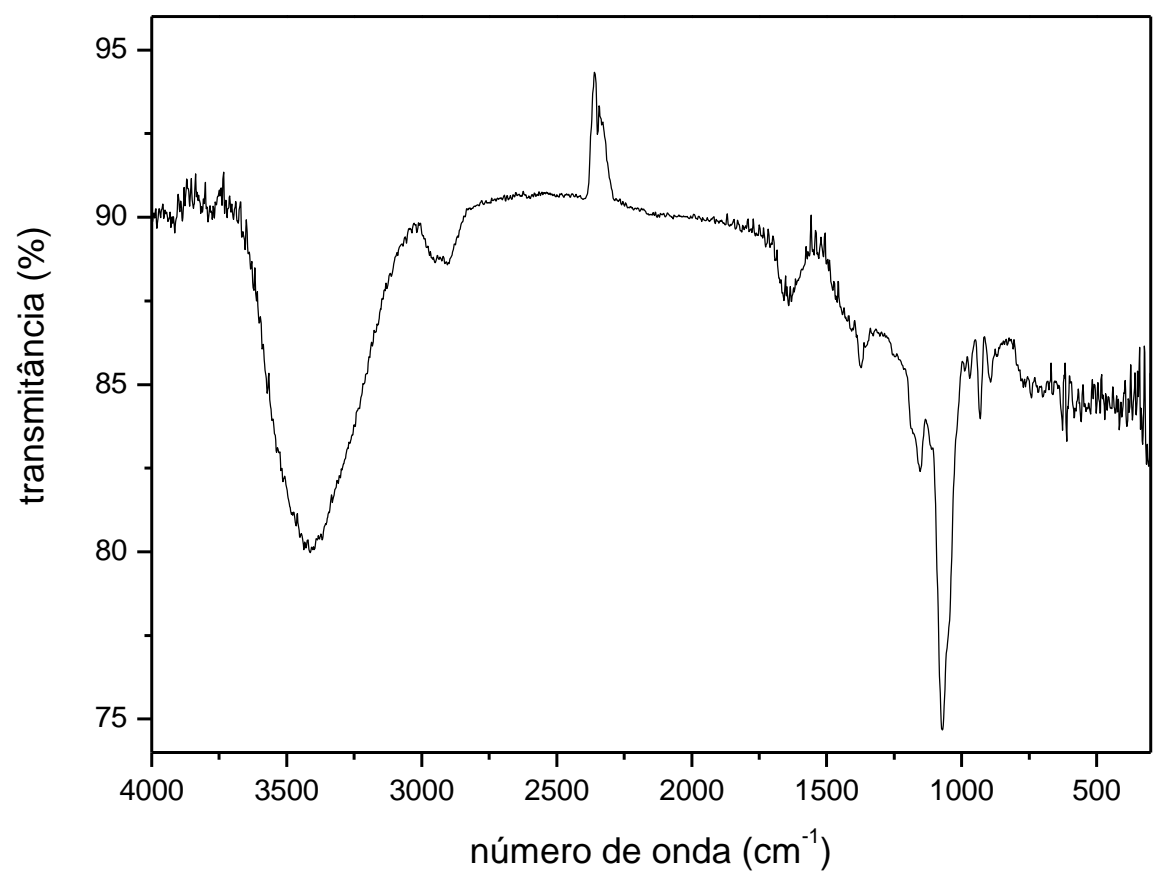

Figura 9: Espectro de FT-IR do agar.

\subsection{4 - Difração de Raios-X}

Analisando-se o difratograma de raios-X, Figura 10, pode-se observar que o agar é um polímero semicristalino, pois apresenta dois ombros sobrepostos. O primeiro pico, centrado em $14,3^{\circ}$ é mais estreito e com menor intensidade que 0 segundo, centrado em $18,6^{\circ}$, mais largo e com intensidade maior. Além dos dois picos observa-se um terceiro ombro de pequena intensidade centrado em 26,9 


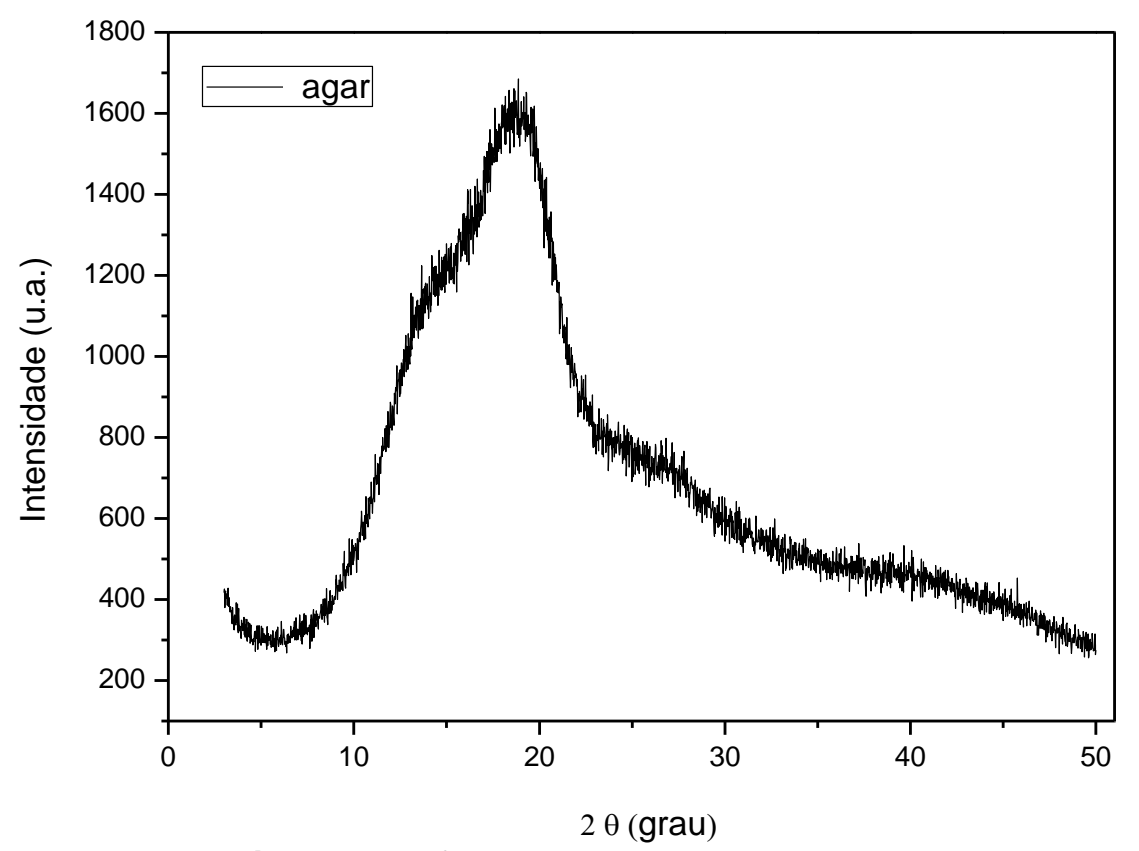

Figura 10: Difratograma de raios-X para o agar.

\section{Referências Bibliográficas}

[1] CUBILLOS R. El agar-agar chileno. Revista de Biología Marina y Oceanografía, v. 3, p. 70 - 88, 1951.

[2] ETCHEVERRY, H. Algas marinas chilenas productoras de ficocoloides, Revista de Biología Marina y Oceanografía, v. 8, p. 153 - 174, 1958.

[3] LLAÑA, A. H. Algas industriales de Chile. Revista de Biología Marina y Oceanografía, v. 1, n. 2, p. 124 - 131, 1948.

[4] BILLMEYER, F. W. Textbook of polymer science. 3.ed. New York: John Wiley, 1984. p. 208-213.

[5] BROWN, W.; HENLEY, O.; OHMAN, J. Studies on Cellulose Derivatives, Part II: the influence of solvent and temperature on the configurational and hydrodynamic behavior of hydroxyethylcellulose in dilute solution. Makromoleculare Chemie, v. 64, p. $49-67,1963$.

[6] ROCHAS, C.; LAHAY, M. Average molecular wight and molecular weight distribution of agarose and agarose type polysaccharides. Carbohydrate Researches, v. 10, p. 289 - 298, 1989. 
[7] SILVERSTEIN, R. M.; BASSLER, G. C.; MORRILL, T. C. Identificação espectrométrica de compostos orgânicos. Tradução de Ricardo Bicca de Alencastro. 5ª . ed. Rio de Janeiro: Guanabara Koogan, 1994. p. 387.

[8] TAKANO, R.; YOSHIKAWA, S.; UEDA, T.; HAYASHI, K.; HIRASE, S.; HARA, S. Sulfation of polysaccharides with sulfuric acid mediated by dicyclohexylcarbodiimide. Journal of Carbohydrate Chemistry, v. 15, p. 449, 1996.

[9] CHHATBAR, M. U.; MEENA, R. PRASAD, K.; SIDDHANTA, A. K. Agar/sodium alginato-graft-polyacrylonitrile, a stable hydrogel system. Indian Journal of Chemistry, v. 48A, p. 1085 - 1090, 2009. 


\section{CAPÍTULO 5 - CARACTERIZAÇÃO DOS ELETRÓLITOS DE ÁGAR COM ÁCIDO ACÉTICO - RESULTADOS E DISCUSSÕES.}

\section{1 - Análise Termogravimétrica (TG)}

Como os eletrólitos poliméricos estão sendo desenvolvidos para serem aplicados em diversos dispositivos eletroquímicos, é interessante conhecer não somente suas vantagens em relação aos valores de condutividade iônica, mas, também, seus limites de funcionamento, ou seja, a temperatura de degradação. Assim, os eletrólitos com diferentes quantidades de ácido acético foram submetidos às análises termogravimétricas (TG), cujos, resultados são mostrados na Figura 11. As propriedades higroscópicas das amostras também podem ser verificadas através da TG. Através dos resultados obtidos pode-se observar que as amostras possuem uma quantidade de água retida de aproximadamente $10 \%$, a qual é eliminada no intervalo de aquecimento de $25^{\circ} \mathrm{C}$ a $120^{\circ} \mathrm{C}$. A saída desta água pode ocorrer até aproximadamente $200^{\circ} \mathrm{C}$. A partir de 230 a $330^{\circ} \mathrm{C}$ há uma brusca perda de massa, em torno de $80 \%$ cuja causa é a degradação das amostras. Esta mudança é citada na literatura como possíveis reações de hidrolise e de oxidação, seguida por reações em 340 a $520^{\circ} \mathrm{C}$, que correspondem ao estágio final da pirólise ${ }^{1}$. Acima de $360^{\circ} \mathrm{C}$ a perda de aproximadamente $8 \%$ de massa é referente provavelmente a pirólise do agar. Os teores de cinzas para as amostras com ácido acético foram em torno de $3 \%$, devido aos produtos formados pela oxidação do ácido acético. 


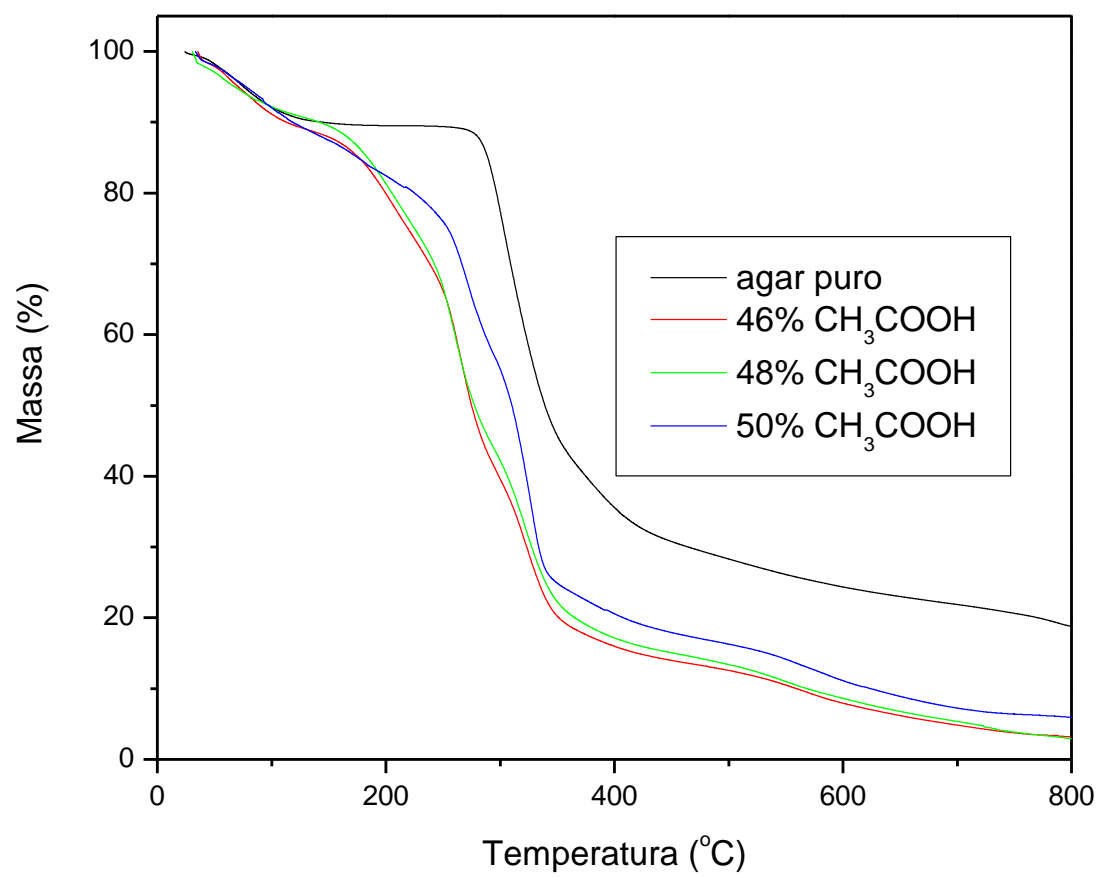

Figura 11 - Curvas de TG do agar puro e dos filmes contendo diferentes quantidades de ácido acético (\% em massa).

A Figura 11 mostra também, que a presença do plastificante e ácido no filme promove uma diminuição da temperatura de degradação das amostras estudadas. Enquanto o agar puro começa se degradar à aproximadamente $300^{\circ} \mathrm{C}$, as amostras plastificadas e contendo ácido acético, começam se degradar a partir de 230 $280^{\circ} \mathrm{C}$. Isto sugere a influência de alguns fatores, como por exemplo, a presença de água e de glicerol no sistema, que favorecem os rearranjos intermoleculares e facilitam a degradação do agar. Entretanto, o fator principal pode ser a presença do ácido, que pode agir como um catalisador nas reações de decomposição. A ação catalítica do ácido acético também pode ser evidenciada através da maior perda de massa das amostras com ácido acético quando comparadas com a amostra do agar puro, em torno de $18 \%$ a $800^{\circ} \mathrm{C}$. Porém, apesar de ocorrer esta diminuição da temperatura de degradação ainda pode-se afirmar que os filmes obtidos são bastante estáveis. 


\section{2 - Calorimetria Diferencial de Varredura (DSC)}

A adição de plastificantes no agar, além de garantir a estrutura predominantemente amorfa dos filmes contribui para a diminuição da temperatura de transição vítrea $\left(T_{g}\right)$ dos mesmos. Na técnica de DSC, uma transição de segunda ordem é identificada quando a curva se desvia da linha de base. Uma vez completada a transição, a difusão térmica reconduz a amostra ao equilíbrio. $\mathrm{O}$ máximo (ou mínimo) da curva pode representar a temperatura para a qual se completa a transição. As análises de DSC para os eletrólitos a base de agar com ácido acético (Figura 12) mostram mudanças na linha de base, típicas de transição vítrea $\left(T_{g}\right)$, onde obteve-se os valores de $T_{g}$ de cada amostra a partir de um ponto reprodutível traçando uma reta tangente à linha de base e outra tangente ao ramo inclinado inicial da curva. A $T_{g}$ está relacionada ao início de movimentos de longo alcance das cadeias poliméricas e influencia diretamente os valores de condutividade iônica, sendo assim constitui um dado de grande importância neste estudo ${ }^{2-4}$

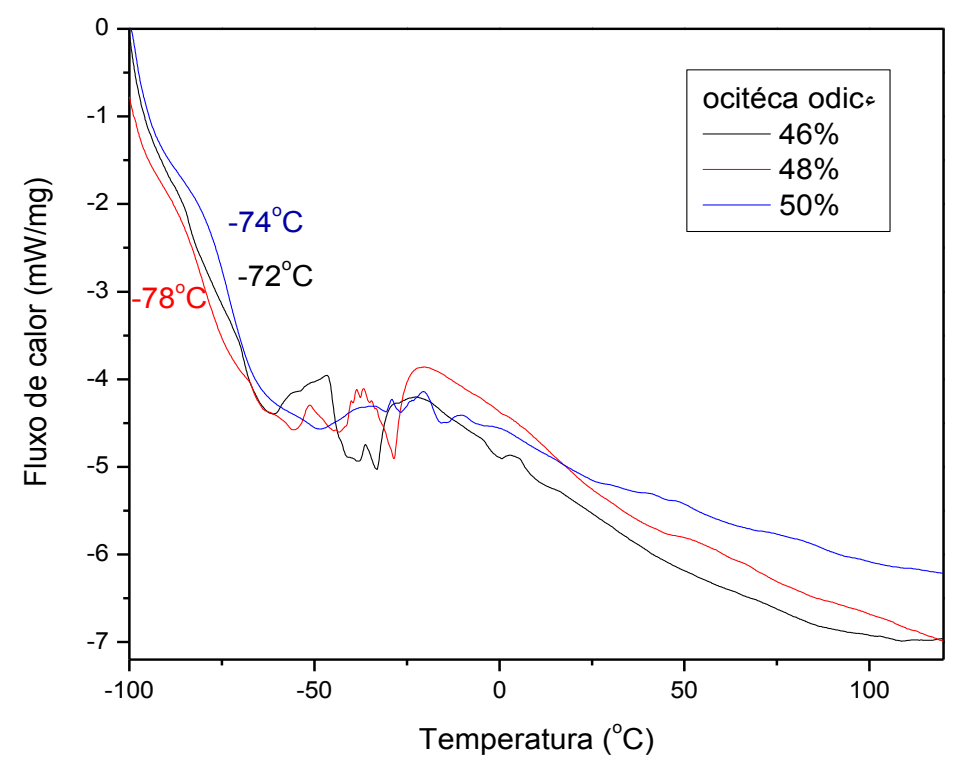

Figura 12 - Curvas de DSC dos filmes contendo diferentes quantidades de ácido acético (\% em massa). 
A Figura 12 mostra as mudanças na linha de base que ocorreram em torno de $-70^{\circ} \mathrm{C}$. Também, pode-se observar que as temperaturas de transição vítrea $(-72,-74$ e $-78^{\circ} \mathrm{C}$ ) são muito próximas para as amostras contendo diferentes quantidades de ácido acético, entretanto todas as amostras apresentaram a transição vítrea em temperatura sub ambiente, resultado este similar a outros eletrólitos a base de polímeros naturais ${ }^{5-6}$. As oscilações na linha de base observadas próximo à -60 até $-40^{\circ} \mathrm{C}$ não representam transições do material, e sim ruído do equipamento durante a realização do experimento.

\section{3 - Espectroscopia de Impedância Eletroquímica (EIE)}

A condutividade iônica depende de uma série de fatores, tais como a concentração das espécies, tipo de carga: iônica ou catiônica, temperatura, etc. ${ }^{7}$. A dependência da condutividade iônica em função da concentração de ácido promove informações sobre a interação específica entre o ácido e a matriz polimérica. Os valores de log $\sigma$ em função da concentração de $\mathrm{CH}_{3} \mathrm{COOH}$ (\% em massa) pode ser observado na Figura 13, onde a condutividade iônica do complexo polímero-próton aumenta com a concentração de próton até atingir um valor máximo de $1.40 \times 10^{-5} \mathrm{~S}$ $\mathrm{cm}^{-1}$ com $50 \%$ em massa de $\mathrm{CH}_{3} \mathrm{COOH}$. Acima desta concentração a condutividade diminui. Estes resultados estão de acordo com o esperado, pois a condutividade iônica tende a aumentar até um limite máximo da inserção de prótons, quando então começa a decrescer, devido principalmente à formação de agregados iônicos, o que prejudica a mobilidade dos íons na matriz ${ }^{8}$. 


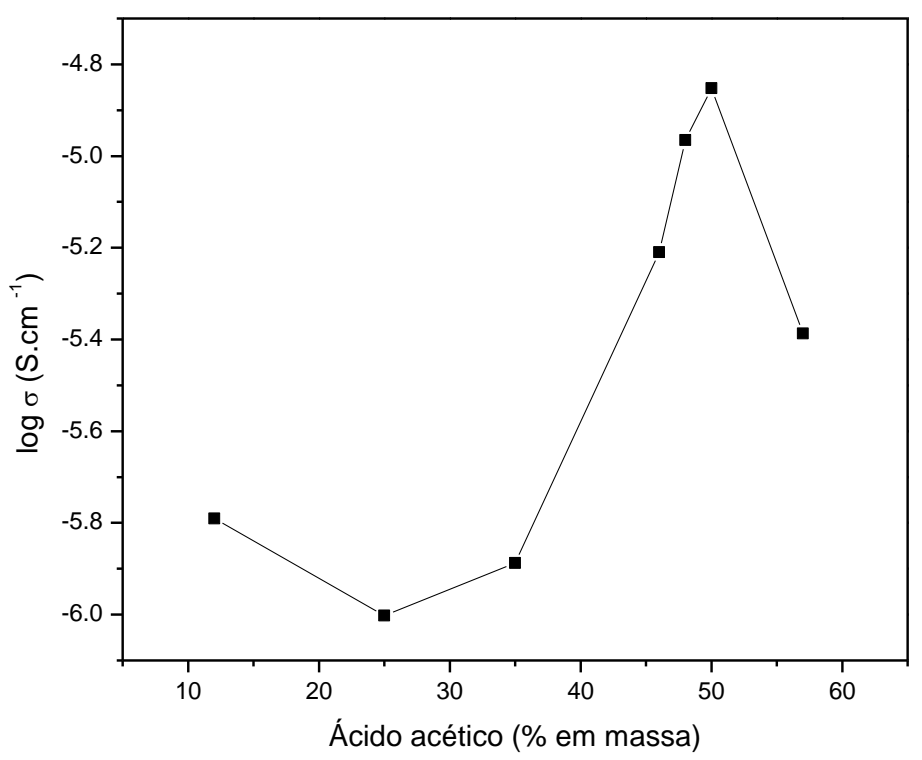

Figura 13 - Log $\sigma$ em função da concentração de ácido acético.

A Figura 14 mostra os gráficos de impedância complexa para o eletrólito a base de agar contendo $50 \%$ de ácido acético medida em diferentes temperaturas. 0 intercepto do semicírculo com o eixo real dá o valor da resistência do eletrólito $(\mathrm{R})$, a partir do qual pode-se calcular a condutividade iônica (conforme descrito anteriormente na sessão 3.3.3). A condutividade iônica aumenta de $1,1 \times 10^{-4} \mathrm{~S} / \mathrm{cm}$ para $9,6 \times 10^{-4} \mathrm{~S} / \mathrm{cm}$, com a variação de temperatura do ambiente até $80^{\circ} \mathrm{C}$, respectivamente. Em temperaturas mais elevadas, o movimento térmico dos segmentos da cadeia do polímero e da dissociação do ácido é melhor, induzindo um aumento na condutividade iônica total. Nos gráficos de impedância complexa (Figura 14), o desaparecimento do semicírculo em temperaturas mais elevadas pode ser observado. Isso indica o desaparecimento de qualquer regime capacitivo e iniciando um processo de difusão simples ${ }^{9}$. Os valores diminuem com o aumento da temperatura da amostra e da mobilidade iônica, no entanto, a concentração de portadores de carga nos eletrólitos poliméricos não aumenta necessariamente com a temperatura ${ }^{10}$. 


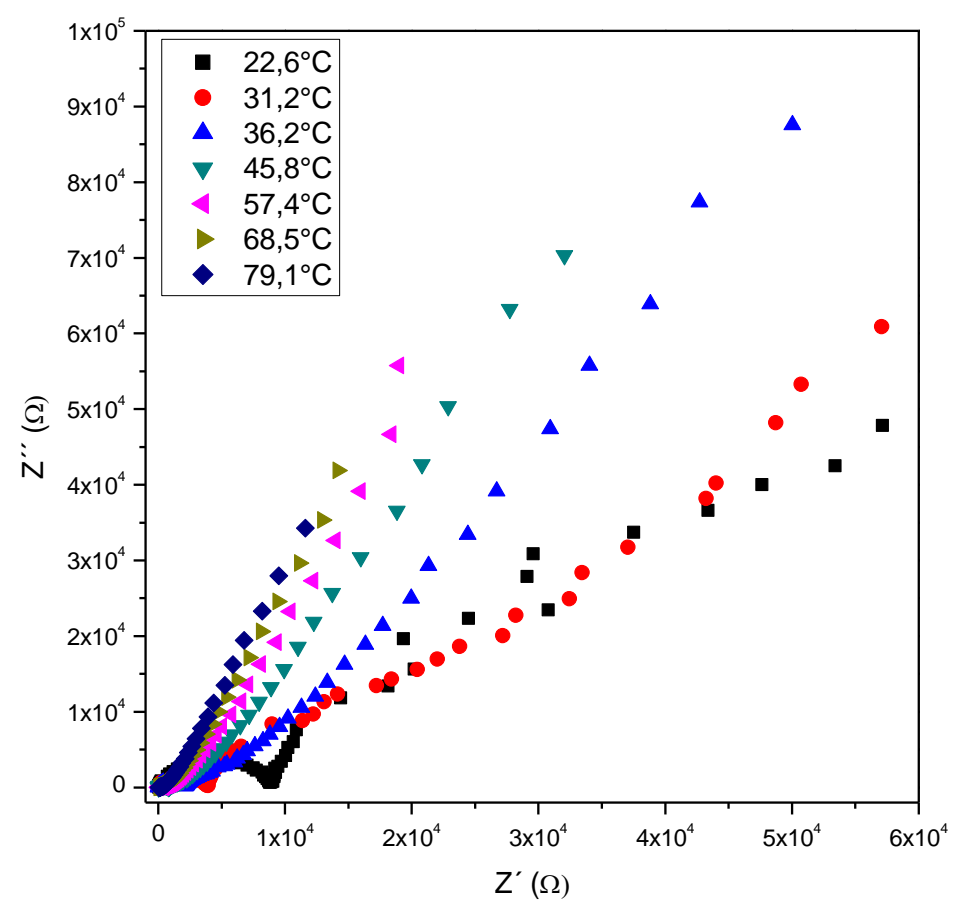

Figura 14 - Impedância complexa para o eletrólito com 50\% de ácido acético a diferentes temperaturas.

As medidas de condutividade iônica em função da temperatura foram realizadas, a fim de analisar o possível mecanismo de condução iônica nestes sistemas. A Figura 15 revela um mecanismo de condução do tipo Arrhenius em todos os eletrólitos de agar com ácido acético, onde não à participação de movimentos da cadeia polimérica no mecanismo de condução. Segundo este mecanismo também não há transição de fase no polímero de domínio e nem na matriz formada pela adição de ácido acético. Ocorre apenas o movimento dos prótons através da cadeia polimérica, onde o aumento da condutividade com a temperatura pode ser interpretado como um mecanismo de hopping entre os sítios de coordenação local, relaxamentos estruturais e movimentos segmentares dos complexos sal-polímero ${ }^{11-13}$. Os dados da Figura 15 estão em concordância com a equação de Arrhenius (1):

$\log \sigma=\log A+\left(-E_{a} / 2,303 R T\right)$ 


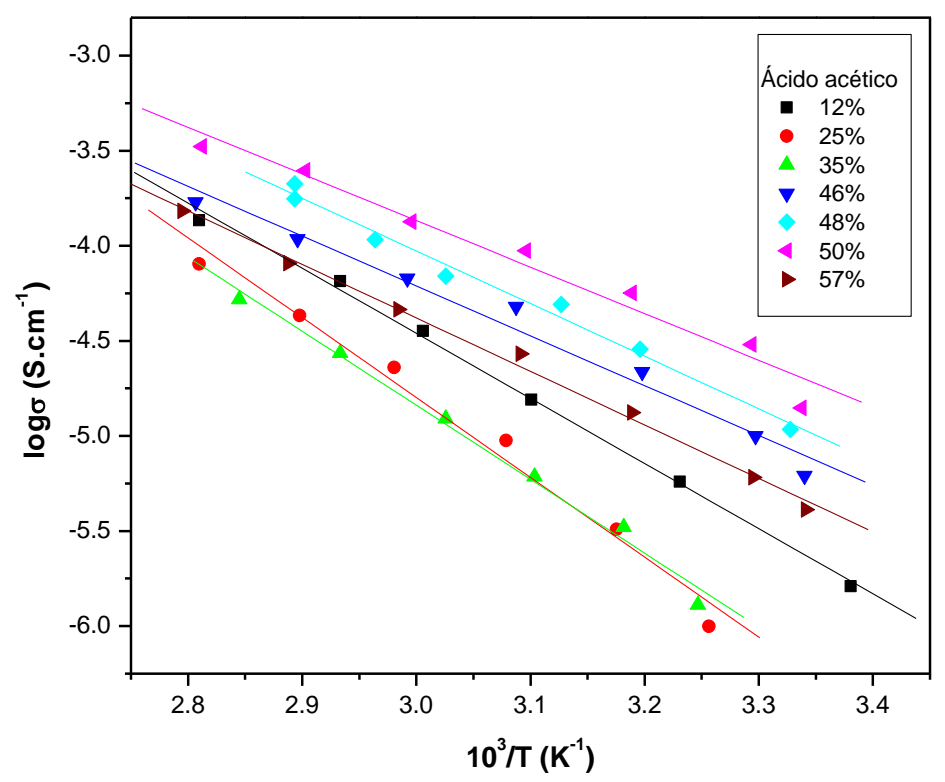

Figura 15 - Log da condutividade em função da temperatura para filmes com diferentes quantidades de ácido acético (\% em massa).

Obtendo-se o coeficiente angular das retas representadas nos gráficos de condutividade (Figura 15), determinou-se a energia de ativação para cada amostra, cujos valores estão apresentados na Figura 16. Nesta figura pode-se observar que a energia de ativação diminui gradualmente com o aumento na concentração de ácido acético. Isso indica que não só aumenta o número de portadores, com o aumento da concentração de ácido acético, mas também que as barreiras de energia são reduzidas ${ }^{14-15}$.

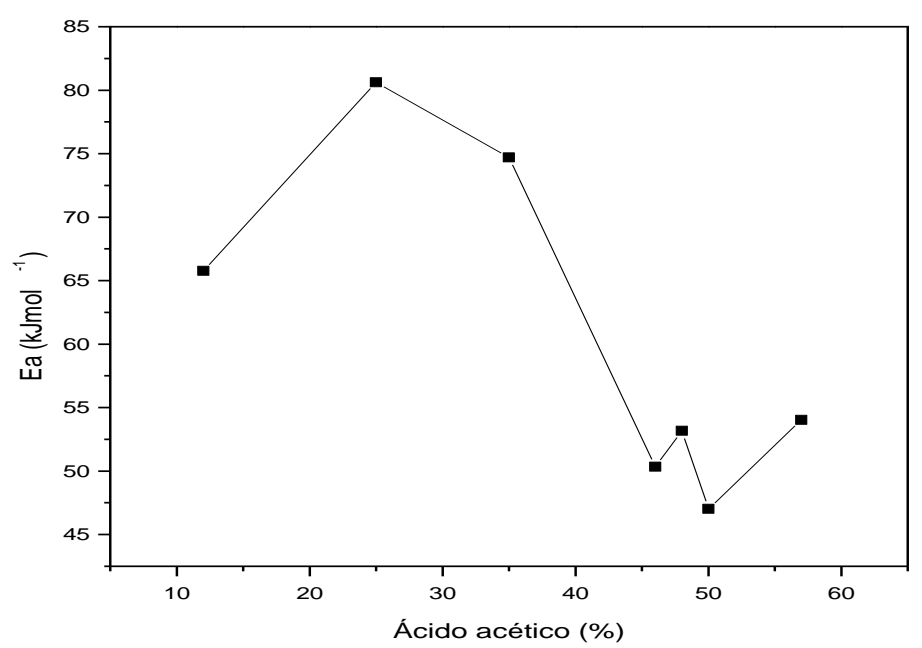

Figura 16 - Energia de ativação versus concentração de ácido acético (\% em massa). 
A Figura 17 apresenta o log da condutividade em função do potencial aplicado para a amostra que revelou a melhor condutividade iônica, i.e., 50\% em massa de ácido acético. Nota-se, para a amostra com ácido acético dois regimes, (i) na faixa de potencial que varia de $-2,5 \mathrm{~V}$ até $2,5 \mathrm{~V}$ e (ii) nas faixas de $-6 \mathrm{~V}$ a $-2,5 \mathrm{~V}$ e $2,5 \mathrm{~V}$ a $+6 \mathrm{~V}$. Nesses dois regimes valor da condutividade permanece quase constante, i.e., $9 \times 10^{-5} \mathrm{Scm}^{-1}$ no intervalo de $-2,5$ até $2,5 \mathrm{~V}$ e $4 \times 10^{-5} \mathrm{Scm}^{-1}$ no intervalo de $-6 \mathrm{~V}$ até $-2,5$ e $2,5 \mathrm{~V}$ até $6 \mathrm{~V}$. Ao passar para $+6,5 \mathrm{~V}$ ou $-6,5 \mathrm{~V}$ ocorre a diminuição do valor da condutividade. Desta forma, constatou-se que acima e abaixo de $6,5 \mathrm{~V}$ o eletrólito polimérico com ácido acético começa a sofrer alguma mudança estrutural, provavelmente devido à ocorrência de reações eletrolíticas.

Portanto, verificou-se que o eletrólito polimérico a base de agar plastificado com glicerol e contendo ácido acético, possui estabilidade em uma faixa de potencial que varia entre -6 a $+6 \mathrm{~V}$. Estes resultados nos indicam que os eletrólitos a base de agar apresentam ótima estabilidade eletroquímica, principalmente porque este eletrólito apresentou um intervalo de estabilidade superior à outros eletrólitos a base de polímeros naturais ${ }^{5}$.

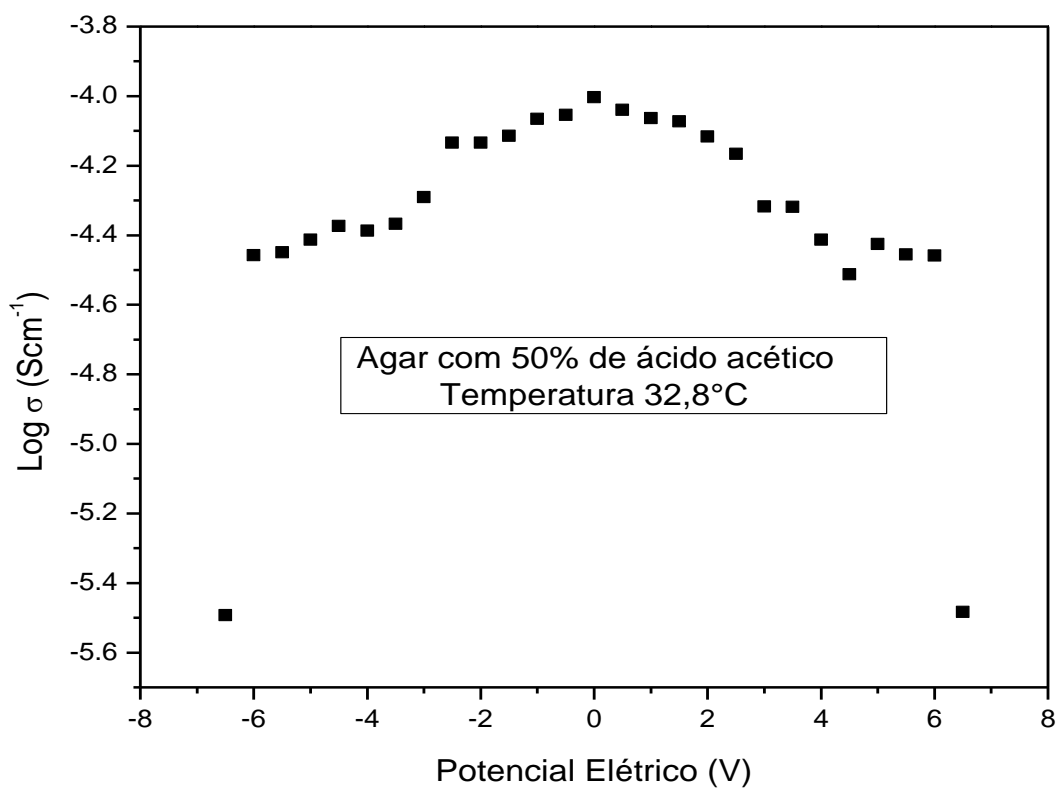

Figura 17: Janela de estabilidade eletroquímica do filme de agar com $50 \%$ (em massa) de ácido acético a temperatura de $32,8^{\circ} \mathrm{C}$. 


\section{4 - Espectroscopia de Impedância Eletroquímica (EIE) com Umidade}

\section{Controlada.}

Também foram realizadas medidas de condutividade iônica dos filmes preparados, controlando-se a umidade do meio, com a finalidade de se evitar a influência de absorção de água sobre a condutividade iônica, onde as amostras de EPGs a base de agar e ácido acético foram mantidas em um recipiente hermeticamente fechado, contendo uma solução saturada de $\mathrm{NaNO}_{3}$, que propicia uma umidade relativa interna fixa de $33 \%$. As medidas de condutividade iônica (Figura 18) foram realizadas em temperatura ambiente. Ao comparar estes resultados com os da Figura 13 pode-se notar que seguem exatamente a mesma evolução da condutividade em função da concentração em ácido acético com umidade e pressão reduzidas (medidas sob pressão reduzida), mas com um aumento dos valores de condutividade. Neste ensaio foi obtida a melhor condutividade de $2,17 \times 10^{-5} \mathrm{Scm}^{-1}$ para o eletrólito com $50 \%$ de ácido acético. Estes resultados comprovam que a presença de água é muito eficaz para aumentar os valores absolutos de condutividade protônica nestes sistemas. Resultados semelhantes também foram relatados para amostras de EPGs a base de amido plastificado, mas contendo sal de lítio ${ }^{16}$, e confirmados por estudos de RMN, que indicaram que a água absorvida melhorou a mobilidade de lítio $^{17}$. 


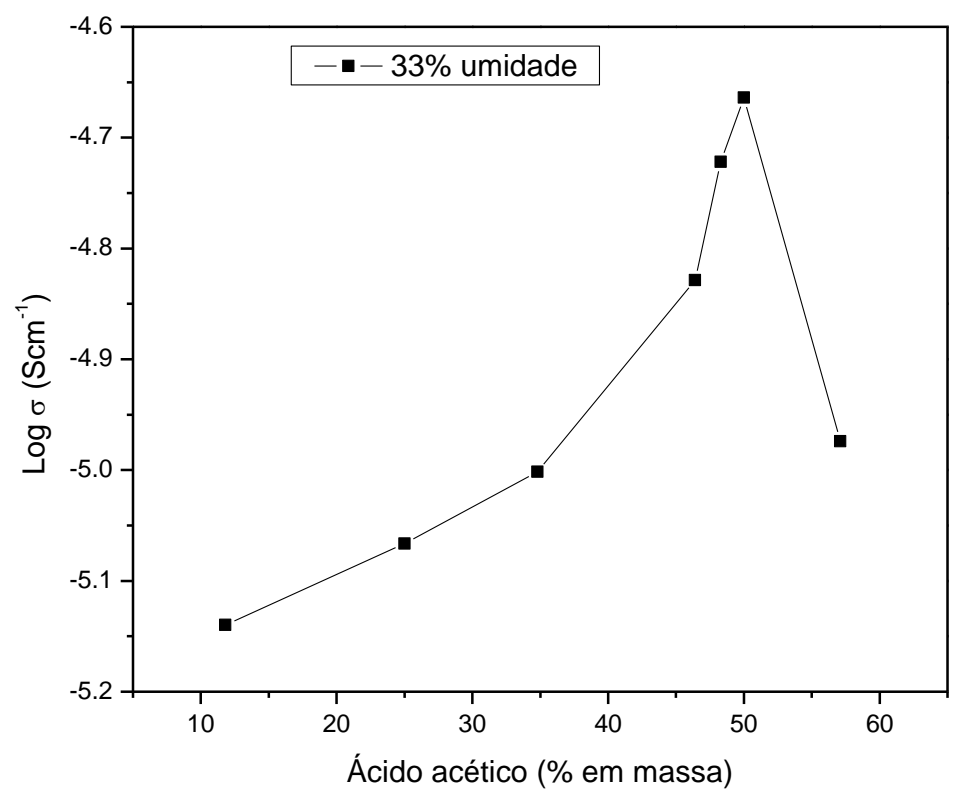

Figura 18 - Condutividade iônica dos filmes com 33\% de umidade relativa.

\section{5 - Espectroscopia no Ultravioleta-Visível (UV-vis)}

A Figura 19 apresenta os espectros de transmitância para os eletrólitos preparados no intervalo de freqüência de 190 a $1000 \mathrm{~nm}$. Pode-se observar que a transmitância de todas as amostras aumenta com o aumento do comprimento de onda, de zero na região UV (200 nm) até entre 70 e 92\% na região visível, dependendo da amostra.

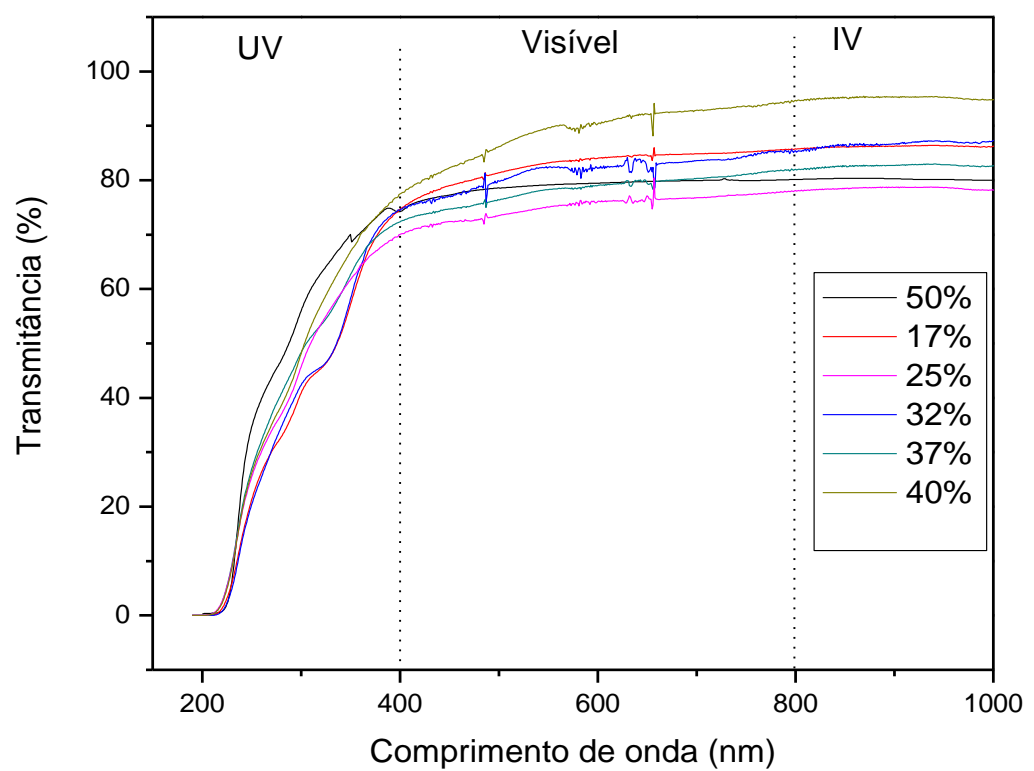

Figura 19 - Espectros de UV-vis para eletrólitos com diferentes concentrações de ácido acético(\%). 
Portanto, estes filmes podem ser considerados transparentes na região visível, o que é de grande importância para a possível utilização destes eletrólitos em dispositivos eletrocrômicos, como janelas eletrocrômicas. Destaca-se, também, uma ótima transparência para o filme contendo $50 \%$ de ácido acético, o qual apresentou um dos melhores valores de condutividade. O mesmo apresentou uma transmitância de aproximadamente 95\%. Estes resultados são semelhantes aos outros ESPs a base de polissacarídeos ${ }^{15-17}$.

\section{6 - Difração de Raios-X}

O agar é um polímero semicristalino constituído de grânulos. A plastificação do agar através da adição de glicerol modifica a sua estrutura. Analisando o processo em nível molecular, ocorre provavelmente a quebra das ligações de hidrogênio intermoleculares, responsável em grande parte pela cristalinidade, diminuindo a probabilidade de arranjo de uma cadeia sobre a outra. Este processo resulta em filmes de ágar plastificado com diminuição da cristalinidade.

A Figura 20 apresenta os difratogramas de raio-x obtidos para os eletrólitos a base do agar, contendo diferentes concentrações de ácido acético e medidos à temperatura ambiente. A adição de plastificantes favorece o caráter amorfo das amostras. Todos os difratogramas mostraram bandas difusas centradas em torno de $2 \theta=20^{\circ}$ e alguns com uma pequena banda em $2 \theta=13^{\circ}$. Comparando com outros eletrólitos a base de polissacarídeos, confirma-se que a adição de plastificante diminui a cristalinidade das amostras ${ }^{17}$. 


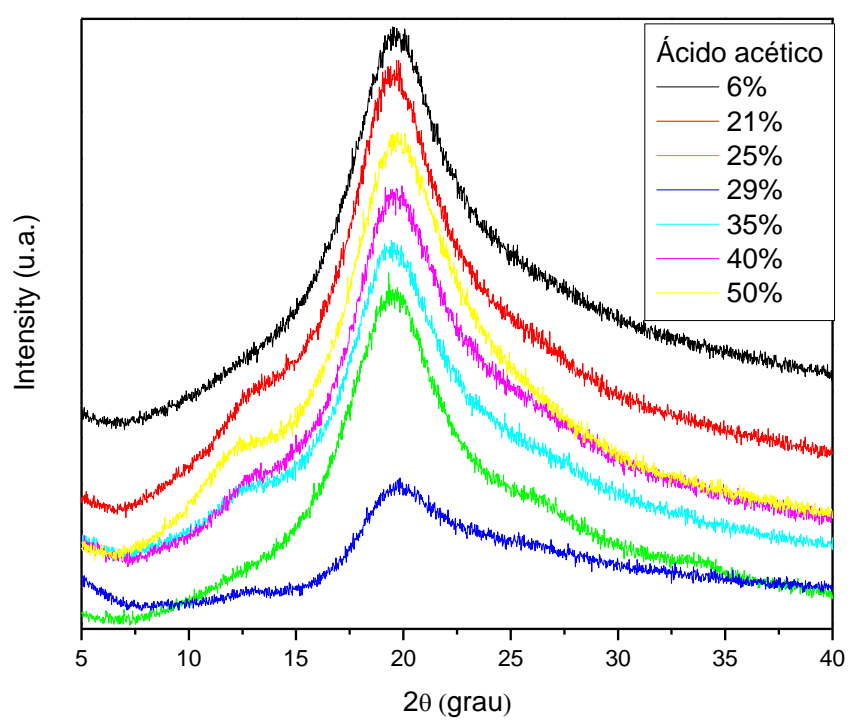

Figura 20 - Difração de raios-X de filmes contendo diferentes quantidades de ácido acético.

\section{7 - Microscopia Eletrônica de Varredura (MEV)}

A superfície das amostras de agar plastificado com glicerol e contendo ácido acético, foi visualizada através de análises por microscopia eletrônica de varredura. As amostras de agar são constituídas de grânulos que após o processo de plastificação são rompidos, resultando em filmes predominantemente amorfos. Ao observar as micrografias dos filmes contendo o ácido acético (Figura 21) nota-se que os filmes apresentaram uma boa uniformidade, com superfície homogênea e sem a presença de grânulos. Desta forma conclui-se que houve boa compatibilização do material com o plastificante e com ácido acético. 

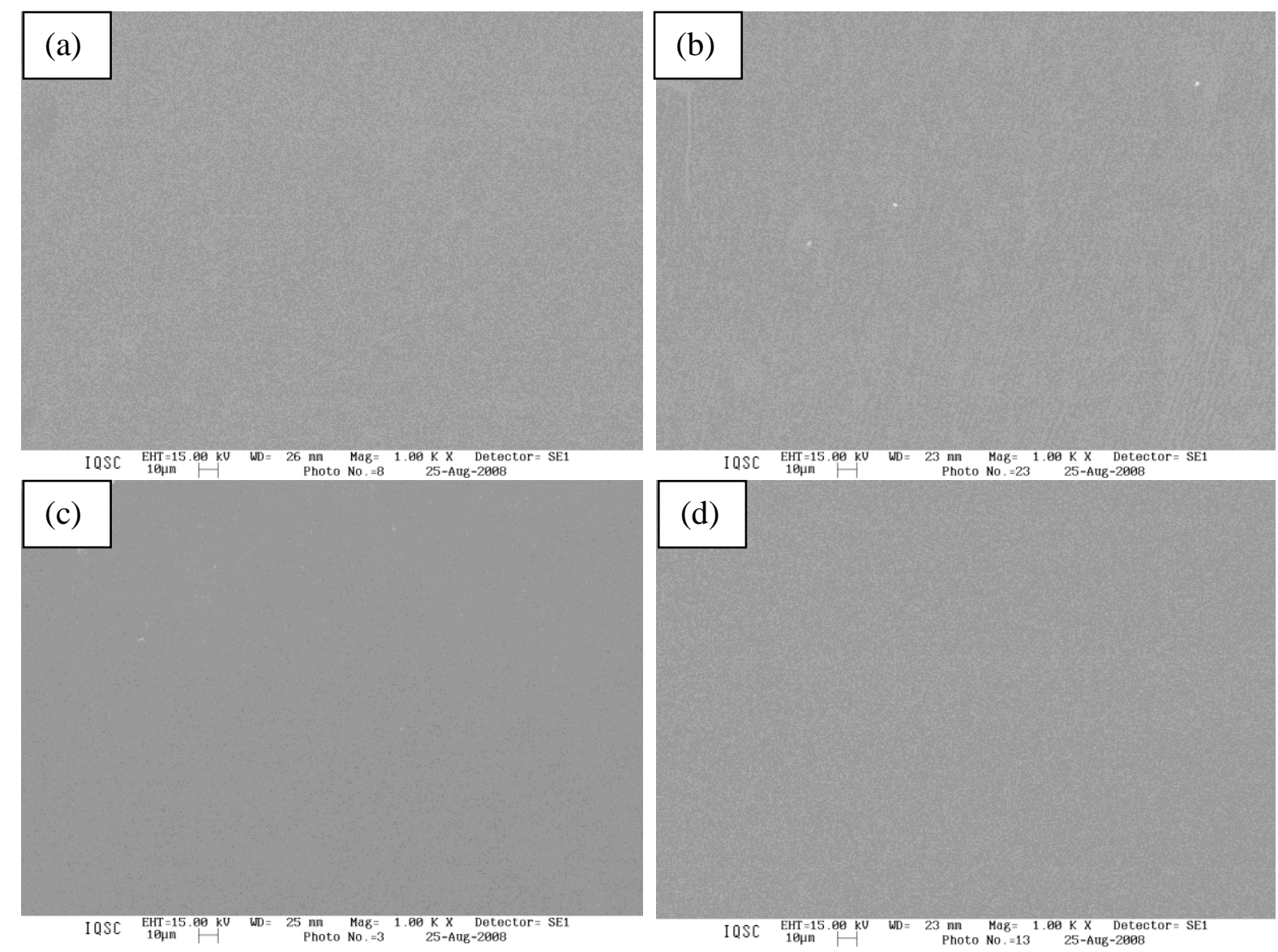

Figura 21 - Micrografias dos filmes de agar com diferentes quantidades de ácido acético, ampliadas 1000x: (a) 12\%; (b) 25\%; (c) 46\% e (d) 50\% em massa.

\section{8-Dispositivos Eletrocrômicos}

As amostras de eletrólitos a base de agar foram então usadas para montagem de pequenos dispositivos eletrocrômicos de $2 \mathrm{~cm}^{2}$ de área. O eletrólito foi introduzido na forma de gel viscoso no espaço entre os filmes de $\mathrm{WO}_{3}$ e $\mathrm{CeO}_{2}-\mathrm{TiO}_{2}$. A Figura 22 apresenta o resultado da transmitância da janela constituída de filme de $\mathrm{WO}_{3}$, eletrólito à base de agar com ácido acético $\left(50 \%\right.$ em massa) e filme de $\mathrm{CeO}_{2}$ $\mathrm{TiO}_{2}$.Nesta figura observa-se a mudança entre o estado colorido e descolorido de aproximadamente $25 \%$ em $550 \mathrm{~nm}$, sendo que no estado descolorido o valor é de $43 \%$ e no estado colorido de $18 \%$. Essa diferença aumenta com o aumento de comprimento de onda até 30\% e permanece estável até $900 \mathrm{~nm}$. A mudança de 
coloração pode ser considerada boa quando comparada com outros dispositivos onde diferenças entre o estado colorido e descolorido de $15-20 \%$ foram obtidas ${ }^{5}$.

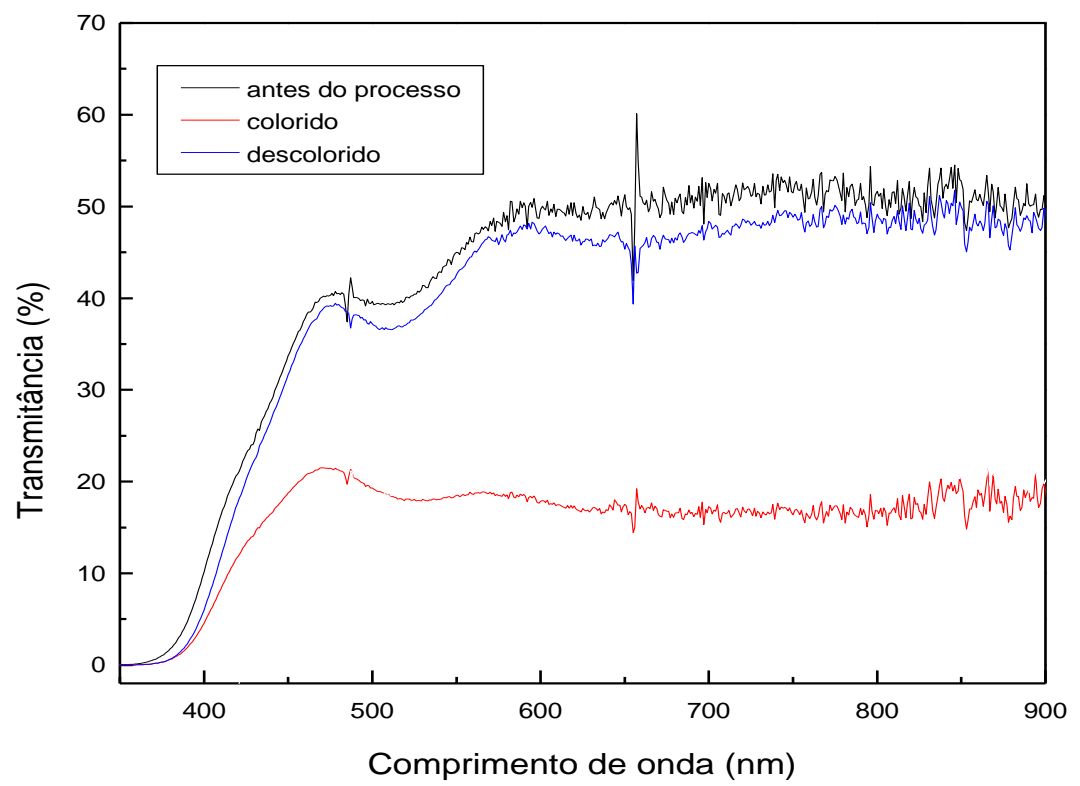

Figura 22: Transmitância dos DECs com eletrólito a base de agar com ácido acético 50\% em massa.

A Figura 23 apresenta o resultado da medida de densidade de carga catódica/anódica da janela constituída de filme de $\mathrm{WO}_{3}$, eletrólito à base de agar com ácido acético e filme de $\mathrm{CeO}_{2}-\mathrm{TiO}_{2}$. Nessa figura observa-se um aumento continuo de densidade de carga com o tempo atingindo $11,4 \mathrm{mC} / \mathrm{cm}^{2}$ em $15 \mathrm{~s}$. $\mathrm{O}$ processo de extração é mais rápido, i.e., de 5s. Após 15s observa-se quase total extração de cargas. O cálculo da razão de carga catódica/anódica é de 0,99, mostrando que o processo de intercalação/deintercalação dos prótons no filme é praticamente reversível. 


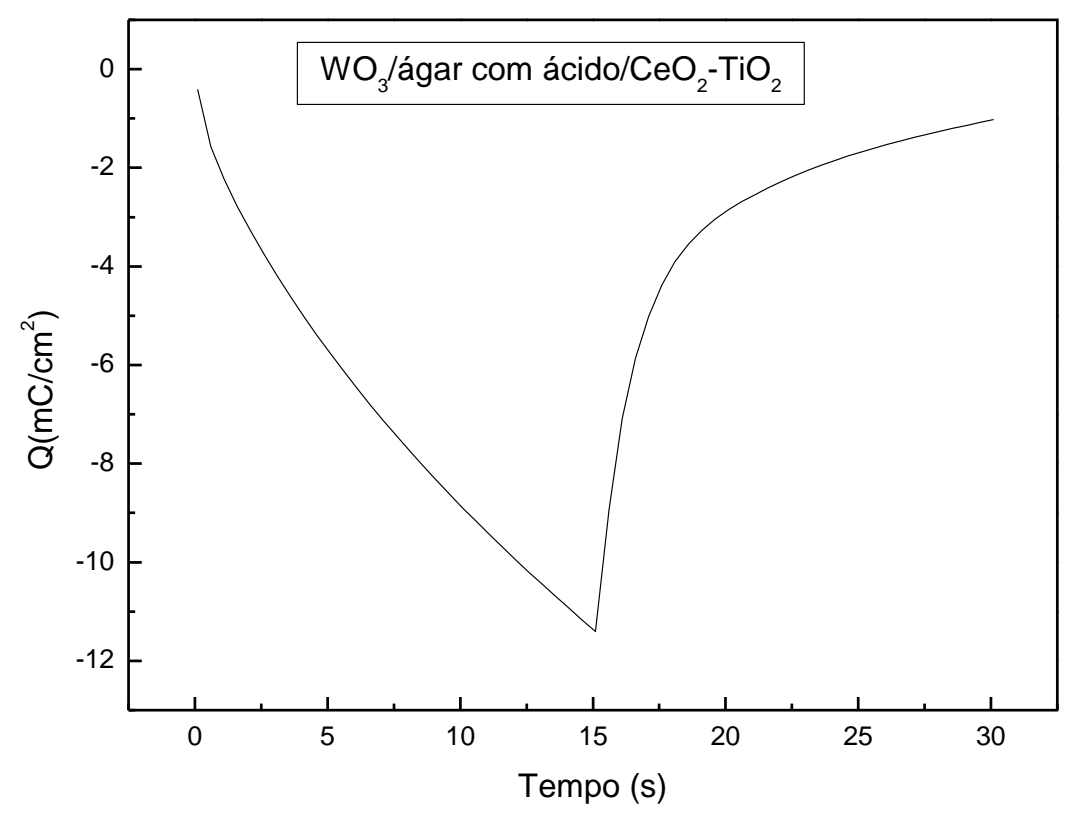

Figura 23: Densidade de carga para o DEC com eletrólito a base de agar e ácido acético na concentração de $50 \%$ em massa.

A Figura 24 apresenta o voltamograma da janela constituída de filme de $\mathrm{WO}_{3}$, eletrólito à base de agar com ácido acético e filme de $\mathrm{CeO}_{2}-\mathrm{TiO}_{2}$ a uma velocidade de varredura de $50 \mathrm{mV} / \mathrm{s}$, com potenciais aplicados entre $-3,5 \mathrm{~V}$ e 3,0V, para 10 ciclos. Nessa figura é possível observar um pico catódico a -1,47V que corresponde a inserção de prótons e elétrons no filme de $\mathrm{WO}_{3}$.e consequentemente sua coloração. A posterior diminuição da corrente elétrica vista nesse voltamograma é provavelmente devido aos outros processos, como inserção de cargas no filme de ITO ou evolução de hidrogênio da água do eletrólito. O voltamograma apresenta também dois picos anódicos, o primeiro a $-0,21 \mathrm{~V}$ correspondendo à extração de prótons e elétrons do filme de $\mathrm{WO}_{3}$, e consequente descoloração do dispositivo e o segundo pico a 0,8V relativo aos processos de oxidação e/ou extração de cargas do filme de ITO. 


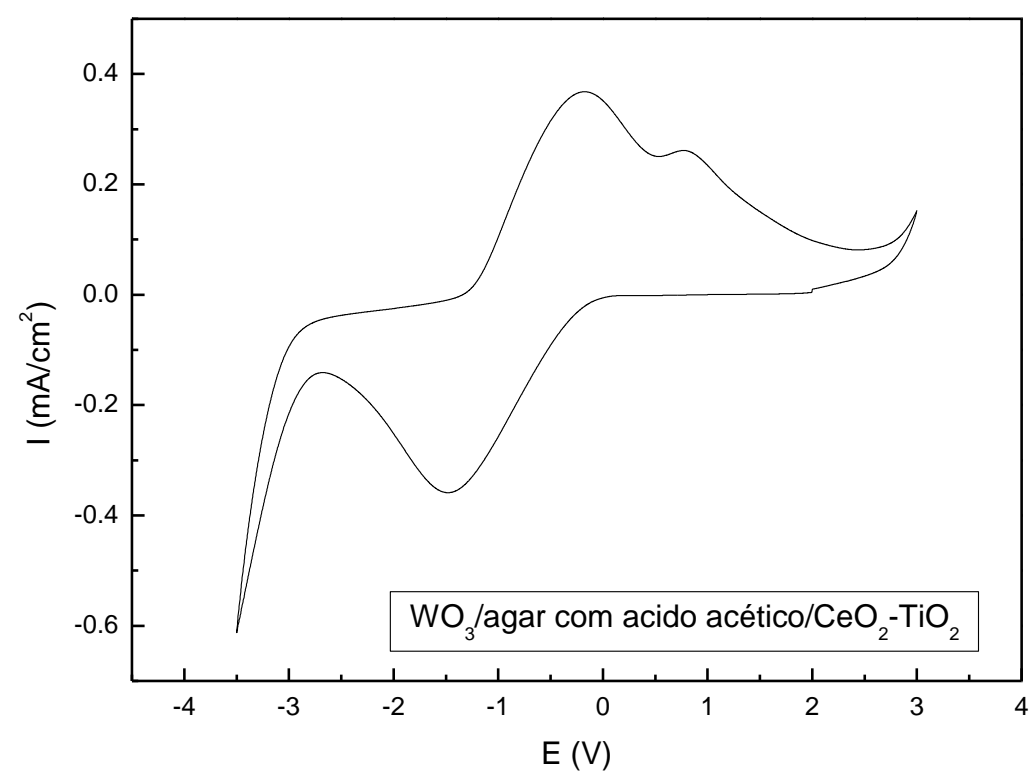

Figura 24: Voltamograma para o DEC com eletrólito a base de agar com ácido acético $50 \%$ em massa.

Os resultados das janelas eletrocrômicas com eletrólitos a base de agar demonstraram-se bastante promissoras, onde $25 \%$ de mudança de coloração é um valor elevado quando comparado com outros dispositivos a base de gelatina ${ }^{5}$.

\section{9 - Conclusões do Capítulo}

Foram preparados novos eletrólitos poliméricos a base de agar e ácido acético. As membranas obtidas apresentaram transparência de 70 a 95\% na região do visível, dependendo da concentração de ácido acético. A quantidade de ácido acético adicionada influencia a condutividade iônica dos eletrólitos, sendo que o melhor resultado da condutividade iônica foi de $1.1 \times 10^{-4} \mathrm{Scm}^{-1}$ à temperatura ambiente e $9.6 \times 10^{-4} \mathrm{Scm}^{-1}$ a $80^{\circ} \mathrm{C}$, para o eletrólito contendo $50 \%$ em massa de ácido acético. Menores valores de condutividade em torno $2 \times 10^{-5} \mathrm{Scm}^{-1}$ foram obtidos em atmosfera com umidade controlada de $33 \%$ o que nos mostrou a influência de água absorvida na condutividade dos eletrólitos. Os resultados de 
condutividade iônica em função da temperatura apresentaram comportamento do tipo Arrhenius e a amostra com 50\% em massa de ácido acético apresentou energia de ativação de $46.5 \mathrm{~kJ} / \mathrm{mol}$. As medidas de difração de raios-x confirmaram que as amostras são predominantemente amorfas. As micrografias mostram que os filmes preparados possuem uma superfície homogênea e uniforme. Os estudos preliminares para aplicação destes eletrólitos em dispositivos eletrocrômicos resultaram em boa reversibilidade do dispositivo, e densidade de carga de 11,4 $\mathrm{mC} / \mathrm{cm}^{2}$. Todos esses resultados sugerem que eletrólitos poliméricos protônicos a base de agar são muito atrativos para serem utilizados em dispositivos eletrocrômicos.

\section{Referências Bibliográficas}

[1] COLONNA, P.; BULEON, A.; MERCIER, C. Physically modified starches. In: STARCH: properties and potencial. Great Brintain: Society of Chemical Industry, 1987. p. 79.

[2] MACHADO, G. O. Preparação e caracterização de eletrólitos sólidos poliméricos a partir dos derivados de hidroxipropilcelulose $e$ hidroxietilcelulose. 2004. 127f. Tese (Doutorado) - Interunidades Ciência e Engenharia de Materiais, Universidade de São Paulo, São Carlos, 2004.

[3] DRAGUNSKI, D. C. Preparação de eletrólitos sólidos poliméricos a partir do amido. 2003. 163f. Tese (Doutorado) - Instituto de Química de São Carlos, Universidade de São Paulo, São Carlos, 2003.

[4] KIM, Y. T.; SMOTKIN, E. S. The effect of plasticizers on transport and electrochemical properties of PEO-based electrolytes for lithium rechargeable batteries. Solid State Ionics, v. 149, p. 29 - 37, 2002. 
[5] MORITA, M.; ARAKI, F.; KASHIWAMURA, K.; YOSHIMOTO, N.; ISHIKAWA, M. lonic structure and conductance behavior of plasticized polymeric electrolytes containing multivalent cations. Electrochimica Acta, v. 45, n 8 - 9, p. 1335 - 1340, 2000.

[6] TSUTSUMI, H.; MATSUO, A.; ONIMURA, K.; OISHI, T. Conductivity enhancement of a polyacrylonitrile-based polymer electrolyte containing cascade nitrile as a plasticizer. Electrochemical Solid-State Letters, v. 1, p. 244, 1998.

[7] DILLIP, K.; PRADHAN, R. N. P.; CHOUDHARY, K.; SAMANTARAY, B. K. Studies of dielectric relaxation and ac conductivity behavior of plasticized polymer nanocomposite electrolytes. International Journal Electrochemical Science, v. 3, p. 597, 2008.

[8] KUMAR, M.; SEKHON, S. S. Role of plasticizer's dielectric constant on conductivity modification of PEO-NH4F polymer electrolytes. European Polymer Journal, v. 38, p. 1297, 2002.

[9] AVELLANEDA, C. O.; VIEIRA, D. F.; AL-KAHLOUT, A.; HEUSING, S.; LEITE, E. R.; PAWLICKA, A.; AEGERTER, M. A. All solid-state electrochromic devices with gelatin-based electrolyte. Solar Energy Materials \& Solar Cells, v. 92, p. 228 - 233, 2008

[10] REDDY J. M.; SREEKANTH T.; SUBBA RAO, U. V. Study of the plasticizer effect on a (PEO + NayF4) polymer electrolyte and its use in an electrochemical cell. Solid State Ionics, v. 126, p. 55, 1999.

[11] TAKANO, R.; YOSHIKAWA, S.; UEDA, T.; HAYASHI, K.; HIRASE, S.; HARA, S. Sulfation of polysaccharides with sulfuric acid mediated by dicyclohexylcarbodiimide. Journal of Carbohydrate Chemistry, v. 15, p. 449, 1996.

[12] GAZOTTI, W. A.; SPINACÉ, M. A. S.; GIROTTO, E. M.; DE PAOLI, M. A. Polymer electrolyte based on ethylene oxide-epichlohydrin copolymers. Solid State Ionics, v. 130, p. 281 - 291, 2000.

[13] NOGUEIRA, A. F.; SPINACÉ, M. A. S.; GAZOTTI, W. A.; GIROTTO, E. M.; DE PAOLI, M. A. Poly(ethylene oxide-co-epichlorohydrin) /Nal: a promising polymer electrolyte for photoelectrochemical cells. Solid State Ionics, v. 140, p. 327 - 335 , 2001 
[14] RAPHAEL, E.; AVELLANEDA, C. O.; MANZOLLI, B.; PAWLICKA, A. Agarbased films for application as polymer electrolytes. Electrochimica Acta, v. 55, p. $1455-1459,2009$.

[15] MARCONDES, R. F. M. S.; D'AGOSTINIA, P. S.; FERREIRA, J.; GIROTTO, E. M.; PAWLICKA, A.; DRAGUNSKI, D.C. Amylopectin-rich starch plasticized with glycerol for polymer electrolyte application. Solid State Ionics, v. 181, p. 586 - 591, 2010.

[16] VIEIRA, D. F.; AVELLANEDA, C. O.; PAWLICKA, A. AC Impedance, X-ray Diffraction and DSC Investigation on Gelatin Based-Electrolyte with LiClO4. Molecular Crystals and Liquid Crystals (Philadelphia). Molecular Crystals Liquid Crystals, v. 485, p. $843-852,2008$.

[17] DRAGUNSKI, D. C.; PAWLICKA, A. Starch based solid polymeric electrolytes. Molecular Crystals and Liquid Crystals Science and Technology. Section A, Molecular Crystals and Liquid Crystals, v. 374, p. 561 - 568, 2002. 


\section{CAPÍTULO 6 - CARACTERIZAÇÃO DOS ELETRÓLITOS DE ÁGAR COM $\mathrm{LiClO}_{4}$ - RESULTADOS E DISCUSSÕES.}

Em sequência ao trabalho proposto, foram preparados e estudados eletrólitos poliméricos a base de agar, utilizando agora como fonte de íons o $\mathrm{LiClO}_{4}$.

\section{1 - Análise Termogravimétrica (TG)}

Como já foi discutido anteriormente o objetivo da preparação dos eletrólitos é sua utilização em dispositivos eletrocrômicos, é importante conhecer a sua estabilidade térmica, ou seja, a temperatura que os mesmos suportam antes que ocorra alguma reação ou degradação. Assim, os filmes preparados com diferentes quantidades de $\mathrm{LiClO}_{4}$ foram submetidos à análise termogravimétrica, cujos resultados são mostrados na Figura 25.

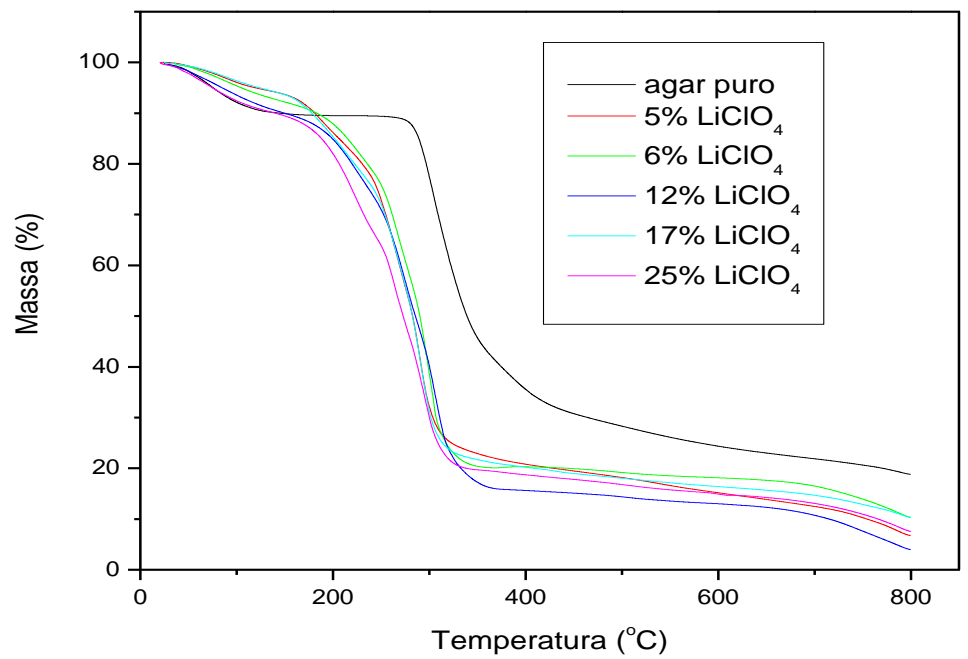

Figura 25 - Curvas de TG dos filmes contendo diferentes quantidades de $\mathrm{LiClO}_{4}(\% \mathrm{em}$ massa).

Das amostras analisadas, percebe-se inicialmente que todas apresentam uma perda de massa inicial de aproximadamente $7 \%$ até a temperatura de $100^{\circ} \mathrm{C}$, perda essa atribuída à presença de umidade residual. Em temperaturas maiores, na faixa 
de 200 a $300^{\circ} \mathrm{C}$ a perda de massa que ocorre nesta etapa pode ser atribuída ao início da decomposição do eletrólito. Observa-se, que a temperatura de início de decomposição é similar para todos os eletrólitos indicando que a variação da quantidade de $\mathrm{LiClO}_{4}$ não influencia na estabilidade térmica das amostras, mas a presença do mesmo atua como um catalisador para a decomposição do material, pois a degradação do agar puro começa a ocorrer em aproximadamente $300^{\circ} \mathrm{C}$, enquanto que no caso dos eletrólitos a degradação começa a partir de $220^{\circ} \mathrm{C}$ (Figura 24).

A região de temperatura superior a $220^{\circ} \mathrm{C}$ até a formação do resíduo a $400^{\circ} \mathrm{C}$ corresponde à etapa principal da decomposição. Nesse intervalo ocorre a grande perda de massa, da ordem de $70 \%$, em uma única etapa. Do ponto de vista molecular, durante esse estágio ocorre a ruptura aleatória das cadeias, provocando liberação de componentes de baixa massa molar que se vaporizam, levando à perda de massa observada por análise de $\mathrm{TG}^{1}$. Acima de $400^{\circ} \mathrm{C}$ a perda de aproximadamente $8 \%$ de massa é referente provavelmente a pirólise do agar. Os teores de cinzas para as amostras foram em torno de $\square 4 \%$, devido aos produtos formados pela oxidação do perclorato de lítio.

A análise deste gráfico revela que a presença do plastificante e ácido no filme promove uma diminuição da temperatura de degradação das amostras estudadas. Enquanto o agar puro se degrada à aproximadamente $300^{\circ} \mathrm{C}$, as amostras plastificadas e contendo $\mathrm{LiClO}_{4}$, se degradam de 220 a $280^{\circ} \mathrm{C}$. Conforme já discutido anteriormente a influência de alguns fatores, como por exemplo, a presença de água e de glicerol no sistema, mas principalmente a presença, nesse caso do $\mathrm{LiClO}_{4}$, favorecem os rearranjos intermoleculares e facilitam a degradação do agar e o sal atua como um catalisador nas reações de decomposição de modo similar como o 
ácido acético ${ }^{2}$. A prova disso, pode ser também o menor conteúdo de cinzas no caso de amostras plastificadas em comparação com o agar puro. Isso também é muito similar ao observado com as amostras contendo o ácido acético. Porém, apesar de ocorrer esta diminuição da temperatura de degradação ainda se pode afirmar que os filmes obtidos são bastante estáveis.

\section{2 - Calorimetria Diferencial de Varredura (DSC)}

Conforme já foi apresentado anteriormente, a utilização de plastificantes no preparo dos eletrólitos, além de garantir filmes amorfos contribui para um abaixamento na temperatura de transição vítrea $\left(T_{g}\right)$. Essa propriedade é muito importante no estudo de EPGs já que a $T_{g}$ está relacionada ao estado amorfo dos filmes e consequentemente aos movimentos das cadeias poliméricas, influenciando diretamente os valores de condutividade iônica ${ }^{2-7}$. As análises de DSC para os eletrólitos a base de agar com $\mathrm{LiClO}_{4}$ (Figura 26) mostram mudanças na linha de base, típicas da transição vítrea. A partir de um ponto reprodutível traçando uma reta tangente à linha de base e outra tangente ao ramo inclinado inicial da curva obtevese os valores de $T_{g}$ para cada amostra. Esses valores também estão mostrados na Figura 26. 


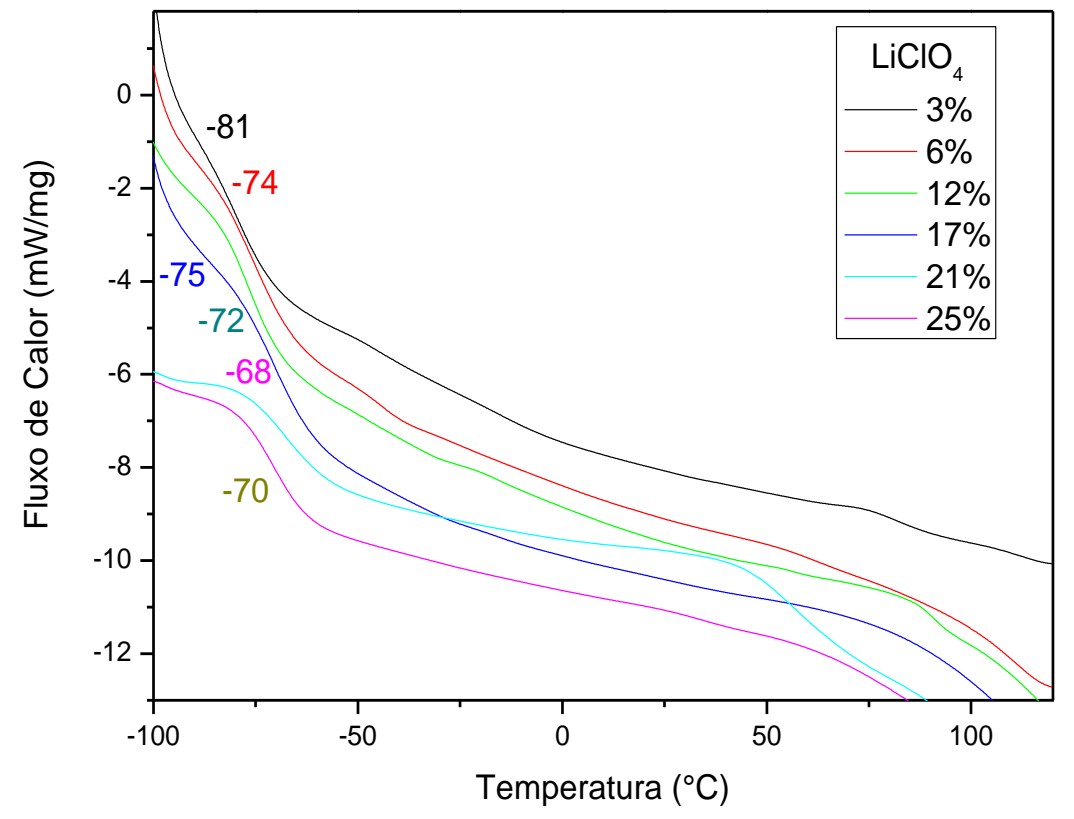

Figura 26 - Curvas de DSC dos filmes contendo diferentes quantidades de $\mathrm{LiClO}_{4}$.

Como pode ser observado na Figura 26, a quantidade de $\mathrm{LiClO}_{4}$ influencia nos valores da $T_{g}$, que aumentam discretamente com o aumento da quantidade de sal de lítio de $-81^{\circ} \mathrm{C}$ para $-68^{\circ} \mathrm{C}$. Esse comportametno é compreensível, uma vez que a adição de $\mathrm{LiClO}_{4}$ promove o aumento de rigidez da nova estrutura formada devido a complexação de íons de lítio com os oxigênios da cadeia de polissacarídeo (Figura 3). Isso também comprovaria a suposição incial de envolvimento de heteroátomos da cadeia de polissacarídeo na complexação e dissociação do sal.

Pode-se observar que as temperaturas de transição vítrea para as amostras com diferentes quantidades de $\mathrm{LiClO}_{4}$ apresentaram uma pequena variação, entretanto todas as amostras apresentaram a transição vítrea em temperatura sub ambiente, resultado este similar a outros eletrólitos a base de polímeros naturais ${ }^{6-7}$.

\section{3 - Espectroscopia de Impedância Eletroquímica (EIE)}

Os eletrólitos de agar foram submetidos às medidas de condutividade iônica por espectroscopia de impedância eletroquímica. Os diagramas de impedância 
complexa para os filmes com diferentes concentrações de $\mathrm{LiClO}_{4}$ à temperatura ambiente são mostrados na Figura 27.

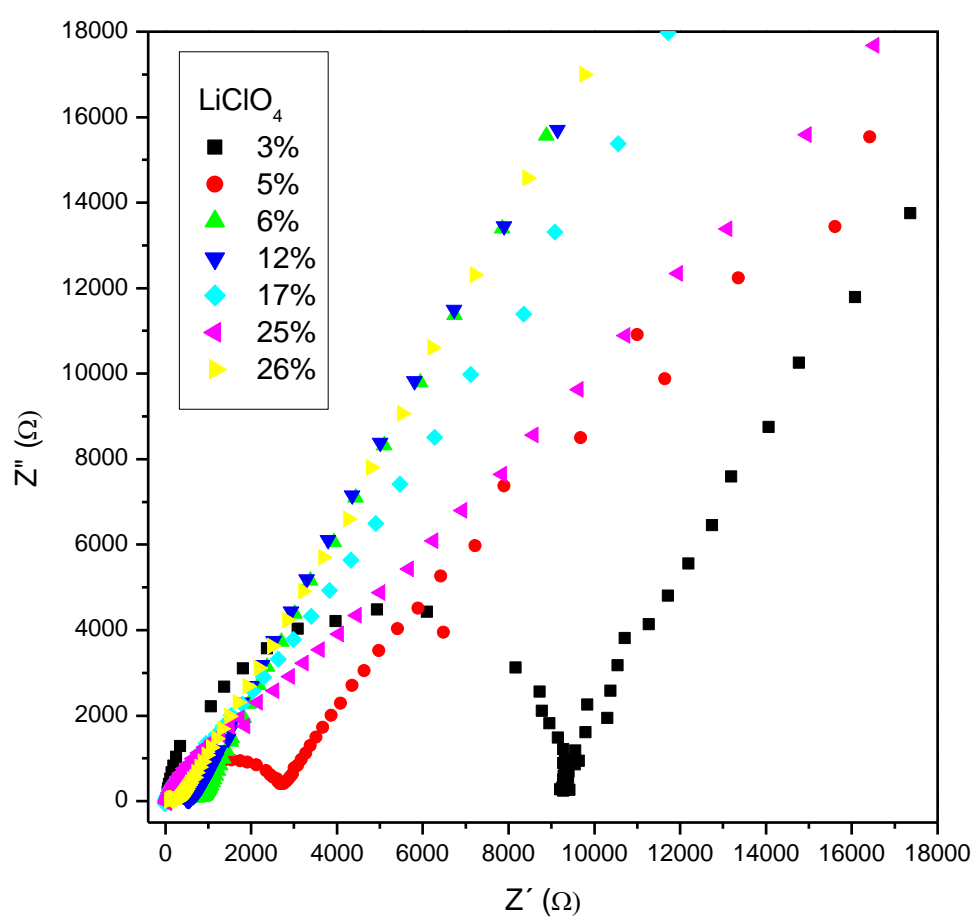

Figura 27 - Gráfico de impedância complexa para os filmes com diferentes concentrações do perclorato de lítio (\% em massa)

A condutividade iônica $(\sigma)$ foi calculada usando a relação: $\sigma=I /(R$. s), onde I é a espessura da amostra de eletrólito, s é a área de contato entre o eletrólito e o eletrodo e $\mathrm{R}$ é a resistência medida, a qual foi determinada pela interseção do semicírculo com o eixo real do gráfico de Nyquist: Z" versus Z ' (Figura 27). Os valores do log da condutividade iônica obtidos para as diferentes concentrações de sal $(3,5,6,12,17,25$ e $26 \%$ em massa) podem ser observados na Figura 28 onde verificou-se que a condutividade iônica aumenta com o aumento da quantidade de $\mathrm{LiClO}_{4}$ até atingir um máximo de $5,9 \times 10^{-5} \mathrm{Scm}^{-1}$ para $17 \%$ em massa de $\mathrm{LiClO}_{4}$. 


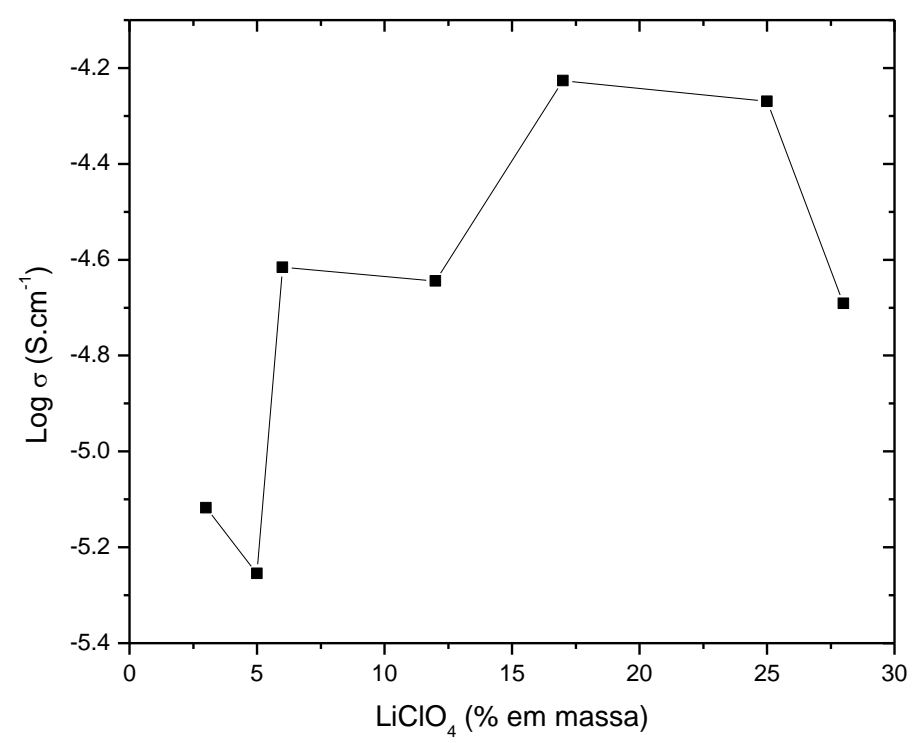

Figura 28 - Log $\sigma$ em função da concentração de $\mathrm{LiClO}_{4}$.

Como já discutido anteriormente, a condutividade iônica depende de uma série de fatores, e o estudo da condutividade iônica em função da concentração de sal fornece informações sobre a interação específica entre o sal e a matriz polimérica ${ }^{7}$. Pode-se observar na Figura 28 que a condutividade aumenta com o aumento da concentração de $\mathrm{LiClO}_{4}$ até $17 \%$, quando então começa a decrescer. O primeiro aumento da condutividade iônica com o aumento da concentração de sal pode ser relacionado ao aumento de número dos portadores de carga, enquanto a diminuição da condutividade iônica em uma concentração de sal superior a $17 \%$ pode ser atribuída à formação dos agregados iônicos ${ }^{8}$. Essa diminuição também pode ser explicada em termos da saturação de sal na amostra, e sua consequente cristalização (resultado confirmado pela difração de raios-X; Figura 34).

As medidas de condutividade iônica em função da temperatura foram realizadas, a fim de analisar o possível mecanismo de condução iônica nestes sistemas. A Figura 29 revela um mecanismo de condução Vogel-Tammann-Fulcher (VTF), no qual o deslocamento de cargas é devido aos movimentos das cadeias poliméricas devido ao aumento do volume livre ${ }^{9}$. 


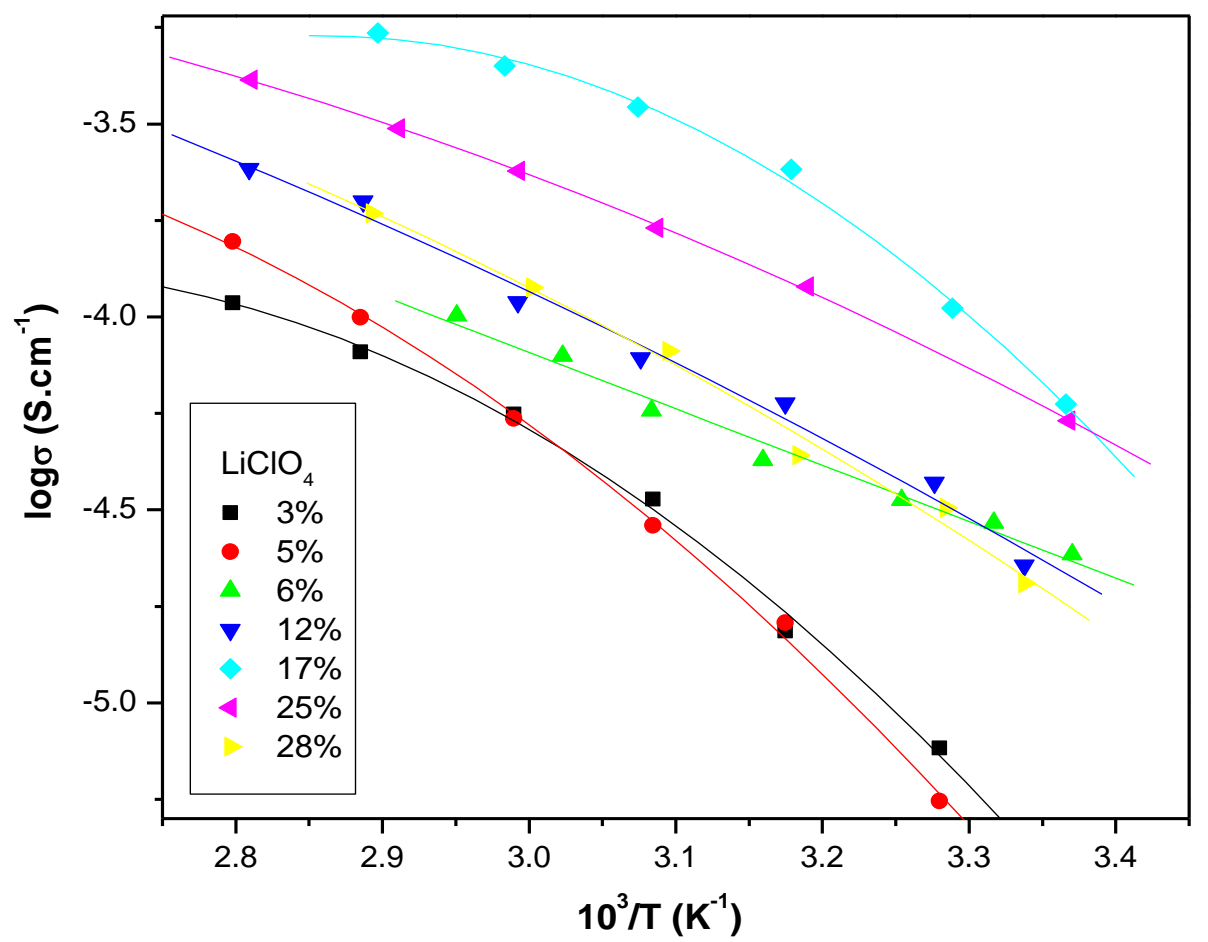

Figura 29 - Log da condutividade em função da temperatura para filmes com diferentes quantidades $\mathrm{LiClO}_{4}$ (\% em massa).

A equação empírica Vogel-Tammann-Fulcher (VTF) (2) ${ }^{10-12}$ :

$\sigma=\mathrm{A} / \mathrm{T}^{1 / 2} \exp \left[-\Delta \mathrm{E} /\left(\mathrm{T}-\mathrm{T}_{0}\right)\right]$,

sendo T é a temperatura absoluta e To é a temperatura ideal de transição vítrea, que é normalmente 30-50 graus abaixo da $T_{g}$, ou seja, a temperatura na qual a entropia configuracional desaparece; $\Delta \mathrm{E}$ é uma energia de ativação aparente, que depende da barreira de energia livre oposicional aos rearranjos configuracionais e A é um fator pré-exponencial relacionado com o número de portadores de carga.

A Figura 30 apresenta o gráfico dos ajustes feitos aplicando o modelo VTF para a determinação da Ea aparente para os eletrólitos que contém $\mathrm{LiClO}_{4}$. 


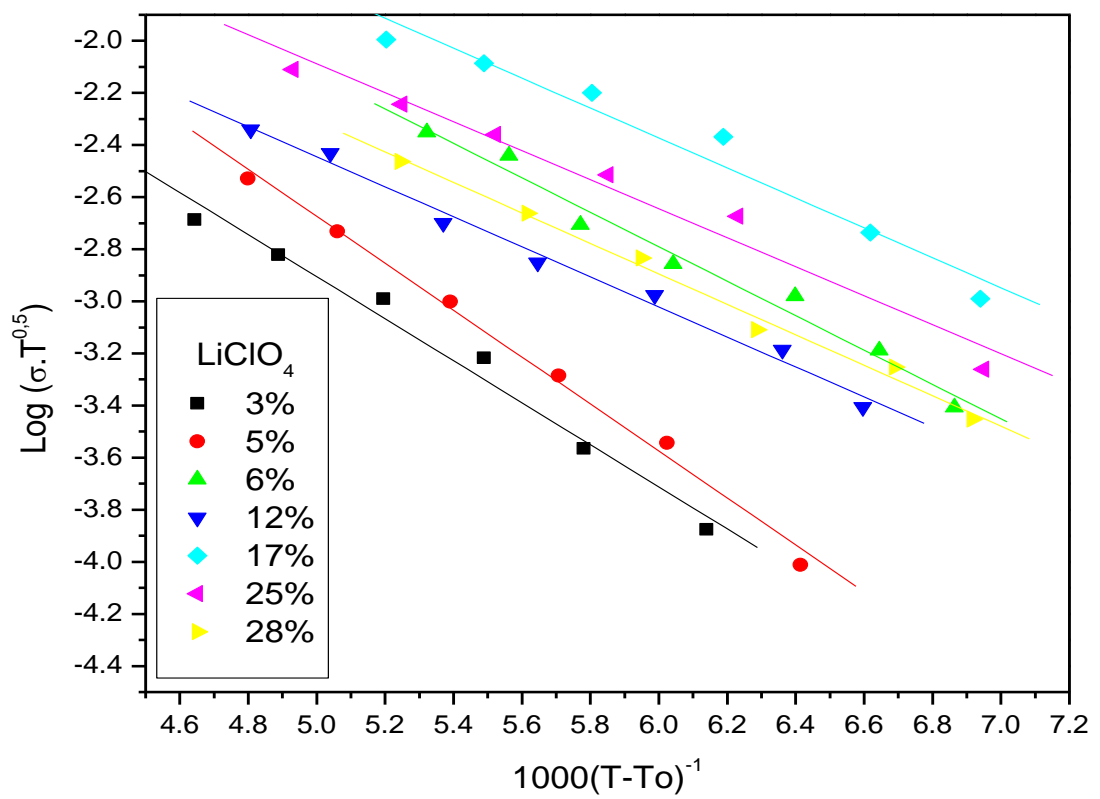

Figura 30 - Ajustes do modelo VTF para determinação das energias de ativação aparentes.

A partir de um ajuste do modelo VTF dos resultados da Figura 30, pode-se determinar a energia de ativação aparente para cada amostra, usando o coeficiente angular das retas. Os valores encontrados para a energia de ativação estão relacionados diretamente com a condutividade iônica dos filmes e podem ser observados na Figura 31. Nesta figura pode ser visto que a energia de ativação diminui gradualmente com o aumento na concentração de $\mathrm{LiClO}_{4}$. Isso indica que não só aumenta o número de portadores, com o aumento da concentração de sal, mas também que as barreiras de energia são reduzidas ${ }^{15,16}$. Os valores obtidos para as energias de ativação aparente estão de acordo com valores obtidos para o eletrólito com ácido acético e também para eletrólitos a base de outros polímeros naturais $^{13-15}$. Entrertanto precisa ressaltar que há diferenças marcantes em relaçào ao mecanismo de condução, enquanto os portadores de carga nas amostras com ácido acético preferem os saltos entre os sítios de complexação, no caso das amostras com $\mathrm{LiClO}_{4}$ há predominância do mecanismo veicular, i.e., deslocamento de cargas auxiliado pelo movimento de cadeias poliméricas ou outras moléculas. 


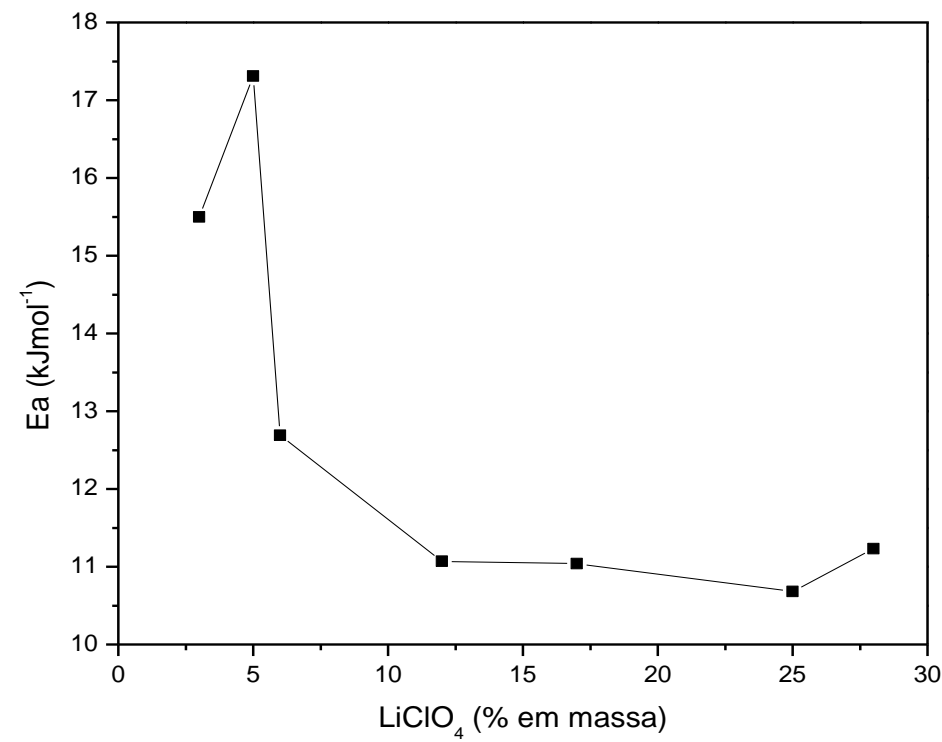

Figura 31 - Energia de ativação aparente versus concentração de $\mathrm{LiClO}_{4}$.

A Figura 32 apresenta o log da condutividade em função do potencial aplicado para a amostra que apresentou a melhor condutividade iônica, i.e., 17\% em massa de $\mathrm{LiClO}_{4}$. Nota-se, para a amostra com $\mathrm{LiClO}_{4}$, que para uma faixa de potencial que varia de $-3 a+3 \mathrm{~V}$, o valor da condutividade permanece quase constante, indicando que não há nenhuma reação eletrolítica. Entretanto, ao passar para $+3,5 \mathrm{~V}$ ou $-3,5 \mathrm{~V}$ ocorre uma diminuição do valor da condutividade. Desta forma, constatou-se que acima de $3,5 \mathrm{~V}$ e abaixo de $-3,5 \mathrm{~V}$ o eletrólito polimérico com $\mathrm{LiClO}_{4}$ começa a sofrer alguma mudança estrutural, provavelmente devido à ocorrência de reações eletrolíticas.

Portanto, verificou-se que o eletrólito polimérico a base de agar plastificado com glicerol e contendo $\mathrm{LiClO}_{4}$, possui estabilidade em uma faixa de potencial que varia entre $-3 a+3 \mathrm{~V}$. Apesar dessa janela de estabilidade ser menor quando comparada com o eletrólito a base de agar e contendo ácido acético, estes resultados indicam que o eletrólito a base de agar apresenta boa estabilidade eletroquímica, o que está de acordo com valores obtidos para outros eletrólitos a base de polímeros naturais ${ }^{2}$. 


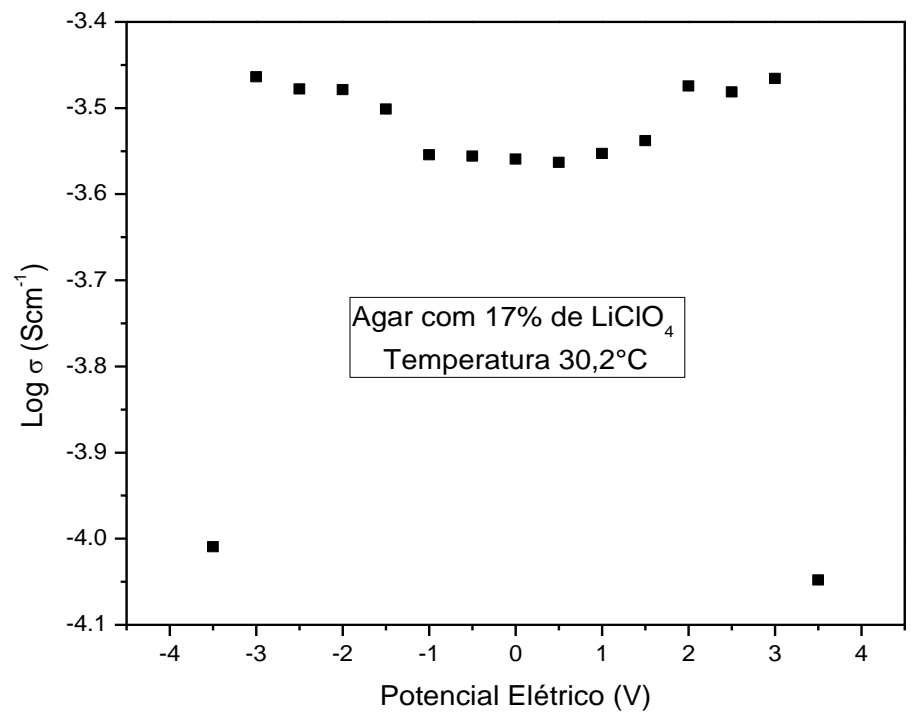

Figura 32 - Janela de estabilidade eletroquímica do filme de agar com $17 \% \mathrm{LiClO}_{4}$ a temperatura de $30,2^{\circ} \mathrm{C}$.

\section{4 - Espectroscopia no Ultravioleta-Visível (UV-vis)}

Como pode ser observado na Figura 33, as amostras obtidas apresentaramse com boa transparência na região do visível, entre 75 e 90\%, resultado similar ao resultado obtido para as amostras a base de agar e ácido acético (Figura 19)

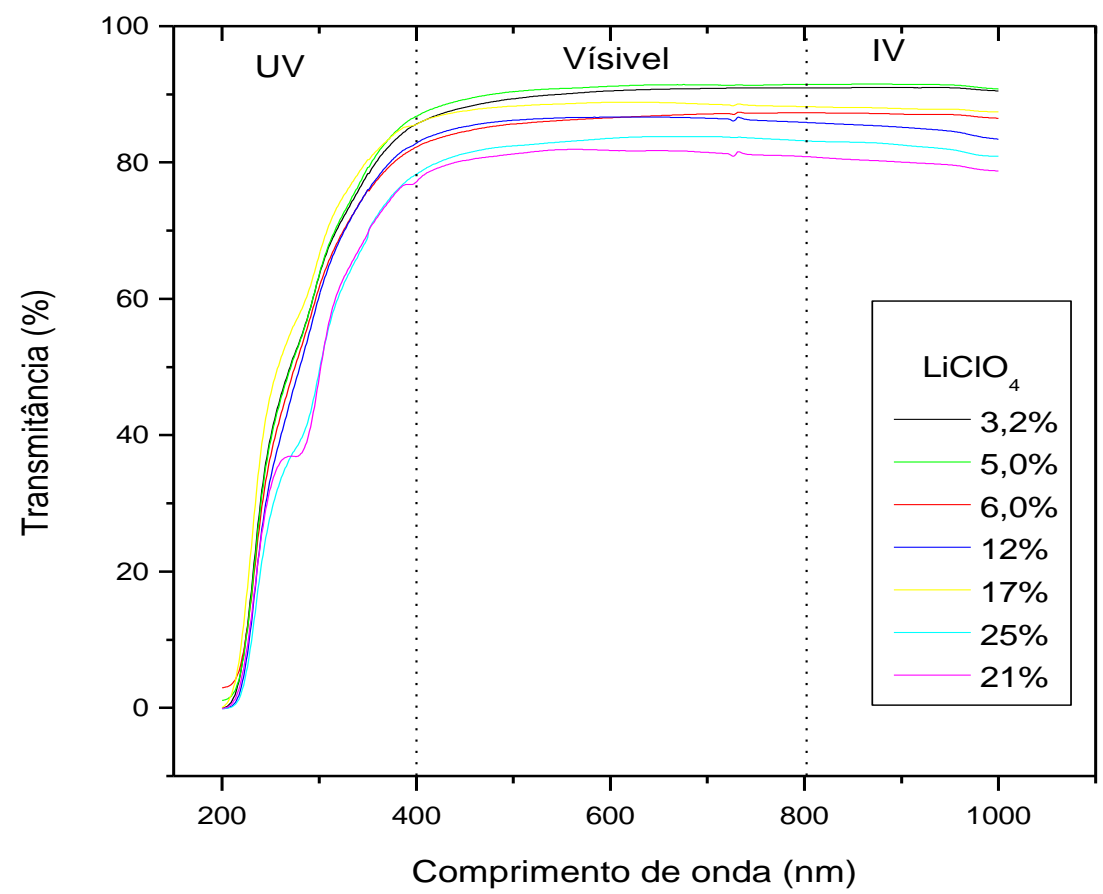

Figura 33 - Espectros de UV-vis para filmes preparados com diferentes concentrações de sal de lítio (\% em massa) 
Portanto, estes filmes podem ser considerados transparentes na região visível (grande parte com transmitância de 75 a 92\% na região do visível e IV próximo), o que é de grande importância para a possível utilização destes eletrólitos em dispositivos eletrocrômicos, como janelas eletrocrômicas. Na região do ultravioleta (200 a 400 nm), os valores de transmitância dos filmes aumentam de próximo de zero em 200 nm, para respectivos valores na região visível.

\section{5 - Difração de Raios-X}

Como já comentado nos capítulo anteriores o agar é um polímero semicristalino constituído de grânulos. A plastificação do agar através da adição de glicerol modifica a sua estrutura. Analisando o processo em nível molecular, ocorre provavelmente a quebra das ligações de hidrogênio intermoleculares, responsável em grande parte pela cristalinidade, diminuindo a probabilidade de arranjo de uma cadeia sobre a outra. Este processo resulta em filmes de ágar plastificado com predominância do estado amorfo.

As estruturas amorfa e cristalinas dos eletrólitos a base de agar, contendo diferentes concentrações de $\mathrm{LiClO}_{4}$ podem ser observadas nos difratogramas de raios-X da Figura 33. Foi verificado que os eletrólitos com 3, 5, 6, 12, 17 e 25\% em massa de $\mathrm{LiClO}_{4}$ (Figura 33 a) apresentam bandas difusas, largas, centradas em aproximadamente $2 \theta=22^{\circ}$ com um pequeno ombro em $2 \theta=13^{\circ}$. Os difratogramas de eletrólitos com 28 e $32 \%$ em massa de $\mathrm{LiClO}_{4}$ (Figura 33 b) exibem picos cristalinos, devido à cristalização do sal nas membranas ${ }^{2}$. 

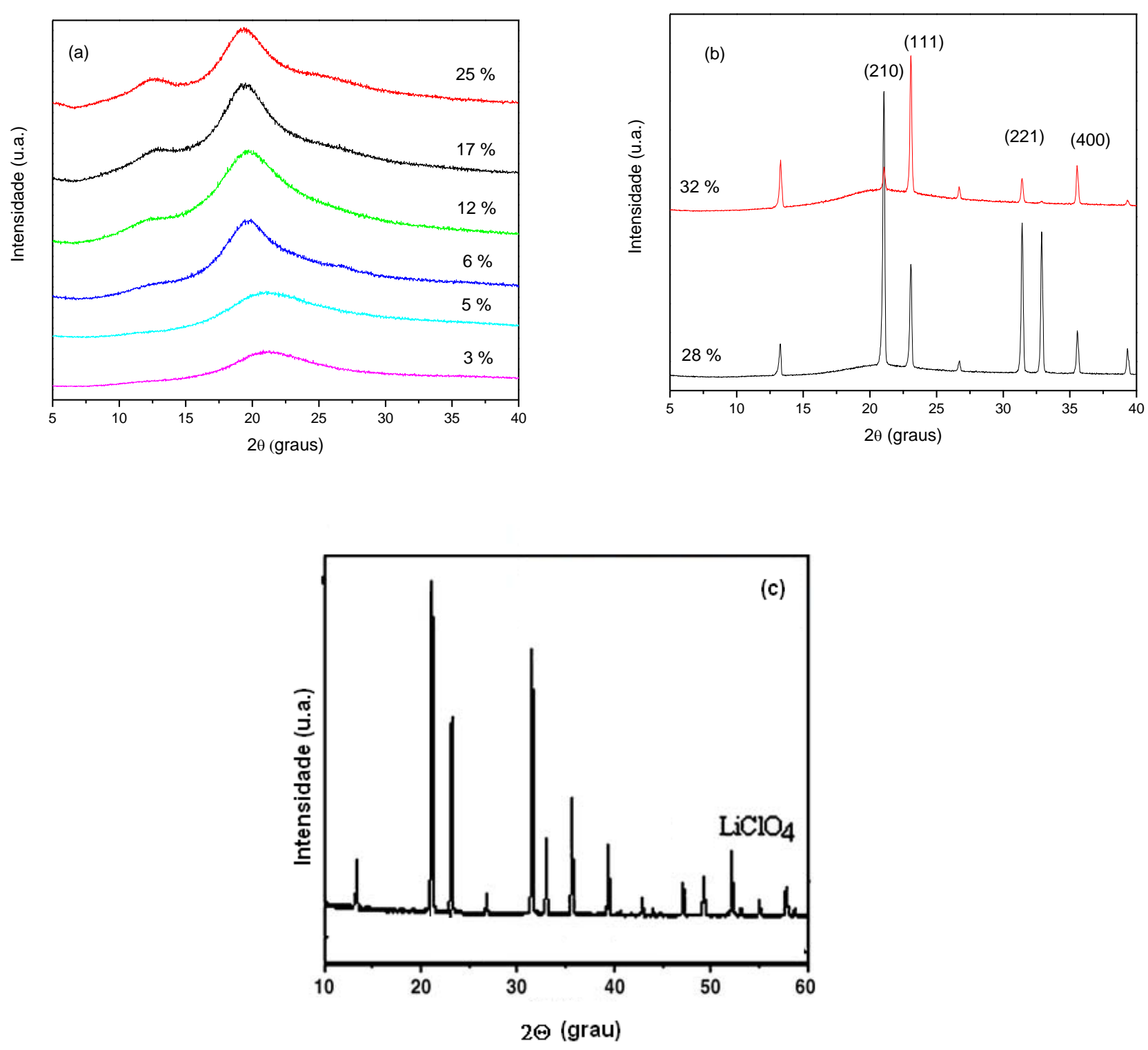

Figura 34 - Difratogramas de raios-X de filmes contendo diferentes quantidades de ácido acético - (a) filmes amorfos (b) filmes com cristalização do $\mathrm{LiClO}_{4}$ e para comparação difratograma do $\mathrm{LiClO}_{4}{ }^{18}$.

\section{6 - Microscopia Eletrônica de Varredura (MEV)}

Ao observar as micrografias dos filmes preparados (Figura 35 a-c), notou-se que os filmes apresentaram uma superfície homogênea, comprovando desta forma, boa compatibilização do material com o plastificante e com $\mathrm{LiClO}_{4}$. No entanto, no filme contendo $32 \%$ em massa de $\mathrm{LiClO}_{4}$ (Figura 35 d) observa-se superfície ondulada e não uniforme. Isso pode ser devido a quantidade de sal adicionado, que 
já começa atingir o limite da solubilização. Isso também é evidenciado pela cristalização do sal na superfície do filme. Este resultado está em conformidade com os valores de condutividade iônica obtidos, pois nessa concentração de sal a condutividade iônica começa a decrescer. Também os difratogramas de raios-X revelaram o aparecimento dos picos cristalinos característicos para o sal.
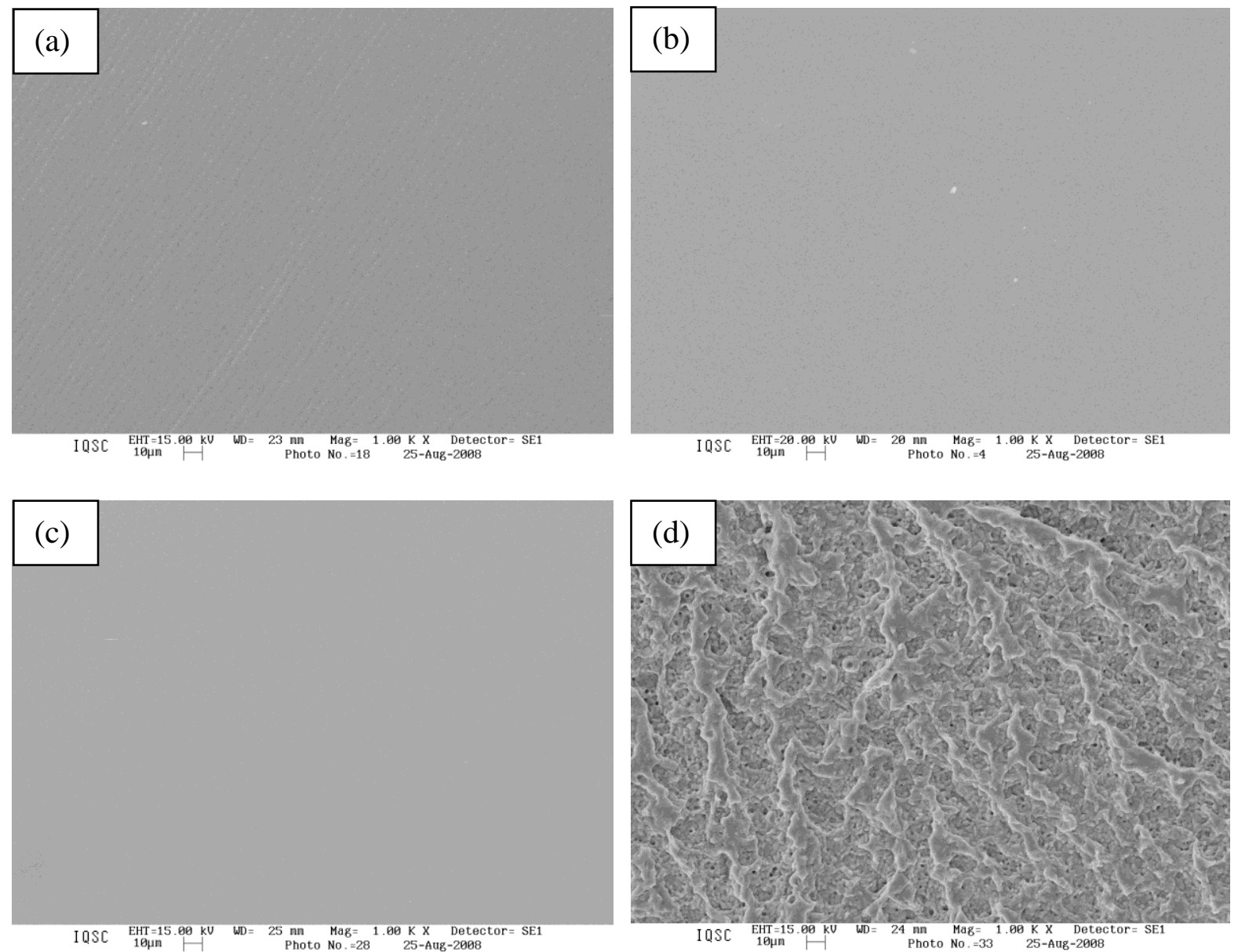

Figura 35 - Micrografias dos filmes de agar com diferentes quantidades de $\mathrm{LiClO}_{4}$, ampliadas 1000x: (a) $12 \%$; (b) $17 \%$; (c) $28 \%$ e (d) $32 \%$ em massa.

\section{7 - Dispositivos Eletrocrômicos}

Para verificar a utilidade dos eletrólitos a base de agar e contendo $\mathrm{LiClO}_{4}$ em aplicação prática no dispositivo eletrocrômico os mesmos foram aplicados em pequenos DECs na forma de gel viscoso. Figura 36 apresenta o resultado da 
transmitância da janela constituída de filme de vidro/ITO/ $\mathrm{WO}_{3}$, eletrólito à base de agar com $\mathrm{LiClO}_{4}\left(17 \%\right.$ em massa) e filme de $\mathrm{CeO}_{2}-\mathrm{TiO}_{2} / \mathrm{ITO} /$ vidro. Nesta figura 36 observa-se transmitância de aproximadamente $68 \%$ da janela antes do processo de coloração que passa para $56 \%$ após o processo de coloração. O consecutivo processo de descoloração promove o aumento da transmitância para $65 \%$ em 550 nm. Para comprimentos de onda maiores, i.e., $700 \mathrm{~nm}$, esta diferença aumenta para $12 \%$ entre o estado colorido e descolorido e permanece constante até $900 \mathrm{~nm}$. Essa diferença entre o estado colorido e transparente foi menor quando comparado com os dispositivos contendo ácido acético, o que pode ser devido ao tamanho do íon e consequentemente maior dificuldade na sua movimentação e acomodação nos interstícios da camada eletrocrômica do filme de $\mathrm{WO}_{3}$.

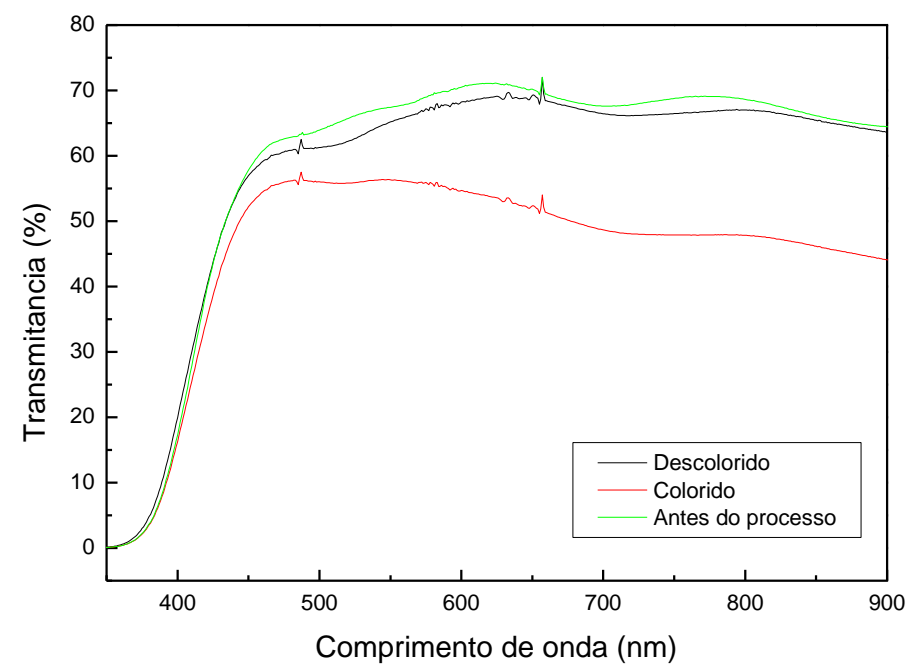

Figura 36: Transmitância do DEC contendo o filme de agar com $\mathrm{LiClO}_{4}$ na concentração de17\% em massa.

A Figura 37 apresenta o resultado da densidade de carga catódica/anódica da janela constituída de filme de vidro/ITO $/ \mathrm{WO}_{3}$, eletrólito à base de agar com $\mathrm{LiClO}_{4}$ e filme de $\mathrm{CeO}_{2}-\mathrm{TiO}_{2} / \mathrm{ITO} /$ vidro, onde observa-se densidade de carga inserida de $6,21 \mathrm{mC} / \mathrm{cm}^{2}$, durante o processo de coloração por $15 \mathrm{~s}$ em potencial de $-2,5 \mathrm{~V}$. O processo de extração é rápido, em 3 s a janela fica transparente e em 15 s quase 
toda a carga é extraída. A razão de carga catódica/anódica obtida foi de 0,89, mostrando que o processo de intercalação/deintercalação dos íons no filme é quase reversível. Resultados esses também são bastante similares aos resultados obtidos com as janelas contendo eletrólito a base de agar com ácido acético, contudo os valores de carga foram menores.

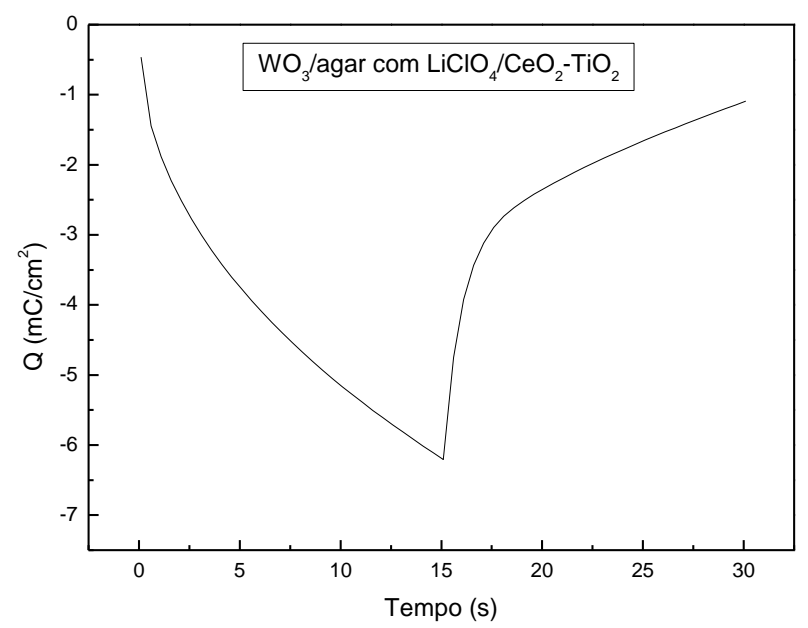

Figura 37: Densidade de carga para o DEC com eletrólito a base de agar com $\mathrm{LiClO}_{4}$ 17\% em massa.

A Figura 38 apresenta o voltamograma cíclico da janela constituída de filme de vidro/ITO/ $\mathrm{WO}_{3}$, eletrólito à base de agar $\mathrm{LiClO}_{4}$ e filme de $\mathrm{CeO}_{2}$ $\mathrm{TiO}_{2} / \mathrm{ITO} / \mathrm{vidro}$ a uma velocidade de varredura de $50 \mathrm{mV} / \mathrm{s}$, com potenciais aplicados entre $-3,5 \vee$ e $3,0 \mathrm{~V}$, para $10^{\circ}$ ciclo, onde é possível observar um pico catódico a 1,74 V. Este pico corresponde à inserção de íons de lítio na camada eletrocrômica de $\mathrm{WO}_{3}$ e posterior aumento de corrente catódica, devido provavelmente à inserção de cargas no filme de ITO. No ciclo anódico observa-se um pico anódico a 0,23V devido à extração de íons e elétrons do filme de $\mathrm{WO}_{3}$.

Os voltamogramas obtidos são bastante similares aos voltamogramas de $\mathrm{WO}_{3}$ em eletrólito líquido e também aos resultados obtidos com janelas contendo eletrólito a base de gelatina ${ }^{8}$. 


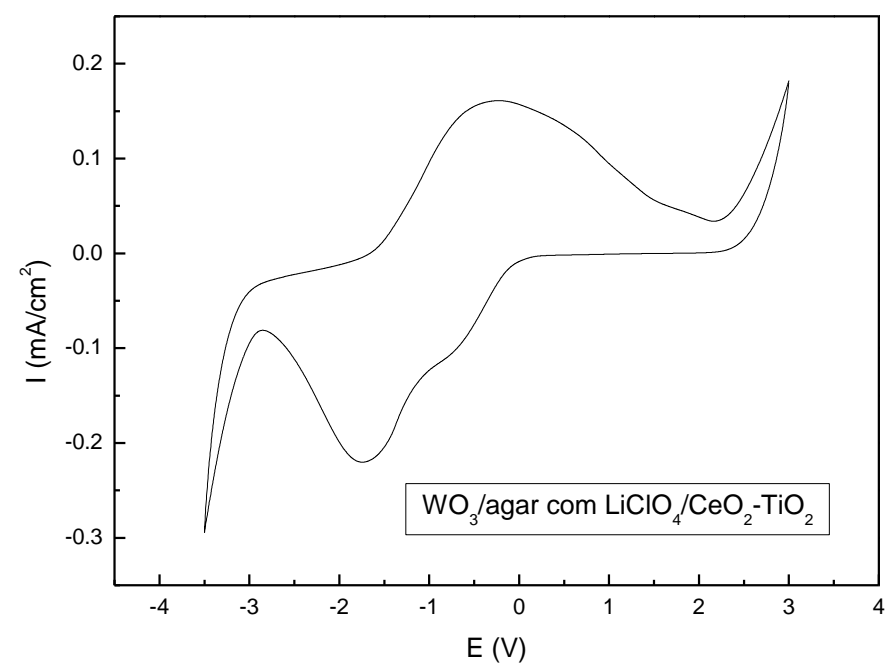

Figura 38: Voltamograma para o DEC com eletrólito a base de agar com $\mathrm{LiClO}_{4}$ 17\% em massa.

Os resultados das janelas eletrocrômicas com eletrólitos a base de agar com $\mathrm{LiClO}_{4}$ demonstraram-se bastante promissoras, onde $12 \%$ de diferença entre estado colorido e descolorido foram encontrados. Este valor é mais baixo quando comparado com dispositivos com eletrólito a base de agar e ácido acético, mas próximo aos valores encontrados para dispositivos a base de gelatina ${ }^{5}$.

\section{8 - Conclusões do Capítulo}

Foram preparados novos eletrólitos poliméricos géis a base de agar e $\mathrm{LiClO}_{4}$ que são interessantes para serem aplicados em diversos dispositivos eletroquímicos. A grande vantagem do uso do agar é a sua vasta disponibilidade na natureza, seu baixo custo e facilidade de preparo. As membranas obtidas apresentaram boa transparência, de 75 a 92\% na região do visível, dependendo da concentração de sal. Foi constatado que a quantidade de $\mathrm{LiClO}_{4}$ adicionada influencia a condutividade iônica dos eletrólitos, sendo que o melhor resultado de condutividade iônica foi de $1.5 \times 10^{-5} \mathrm{Scm}^{-1}$ à temperatura ambiente e $5 \times 10^{-4} \mathrm{Scm}^{-1}$ a $80^{\circ} \mathrm{C}$, obtido para o eletrólito contendo $17 \%$ em massa de $\mathrm{LiClO}_{4}$. Os resultados de condutividade iônica em função da temperatura apresentaram comportamento do tipo VTF e o 
melhor valor de energia de ativação obtido foi de $11,2 \mathrm{~kJ} / \mathrm{mol}$. As medidas de difração de raios- $X$ confirmaram que as amostras são predominantemente amorfas exceto as amostras com concentração de sal superior a $17 \%$ em massa, onde começou-se a observar os picos cristalinos referentes ao $\mathrm{LiClO}_{4}$. As micrografias de MEV apresentaram superfície homogênea e boa uniforme para os filmes preparados com até $17 \%$ em massa de $\mathrm{LiClO}_{4}$. Nos estudos preliminares de aplicação destes eletrólitos em DECs foram feitas caracterizações por medidas óticas e eletroquímicas. Foi observado que a transmitância do dispositivo variou $12 \%$ entre estado colorido e descolorido. As medidas eletroquímicas mostraram boa reversibilidade do dispositivo e capacidade de carga inserida/extraída de 6,21 $\mathrm{mC} / \mathrm{cm}^{2}$. Todos esses resultados sugerem que eletrólitos poliméricos a base de agar e $\mathrm{LiClO}_{4}$ são muito atrativos para serem utilizados em dispositivos eletrocrômicos.

\section{Referências Bibliográficas}

[1] COLONNA, P.; BULEON, A.; MERCIER, C. Physically modified starches. In: STARCH: properties and potencial. Great Brintain: Society of Chemical Industry, 1987. p. 79.

[2] MACHADO, G. O. Preparação e caracterização de eletrólitos sólidos poliméricos a partir dos derivados de hidroxipropilcelulose e hidroxietilcelulose. 2004, 127p. Tese (Doutorado) - Interunidades Ciência e Engenharia de Materiais, Universidade de São Paulo, São Carlos, 2004.

[3] DRAGUNSKI, D. C. Preparação de eletrólitos sólidos poliméricos a partir do amido. 2003. 163f. Tese (Doutorado) - Instituto de Química de São Carlos, Universidade de São Paulo, São Carlos, 2003.

[4] MORITA, M.; ARAKI, F.; KASHIWAMURA, K.; YOSHIMOTO, N.; ISHIKAWA, M. lonic structure and conductance behavior of plasticized polymeric electrolytes containing multivalent cations. Electrochimica Acta, v. 45, n 8 - 9, p. 1335 - 1340, 2000. 
[5] KIM, Y. T.; SMOTKIN, E. S. The effect of plasticizers on transport and electrochemical properties of PEO-based electrolytes for lithium rechargeable batteries. Solid State Ionics, v. 149, p. 29 - 37, 2002.

[6] TSUTSUMI, H.; MATSUO, A.; ONIMURA, K.; OISHI, T. Conductivity enhancement of a polyacrylonitrile-based polymer electrolyte containing cascade nitrile as a plasticizer. Electrochemical Solid-State Letters, v. 1, p. 244, 1998.

[7] DILLIP, K.; PRADHAN, R. N. P.; CHOUDHARY, K.; SAMANTARAY, B. K. Studies of dielectric relaxation and ac conductivity behavior of plasticized polymer nanocomposite electrolytes. International Journal Electrochemical Science, v. 3, p. $597,2008$.

[8] KUMAR, M.; SEKHON, S. S. Role of plasticizer's dielectric constant on conductivity modification of PEO-NH4F polymer electrolytes. European Polymer Journal, v. 38, p. 1297, 2002.

[9] AVELLANEDA, C. O.; VIEIRA, D. F.; AL-KAHLOUT, A.; HEUSING, S.; LEITE, E. R.; PAWLICKA, A.; AEGERTER, M. A. All solid-state electrochromic devices with gelatin-based electrolyte. Solar Energy Materials \& Solar Cells, v. 92, p. $228-233$, 2008

[10] REDDY J. M.; SREEKANTH T.; SUBBA RAO, U. V. Study of the plasticizer effect on a (PEO + NayF4) polymer electrolyte and its use in an electrochemical cell. Solid State Ionics, v. 126, p. 55, 1999.

[11] TAKANO, R.; YOSHIKAWA, S.; UEDA, T.; HAYASHI, K.; HIRASE, S.; HARA, S. Sulfation of polysaccharides with sulfuric acid mediated by dicyclohexylcarbodiimide. Journal of Carbohydrate Chemistry, v. 15, p. 449, 1996.

[12] GAZOTTI, W. A.; SPINACÉ, M. A. S.; GIROTTO, E. M.; DE PAOLI, M. A. Polymer electrolyte based on ethylene oxide-epichlohydrin copolymers. Solid State lonics, v. 130, p. 281 - 291, 2000.

[13] NOGUEIRA, A. F.; SPINACÉ, M. A. S.; GAZOTTI, W. A.; GIROTTO, E. M.; DE PAOLI, M. A. Poly(ethylene oxide-co-epichlorohydrin)/Nal: a promising polymer electrolyte for photoelectrochemical cells. Solid State Ionics, v. 140, p. 327 - 335, 2001 
[14] RAPHAEL, E.; AVELLANEDA, C. O.; MANZOLLI, B.; PAWLICKA, A. Agarbased films for application as polymer electrolytes. Electrochimica Acta, v. 55, p. $1455-1459,2009$.

[15] MARCONDES, R. F. M. S.; D'AGOSTINIA, P. S.; FERREIRA, J.; GIROTTO, E. M.; PAWLICKA, A.; DRAGUNSKI, D.C. Amylopectin-rich starch plasticized with glycerol for polymer electrolyte application. Solid State lonics, v. 181, p. 586 - 591, 2010.

[16] VIEIRA, D. F.; AVELLANEDA, C. O.; PAWLICKA, A. AC Impedance, X-ray Diffraction and DSC Investigation on Gelatin Based-Electrolyte with LiClO4. Molecular Crystals and Liquid Crystals (Philadelphia). Molecular Crystals Liquid Crystals, v. 485, p. $843-852,2008$.

[17] DRAGUNSKI, D. C.; PAWLICKA, A. Starch based solid polymeric electrolytes. Molecular Crystals and Liquid Crystals Science and Technology. Section A, Molecular Crystals and Liquid Crystals, v. 374, p. 561 - 568, 2002.

[18] SHUKLA N., THAKUR A.K., "Role of salt concentration on conductivity optimization and structural phase separation in a solid polymer electrolyte based on PMMA-LiClO4 “Ionics, v. 15, p. 357 - 367, 2009. 


\section{CAPÍTULO 7 - CARACTERIZAÇÃO DOS ELETRÓLITOS A BASE DE BLENDAS DE POLÍMEROS NATURAIS: AGAR- GELATINA E AGAR-QUITOSANA - RESULTADOS E DISCUSSÕES.}

Nesta parte do trabalho foram estudados eletrólitos poliméricos obtidos a partir de blendas de agar com outras macromoléculas naturais, e tendo como fonte de prótons o ácido acético. Como o objetivo dos trabalhos em nosso grupo é desenvolver novos materiais, e os recentes estudos sobre polímeros naturais para a obtenção de novos sistemas de condução iônica têm apresentado resultados muito promissores $^{1-9}$, foi proposto estudar as blendas a base de agar com gelatina e de agar com quitosana. Tanto a gelatina como a quitosana são macromoléculas naturais, sendo esta última também um polissacarídeo o que nos indica que pode ocorrer uma boa compatibilidade entre eles, e conseqüente possibilidade de agregar os bons resultados encontrados para os eletrólitos obtidos com estes materiais separadamente ${ }^{2-6}$ em um novo tipo de material.

Para o preparo dos filmes destas blendas, foram utilizadas as quantidades de plastificante (glicerol) e de ácido acético que proporcionaram as melhores concentrações, em estudos prévios de cada um deles ${ }^{2,4-6}$. Estes EPGs a base de blendas, foram preparados e caracterizados por análises térmicas, espectroscopia de impedância eletroquímica, espectroscopia no UV-vis, difração de raios-x e microscopia eletrônica de varredura. Foi feito um estudo preliminar da aplicação destes EPGs em dispositivos eletrocrômicos, onde foram preparados pequenos dispositivos e analisados por medidas óticas e eletroquímicas. Os resultados obtidos das caracterizações descritas acima estão apresentados e discutidos ao longo deste capítulo. 


\section{1 - Análise Termogravimétrica (TG)}

Como já foi discutido nos capítulos anteriores, os filmes preparados foram submetidos às análises termogravimétricas com o objetivo principal de estudar as sua estabilidade térmica. Os gráficos de perda de massa em função da temperatura estão apresentados na Figura 39.

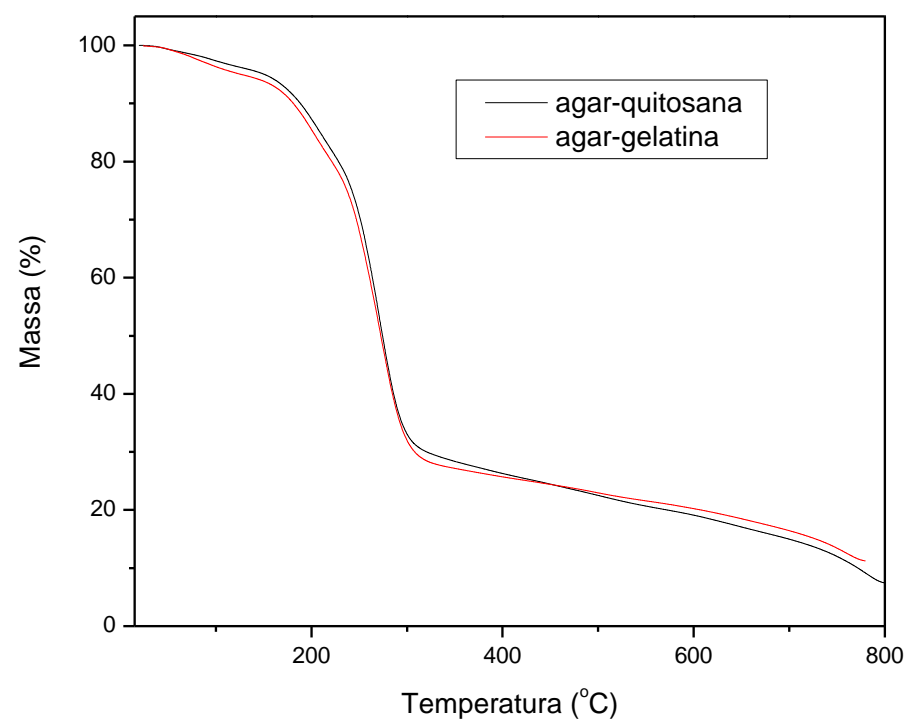

Figura 39 - Curvas de TG dos eletrólitos a base de blendas de agar com quitosana e com gelatina.

Das amostras analisadas, percebe-se inicialmente que todas apresentam uma perda de massa inicial de aproximadamente $8 \%$ até a temperatura de $100^{\circ} \mathrm{C}$, resultado comparável com os resultados obtidos para as amostras apresentadas nos capítulos 5 e 6 . Como explicado anteriormente essa perda é atribuída à presença de umidade residual. Em temperaturas maiores, na faixa de 190 a $220^{\circ} \mathrm{C}$ ocorre uma perda de massa que é atribuída ao início da decomposição do eletrólito. Observa-se, que a temperatura de início de decomposição é similar para os dois eletrólitos indicando que as diferentes macromoléculas utilizadas não influenciam na estabilidade térmica das amostras ${ }^{7}$.

A região de temperatura superior a $230^{\circ} \mathrm{C}$ até a formação do resíduo a $300^{\circ} \mathrm{C}$ corresponde à etapa principal da decomposição. Nesse intervalo ocorre grande 
perda de massa, da ordem de 70\%, em uma única etapa. Conforme já discutido anteriormente durante esse estágio ocorre a ruptura aleatória das cadeias, provocando liberação de componentes de baixa massa molar que se vaporizam, levando à perda de massa observada ${ }^{1,12}$. Também nesse caso há provavelmente a ação catalítica do ácido acético no processo de decomposição, evidenciado pela pequena quantidade de cinzas a $800^{\circ} \mathrm{C}$.

Os dois diferentes eletrólitos preparados a base de blendas de macromoléculas naturais, mostraram-se bastante estáveis térmicamente, o que é de grande interesse para suas aplicações tecnológicas.

\section{2 - Calorimetria Diferencial de Varredura (DSC)}

As análises térmicas (DSC) dos filmes preparados com blendas de polímeros naturais mostraram mudanças na linha de base, típicas de transição vítrea $\left(T_{g}\right)$ em temperaturas muito abaixo da temperatura ambiente (Figura 40), o que é de grande interesse para aplicação como ESPs, já que a temperatura de transição vítrea está relacionada aos valores de condutividade iônica desta classe de materiais ${ }^{1-8,12}$.

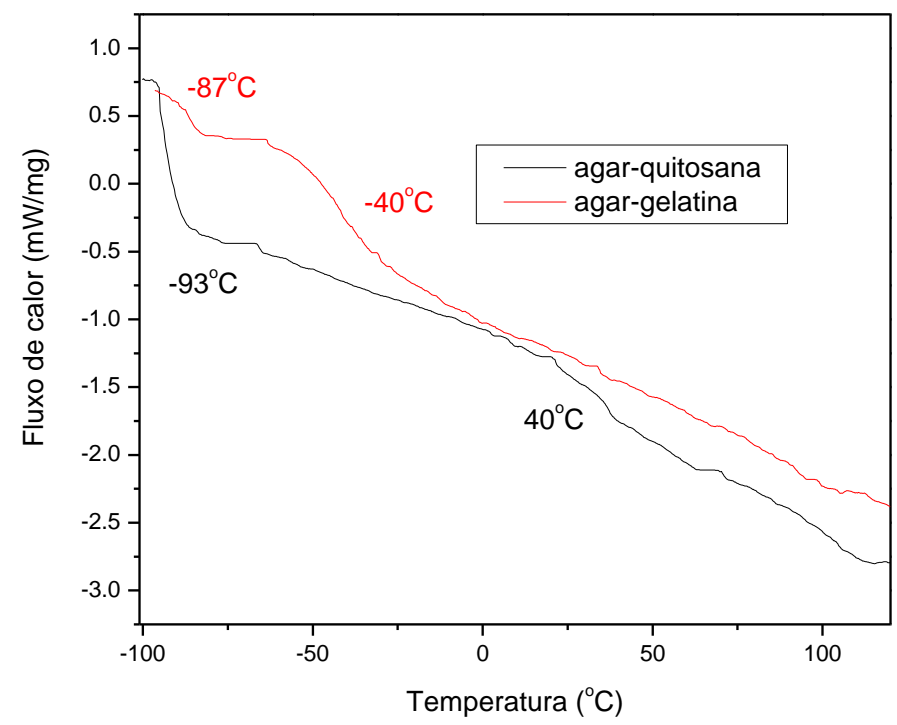

Figura 40 - Curvas de DSC dos filmes preparados das duas blendas. 
As duas amostras apresentaram duas $\mathrm{T}_{\mathrm{g}}$ cada, sendo a primeira mudanças na linha de base em torno de $-93^{\circ} \mathrm{C}$ e $-87^{\circ} \mathrm{C}$, para a blenda a base de agarquitosana e agar-gelatina, respectivamente. A segunda mudança de linha de base é observada em temperatura de $-40^{\circ} \mathrm{C}$ e $40^{\circ} \mathrm{C}$ para a blenda a base de agarquitosana e agar-gelatina, respectivamente. A ocorrência dessas duas transições pode ser devida a não total compatibilidade (confirmado pelas medidas microscópicas; item 7.6) entre as macromoléculas, onde cada um dos sistemas apresenta as dinâmicas diferentes ou as diferentes interrações entre essas macromoléculas como mostrado nas Figuras 41 e 42 . Contudo, tanto no caso de quitosana quanto no caso de gelatina há grupos amina que podem apresentar a interação iônica com os grupos sulfato da amilopectina. Nesse ponto precisa ressaltar que no caso de blenda de agar com a gelatina foram misturadas cadeias de um polissacarídeo com as cadeias lineares de proteína. No caso da blenda de agar com quitosana, onde foram misturados dois polissacaríedos, há provavelmente a interação forte do tipo ligações hidrogênio entre as cadeias poliméricas, como mostrado nas Figuras 41 e 42. Além disso, as amostras contêm o plastificante que também provavelmente interrage com as cadeias de polissacarídeos através de ligações de hidrogênio, devido aos três grupos hidroxila na sua estrutura e com isso aumenta a rigidez da estrutura formada. A presença de duas transições vítreas já foi observada nas amostras de amido plastificado com glicerol e explicada em termos de a primeira $T_{g}$, e mais baixa ser devida ao plastificante e a segunda ao próprio sistema $^{1,7}$. Contudo, pode haver também outra explicação onde a primeira Tg é relativa a transição a e a segunda a transição $\beta$, como observado através das medidas de DMTA (Dynamic Mechanic Thermal Analysis) das amostras de alginato $^{13}$. Nesse caso poderia se explicado como a movimentação dos menores 
segmentos em temperaturas mais baixas seguida por movimentação de maiores segmentos de cadeias poliméricas em temperaturas mais elevadas. Resultados parecidos foram obtidos com as amostras condutoras iônicas a base de alginato de sódio $^{14}$

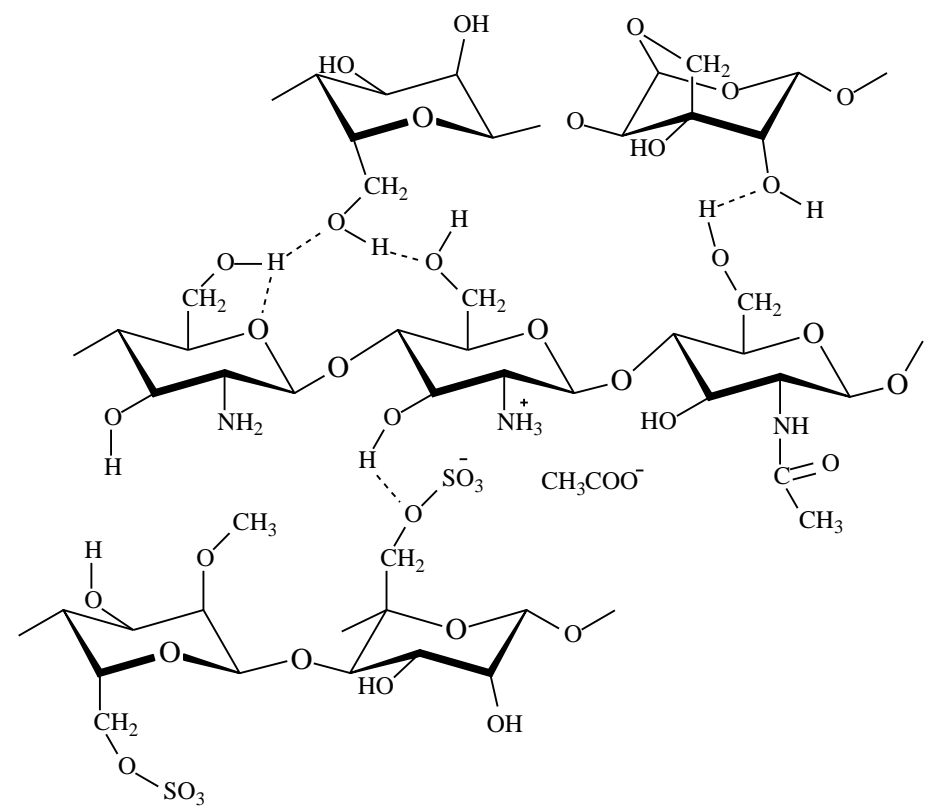

Figura 41. Representação da interração de agarose e agaropectina com as cadeias de quitosana.

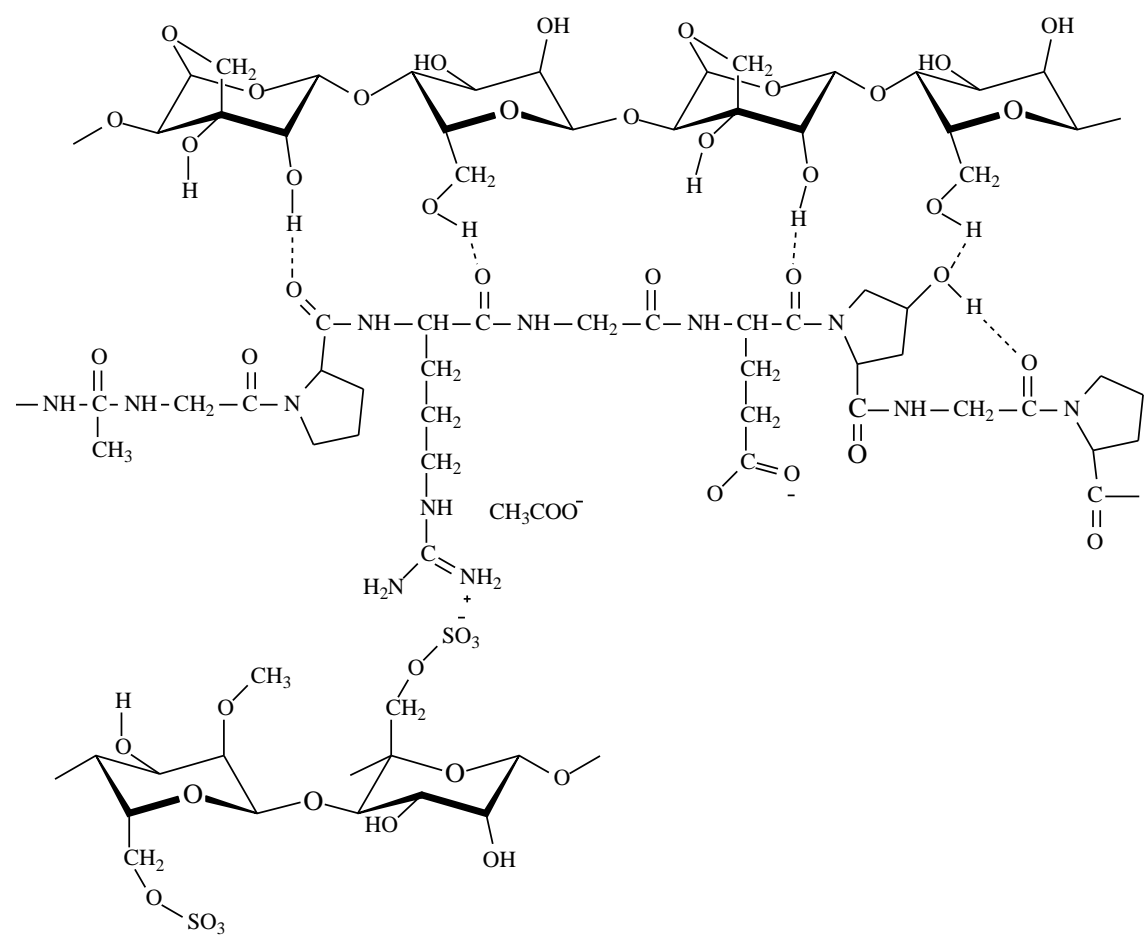

Figura 42 - Representação da interração da agarose e agaropectina com o fragmento da macromolécula de gelatina. 


\section{3 - Espectroscopia de Impedância Eletroquímica (EIE)}

Os eletrólitos a base de blendas também foram submetidos à análise de impedância eletroquímica para determinação da condutividade iônica em função da temperatura com intuito de obter as informações sobre o mecanismo de condução nesses eletrólitos ${ }^{11-16}$. A Figura 43 apresenta os resultados das condutividades iônicas em função da temperatura para estes eletrólitos.

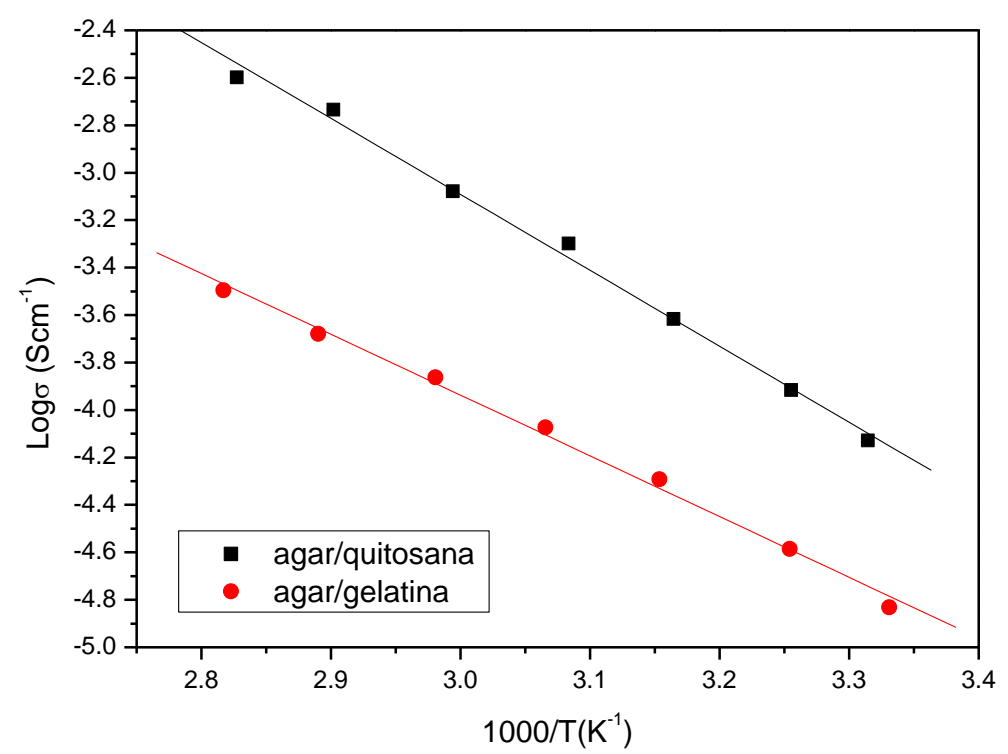

Figura 43 - Log da condutividade em função da temperatura para filmes com blendas de agar com quitosana e agar com gelatina.

Os resultados obtidos revelaram que o eletrólito de blenda agar-quitosana, apresentou melhores valores de condutividade iônica em relação ao eletrólito de blenda agar-gelatina, sendo obtidos valores de condutividade de $7,9 \times 10^{-5} \mathrm{~S} / \mathrm{cm} \mathrm{e}$ $1,53 \times 10^{-5} \mathrm{~S} / \mathrm{cm}$, respectivamente, à temperatura ambiente . O aumento de temperatura até $80^{\circ} \mathrm{C}$ promoveu um aumento linear dos valores de condutividade atingindo $2,4 \times 10^{-3} \mathrm{~S} / \mathrm{cm}$ para a blenda de agar-quitosana e $3,3 \times 10^{-4} \mathrm{~S} / \mathrm{cm}$ para a blenda de agar-gelatina. Estes resultados estão de acordo com os valores de condutividade observados para sistemas a base de polímeros naturais ${ }^{1-7}$.

Também, uma comparação destes resultados com os valores obtidos para os eletrólitos a base de agar com glicerol e ácido acético, estudado no capítulo 5, revela 
que os valores de condutividade obtidos para os eletrólitos a base de blenda agarquitosana foram melhores em quase uma ordem de grandeza (no intervalo de temperatura estudado) quando comparados com os eletrólitos a base de agar e os eletrólitos a base de blenda agar-gelatina. A mesma comparação com os eletrólitos a base de quitosana ${ }^{25,26}$, mas com ácido clorídrico, revela proximidade dos resultados. Isso indica, que esse novo sistema de blenda condutora iônica a base de agarquitosana quando comprado com a blenda de agar-gelatina possui um arranjo de cadeias poliméricas mais favorável para o deslocamento de ions e com isso melhor transporte de carga. Isso também era esperado uma vez que ambas as macromoléculas naturais são da mesma família de polissacarídeos, cujas soluções formam polieletrólitos uma com cadeia carregada positivamente (quitosana) e outra com cadeia carregada negativamente (agar) (Figura 41). A blenda agar-gelatina apresentou resultados de condutividade muito semelhantes ao eletrólito a base de agar, porém inferior ao eletrólito a base de gelatina ${ }^{4}$. Os valores de condutividade iônica obtidos para estes diferentes eletrólitos podem estão apresentados na Tabela 3 abaixo.

Tabela 3: Valores de condutividades ionicas para diferentes eletrólitos a base de polímeros naturais

\begin{tabular}{|ccc|}
\hline Eletrólito & $\begin{array}{c}\text { Condutividade iônica a } \\
\text { temperatura ambiente } \mathbf{( S / c m})\end{array}$ & $\begin{array}{c}\text { Condutividade } \\
\text { iônica a } \mathbf{8 0}{ }^{\circ} \mathbf{C ~ ( S / c m )}\end{array}$ \\
\hline Agar com $\mathbf{C H}_{3} \mathbf{C O O H}$ & $1,4 \times 10^{-5}$ & $3,1 \times 10^{-4}$ \\
\hline $\begin{array}{c}\text { Blenda agar-gelatina com } \\
\mathbf{C H}_{3} \mathbf{C O O H}\end{array}$ & $1,5 \times 10^{-5}$ & $3,3 \times 10^{-4}$ \\
\hline $\begin{array}{c}\text { Gelatina com } \mathbf{C H}_{3} \mathbf{C O O H}^{4} \\
\text { Blenda agar-quitosana } \\
\text { com } \mathbf{C H}_{3} \mathbf{C O O H}\end{array}$ & $4,5 \times 10^{-5}$ & $6,3 \times 10^{-4}$ \\
\hline Quitosana com $\mathrm{HCl}^{25,26}$ & $7,9 \times 10^{-5}$ & $2,4 \times 10^{-3}$ \\
\hline
\end{tabular}


Os resultados comparativos entre blendas preparadas e o eletrólito a base de agar (estudado no capítulo 5) podem ser melhor visualizados na Figura 44.

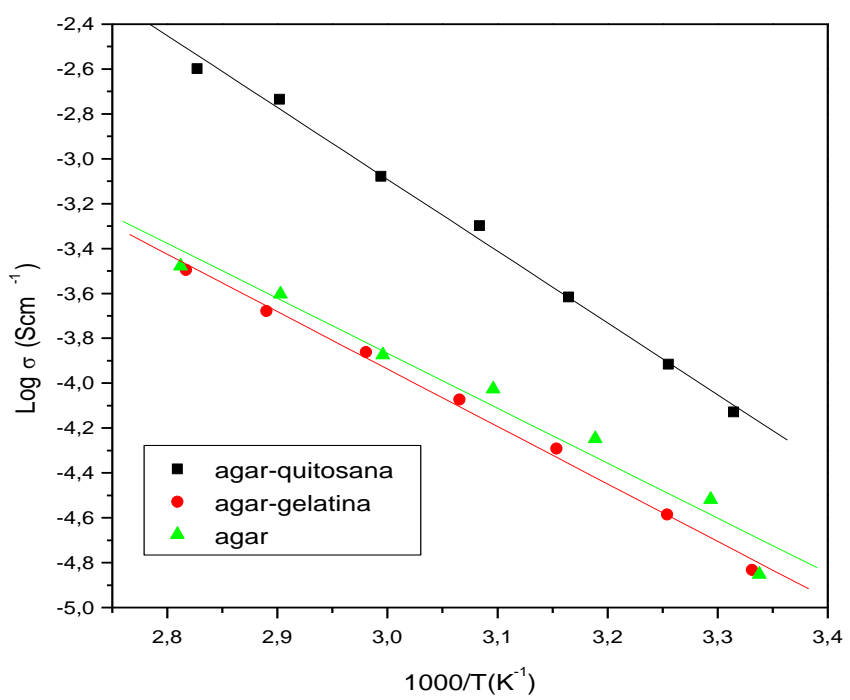

Figura 44 - Log da condutividade em função da temperatura para eletrólito a base de agar e de blendas de agar com quitosana e com gelatina, todas contendo ácido acético.

As medidas de condutividade iônica em função da temperatura foram realizadas, a fim de analisar o possível mecanismo de condução iônica nestes sistemas. Os resultados apresentados nas Figuras 43 e 44 revelam um mecanismo de condução tipo Arrhenius nos três eletrólitos a base de agar, onde a participação de movimentos da cadeia polimérica no mecanismo de condução é superado pelo hopping dos portadores de carga entre os sítios de coordenação local. Além disso, há provavelmente também a forte participação dos relaxamentos estruturais e movimentos segmentares dos complexos sal-polímero ${ }^{21-23}$. Os dados da Figura 44 estão em concordância com a equação de Arrhenius (1):

$\log \sigma=\log A+\left(-E_{a} / 2,303 R T\right)$

Obtendo-se o coeficiente angular das retas representadas nos gráficos de condutividade (Figura 44), determinou-se a energia de ativação para cada amostra e os resultados obtidos estão apresentados na Tabela 4. 
Tabela 4: Valores de condutividades e energia de ativação para os eletrólitos a base de agar e a base de blendas de agar com quitosana e com gelatina

\begin{tabular}{|cccc|}
\hline Eletrólito & $\begin{array}{c}\text { Condutividade iônica a } \\
\text { temperatura ambiente } \mathbf{( S / c m )}\end{array}$ & $\begin{array}{c}\text { Condutividade } \\
\text { iônica a } \mathbf{8 0}^{\circ} \mathbf{C}(\mathbf{S} / \mathbf{c m})\end{array}$ & $\begin{array}{c}\text { Energia de } \\
\text { Ativação (kJ/mol) }\end{array}$ \\
\hline Agar & $1,4 \times 10^{-5}$ & $3,1 \times 10^{-4}$ & 49 \\
\hline Agar-gelatina & $1,5 \times 10^{-5}$ & $3,3 \times 10^{-4}$ & 47 \\
\hline Agar-quitosana & $7,9 \times 10^{-5}$ & $2,4 \times 10^{-3}$ & 62 \\
\hline
\end{tabular}

Nesta tabela observa-se que os valores encontrados para a energia de ativação estão relacionados diretamente com a condutividade iônica dos filmes, onde os filmes a base de agar e a base de blenda agar-gelatina apresentaram valores muito próximos, i.e., $47 \mathrm{~kJ} / \mathrm{mol}$ e $49 \mathrm{~kJ} / \mathrm{mol}$ respectivamente, assim como, os valores de condutividade observados para esses filmes $\left(3,1 \times 10^{-4}\right.$ e $3,3 \times 10^{-4} \mathrm{~S} / \mathrm{cm}$, respectivamente). A amostra a base da blenda agar-quitosana apresentou um valor de energia de ativação mais elevado, i.e., $62 \mathrm{~kJ} / \mathrm{mol}$. Esse último valor é diferente do que era esperado para este eletrólito, já que o mesmo apresentou valores de condutividade iônicas mais elevados, o que nos indica que embora a condutividade iônica tenha sido melhor para este tipo de eletrólito, as barreiras de energia são mais reduzidas nos eletrólitos a base de agar ou a base de blenda agar-gelatina ${ }^{2,23,27}$.

\section{4 - Espectroscopia no Ultravioleta-Visível (UV-vis)}

A Figura 44 apresenta os espectros de transmitância para os eletrólitos preparados no intervalo de freqüência de 200- 900 nm. Pode-se observar que a transmitância das duas amostras aumenta com o aumento do comprimento de onda, de zero na região UV (200nm) até entre 73 e $86 \%$ na região visível, dependendo da amostra. Além disso, também se observa que no caso da blenda de agar com gelatina o aumento de transmitância ocorre já em 300 nm, ie., ainda na faixa UV do 
espectro eletromagnético. Isso significa que as amostras contendo gelatina são mais transparentes do que as amostras contendo dois polissacarídeos. Isso também está de acordo com os resultados anteriores sobre eletrólitos a base de gelatina com ácido acético ${ }^{27}$.

A amostra a base de blenda do agar com quitosana apresenta os espectros UV-vis bastante similares contudo, o aumento de transmitância ocorre em 400 nm. Isso deve ser devido ao grande número de anéis glicosídicos presentes na amostra. Acima de $500 \mathrm{~nm}$ ambas as amostras apresentam transmitâncias acima de 70\%, sendo a amostra contendo gelatina apresentar o valor superior a $80 \%$.

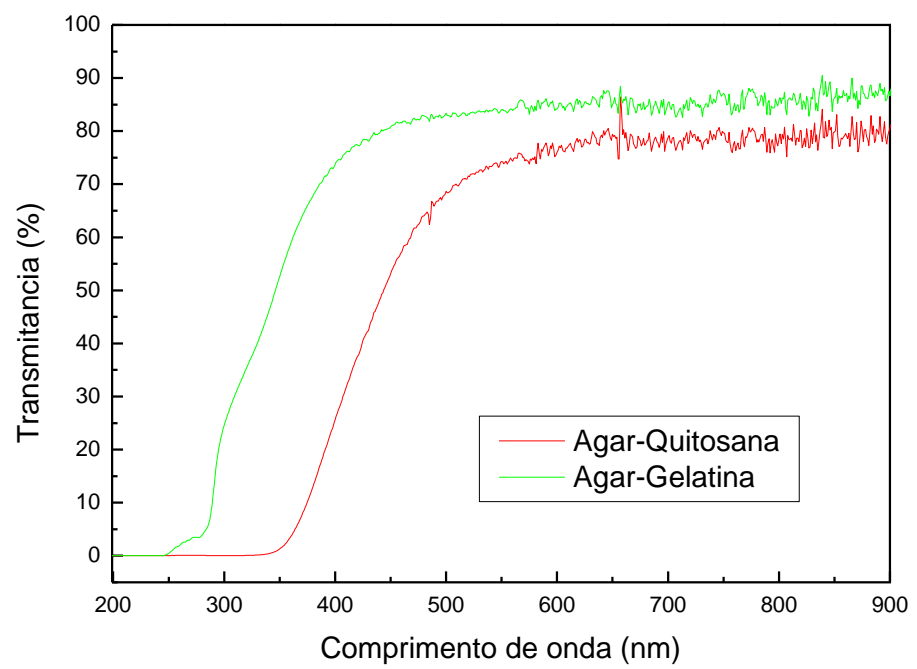

Figura 45 - Espectros de UV-vis para filmes a base de blendas de agar com quitosana e com gelatina.

Portanto, estes filmes podem ser considerados transparentes na região visível, o que é de grande importância para a possível utilização destes eletrólitos em dispositivos eletrocrômicos, como janelas eletrocrômicas. Estes resultados são semelhantes à outros ESPs a base de polissacarídeos ${ }^{1-7}$, bem como, aos eletrólitos a base de agar com ácido acético (capítulo 5). 


\section{5 - Difração de raios-X}

Como já foi discutido anteriormente, o agar é um polímero semicristalino constituído de grânulos. A plastificação do agar através da adição de glicerol modifica a sua estrutura, resultando em filmes com predominância do estado amorfo. O mesmo pode ser dito a respeito da gelatina e da quitosana. A Figura 46 apresenta os difratogramas de raios- $x$ obtidos para os eletrólitos a base de blendas de agar, medidos à temperatura ambiente. A adição de plastificantes deveria assegurar o caráter amorfo das amostras ${ }^{1,12}$ contudo, nesse caso, observa se bandas bastante estreitas e centradas em torno de $2 \theta=20^{\circ}$ o que indica um certo arranjo na estrutura das amostras que pode ser devido às interrações entre os componentes das mesmas. Os difratogramas parecidos já foram observados no caso de amostras condutoras iônicas a base de geltaina e contendo ácido acético ${ }^{27}$. Entretanto, como não foi observado nenhum pico de fusão nem de cristalização nos resultados de análises térmicas, assim como, os resultados de condutividade iônica seguiram o comportamento linear, pode se dizer, que há predominância do estado amorfo das amostras analisadas ${ }^{1-7}$.

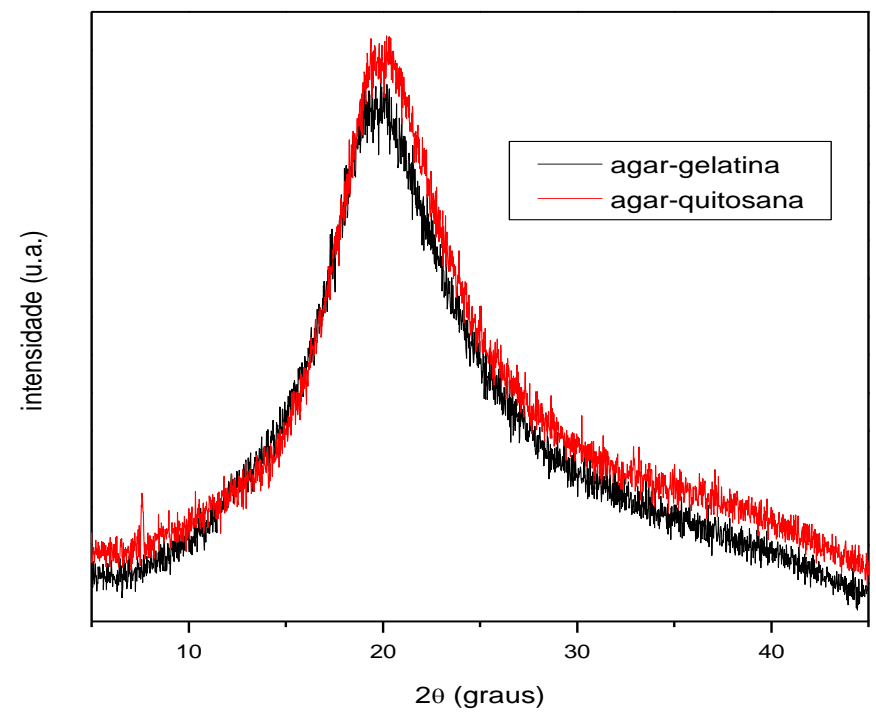

Figura 46 - Difração de raios- $X$ dos filmes a base de blendas de agar. 


\section{6 - Microscopia Eletrônica de Varredura (MEV)}

Ao observar as micrografias dos filmes preparados, (Figura 47), nota-se que 0 filme a base de blenda de agar com gelatina não apresentou uma superfície totalmente homogênea, ocorreram algumas pequenas rachaduras, o que indica que não houve completa compatibilidade entre a proteína e o polissacarídeo. O filme a base de blenda de agar com quitosana apresenta a superfície mais homogênea, indicando desta forma, boa compatibilização entre os dois polissacarídeos e comprovando os elevados valores de condutividade iônica.
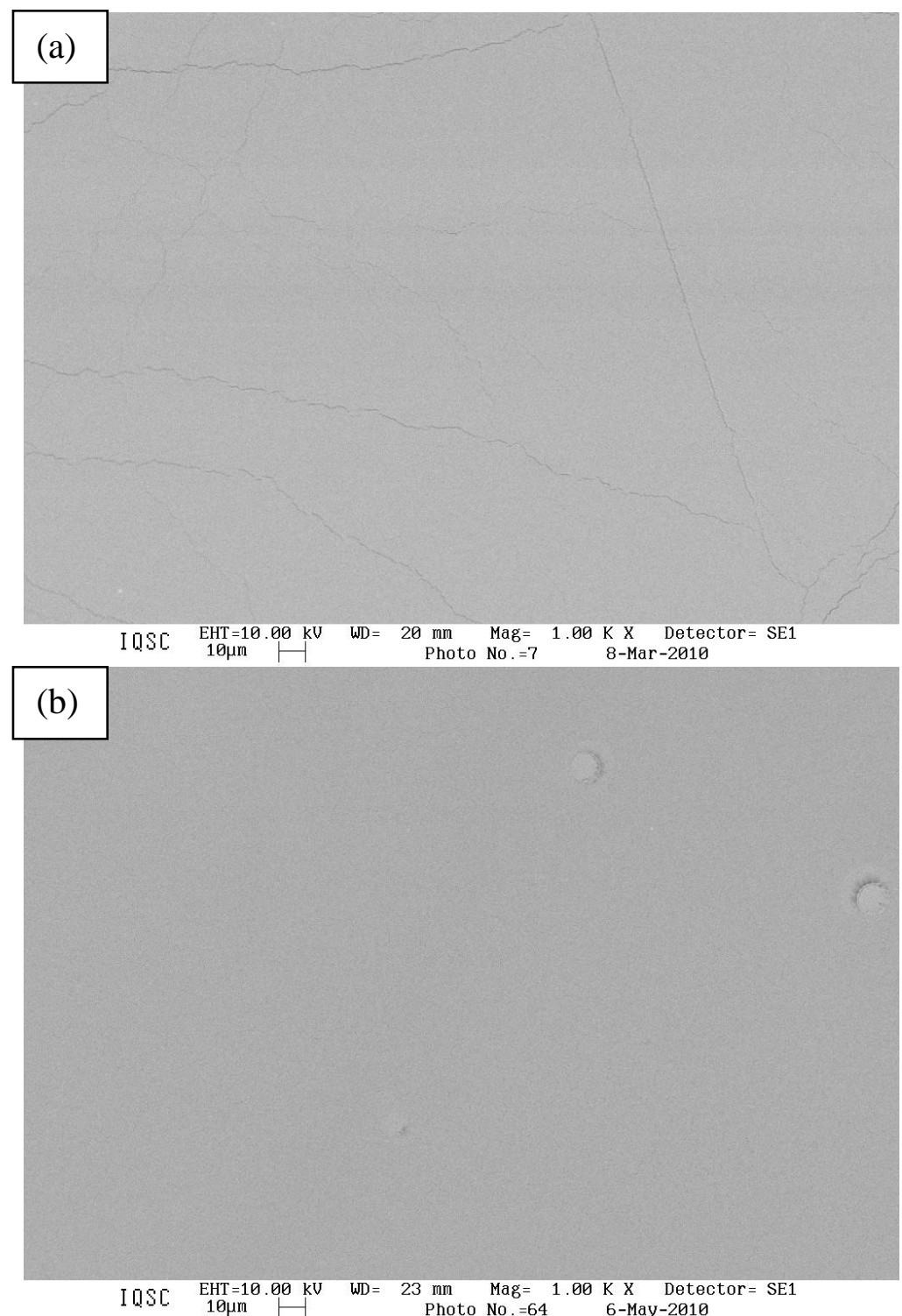

Figura 47 - Micrografias dos filmes a base de blendas de agar: (a) agar-gelatina e (b) agar-quitosana, ampliadas 1000x. 


\section{7 - Dispositivos Eletrocrômicos}

As amostras de eletrólitos a base de blendas de agar foram então usadas para montagem de pequenos dispositivos eletrocrômicos de $2 \mathrm{~cm}^{2}$ de área. $\mathrm{O}$ eletrólito foi introduzido na forma de gel viscoso no espaço entre os filmes de $\mathrm{WO}_{3} \mathrm{e}$ $\mathrm{CeO}_{2}-\mathrm{TiO}_{2}$. A Figura 48 apresenta o resultado da transmitância da janela constituída de filme de $\mathrm{WO}_{3}$, eletrólito à base de blenda de agar com quitosana e filme de $\mathrm{CeO}_{2-}$ $\mathrm{TiO}_{2}$, onde observa-se a mudança entre o estado colorido e descolorido de aproximadamente $22 \%$ em $550 \mathrm{~nm}$, sendo que no estado descolorido o valor é de $40 \%$ e no estado colorido de $18 \%$. Essa diferença aumenta com o aumento de comprimento de onda até $40 \%$ e permanece estável até $800 \mathrm{~nm}$. A mudança de coloração pode ser considerada boa quando comparada com outros dispositivos onde diferenças de $15-20 \%$ foram obtidas ${ }^{2}$.

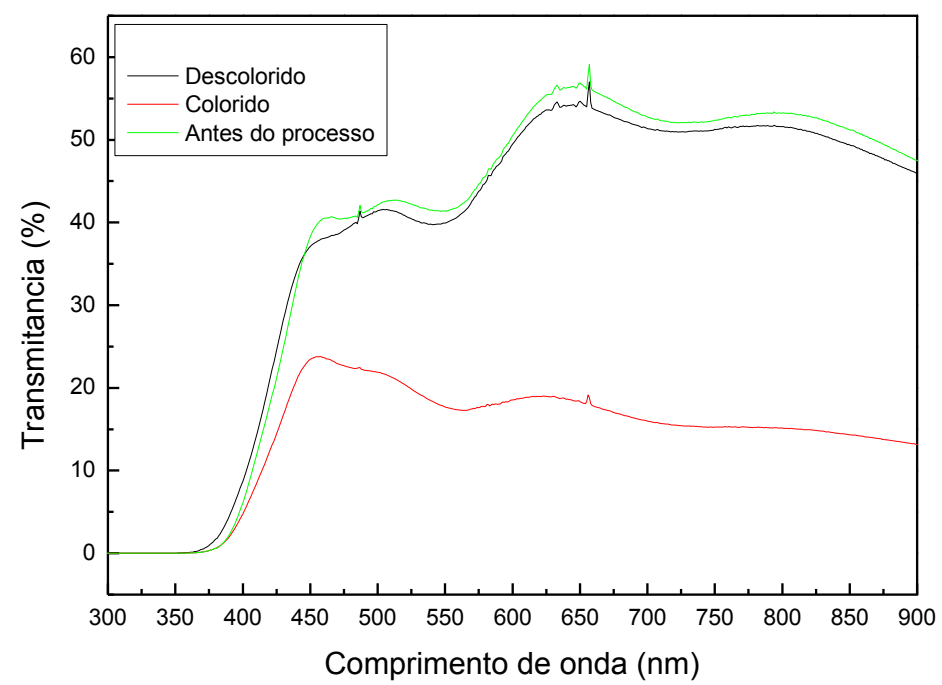

Figura 48: Transmitância dos DECs contendo o eletrólito a base de blenda de agar com quitosana.

A Figura 49 apresenta o resultado da densidade de carga catódica/anódica da janela constituída de filme de $\mathrm{WO}_{3}$, eletrólito à base de blenda de agar com quitosana e filme de $\mathrm{CeO}_{2}-\mathrm{TiO}_{2}$. Nessa figura observa-se um aumento continuo da densidade de carga com o tempo atingindo $8 \mathrm{mC} / \mathrm{cm}^{2}$ em $15 \mathrm{~s}$. O processo de extração é mais rápido, i.e., de 5s. Após 15s observa-se quase total extração de 
cargas. O cálculo da razão de carga catódica/anódica é de 0,96, mostrando que o processo de intercalação/deintercalação dos prótons no filme é quase reversível. 0 valor de carga obtido foi menor do que o valor de carga obtido para a amostra a base de agar com ácido acético. Isso significa que embora o mecanismo de condução e do tipo Arrhenius, i.e., via saltos entre os sítios de complexação, há provavelmente uma parte de cargas deslocada através do mecanismo veicular. Desta maneira e por causa do seu volume algumas cargas não conseguem ser inseridas dentro da camada do filme fino de $\mathrm{WO}_{3}$. A ocorrência de dois mecanismos de condução em eletrólitos sólidos poliméricos já foi observada através de medidas de ressonância magnética assim como, nas medidas de condutividade iônica onde dependendo da quantidade de portadores de carga um dos mecanismos prevalecia 5,8 .

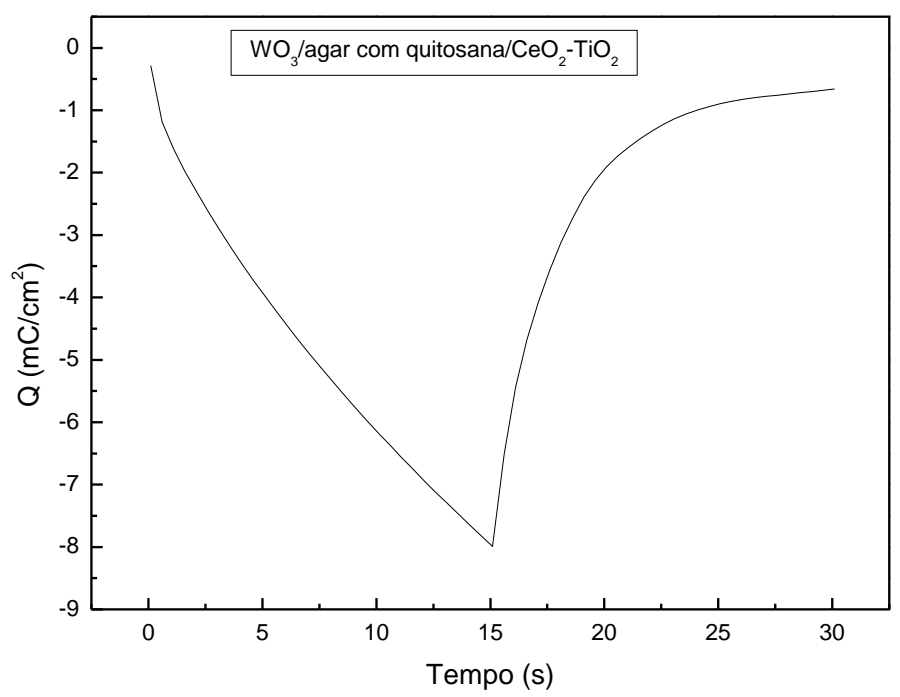

Figura 49: Densidade de carga para o DEC com eletrólito a base de blenda de agar com quitosana.

A Figura 50 apresenta o voltamograma da janela constituída de filme de $\mathrm{WO}_{3}$, eletrólito à base de blenda de agar com quitosana e filme de $\mathrm{CeO}_{2}-\mathrm{TiO}_{2}$ a uma velocidade de varredura de $50 \mathrm{mV} / \mathrm{s}$, com potenciais aplicados entre $-3,5 \mathrm{~V}$ e $3,0 \mathrm{~V}$, para 10 ciclos, onde é possível observar um pico catódico a -1,4 V que corresponde 
a inserção de prótons e elétrons do filme de $\mathrm{WO}_{3}$.e consequentemente sua coloração. A posterior diminuição da corrente elétrica vista nesse voltamograma é provavelmente devida aos outros processos, como inserção de cargas no filme de ITO ou evolução de hidrogênio da água do eletrólito. O voltamograma apresenta também dois picos anódicos, o primeiro a $-0,21 \mathrm{~V}$ correspondendo à extração de prótons e elétrons do filme de $\mathrm{WO}_{3}$, e consequente descoloração do dispositivo e o segundo pico a 1,8V relativo aos processos de oxidação e/ou extração de cargas do filme de ITO.

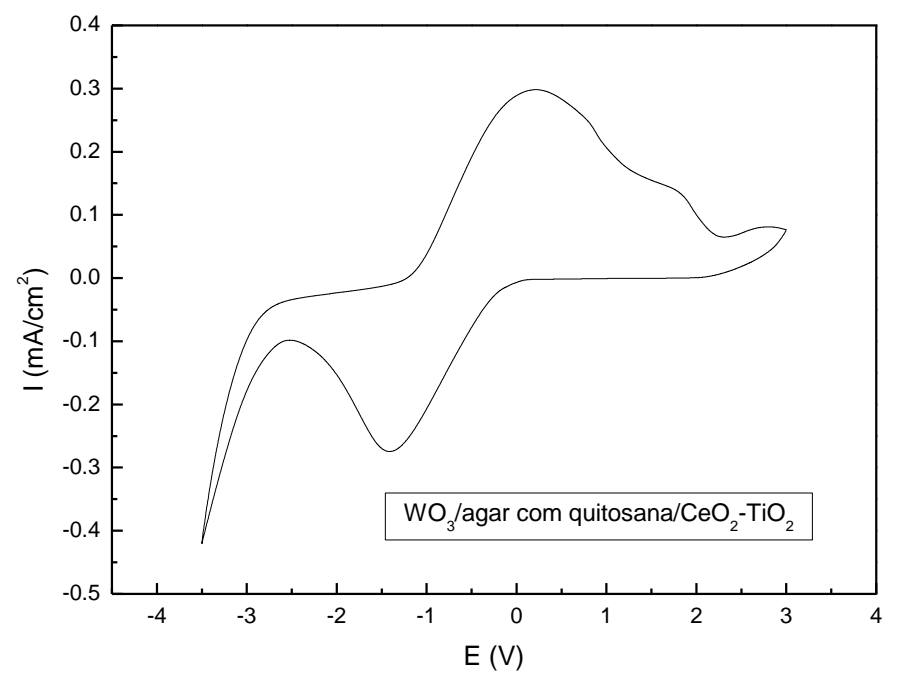

Figura 50: Voltamograma para o DEC com eletrólito a base de blenda de agar com quitosana.

Além das janelas eletroquímicas com blenda de agar com quitosana foram montadas e analisadas as janelas contendo como eletrólito a blenda de agar com geltaina. A Figura 51 apresenta o resultado da transmitância da janela constituída de filme de $\mathrm{WO}_{3}$, eletrólito à base de blenda de agar com gelatina e filme de $\mathrm{CeO}_{2}-\mathrm{TiO}_{2}$, onde observa-se a mudança entre 0 estado colorido e descolorido de aproximadamente $25 \%$ em $550 \mathrm{~nm}$, sendo que no estado descolorido o valor é de $51 \%$ e no estado colorido de $26 \%$. Essa diferença aumenta com o aumento de comprimento de onda até $30 \%$ e permanece estável até $900 \mathrm{~nm}$. A mudança de 
coloração pode ser considerada boa quando comparada com outros dispositivos onde diferenças de $15-20 \%$ foram obtidas ${ }^{2}$.

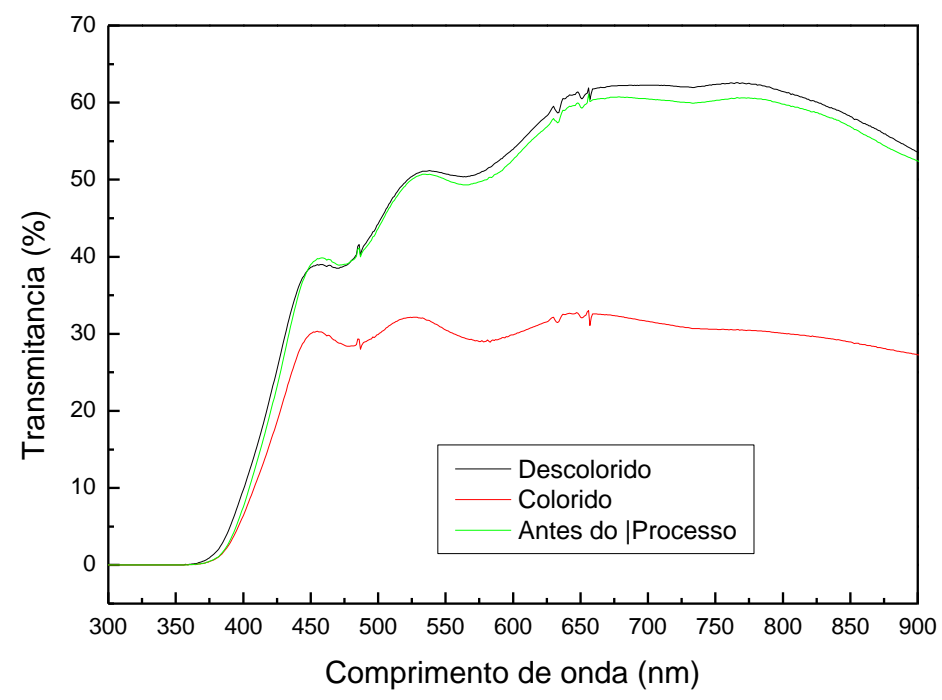

Figura 51: Transmitância dos DECs para o filme de blenda de agar com gelatina.

A Figura 52 apresenta o resultado da densidade de carga catódica/anódica da janela constituída de filme de $\mathrm{WO}_{3}$, eletrólito à base de blenda de agar com gelatina e filme de $\mathrm{CeO}_{2}-\mathrm{TiO}_{2}$. Nessa figura observa-se um aumento continuo de densidade de carga com o tempo atingindo $5,4 \mathrm{mC} / \mathrm{cm}^{2} \mathrm{em} 15 \mathrm{~s}$. O processo de extração é mais rápido, i.e., de 5s. Após 15s observa-se quase total extração de cargas. O cálculo da razão de carga catódica/anódica é de 1,0, mostrando que o processo de intercalação/deintercalação dos prótons no filme é reversível. Nesse caso observase de novo a diminuição dos valores de carga inserida/extraida da camada eletrocrômica quando comparada com as janelas contendo eletrólito de agar com $\mathrm{CH}_{3} \mathrm{COOH}$ (Figura 23), Embora a condutividade iônica desses eletrólitos assim como, seu aumento linear é igual (Figura 44) os valores de carga são metade dos valores de carga encontrados para as janelas contendo eletrólito a base de agar com $\mathrm{CH}_{3} \mathrm{COOH}$. Novamente isso pode ser devido a presença de dois mecanismos 
de transporte de carga assim como a mais forte associação dessas cargas com os seus portadores, impedindo sua intercalação na estrutura de filme de $\mathrm{WO}_{3}$. Contudo, aparentemente isso não tem muita influência na coloração do filme óxido de tungstênio onde a diferença entre o estado colorido e descolorido foi igual para as duas janelas, i.e., de $25 \%$ em 550 nm (Figuras 22 e 51). Isso também sugerre que os processos de oxi/redução do $\mathrm{WO}_{3}$ ocorrem na interface filme/eletrólito.

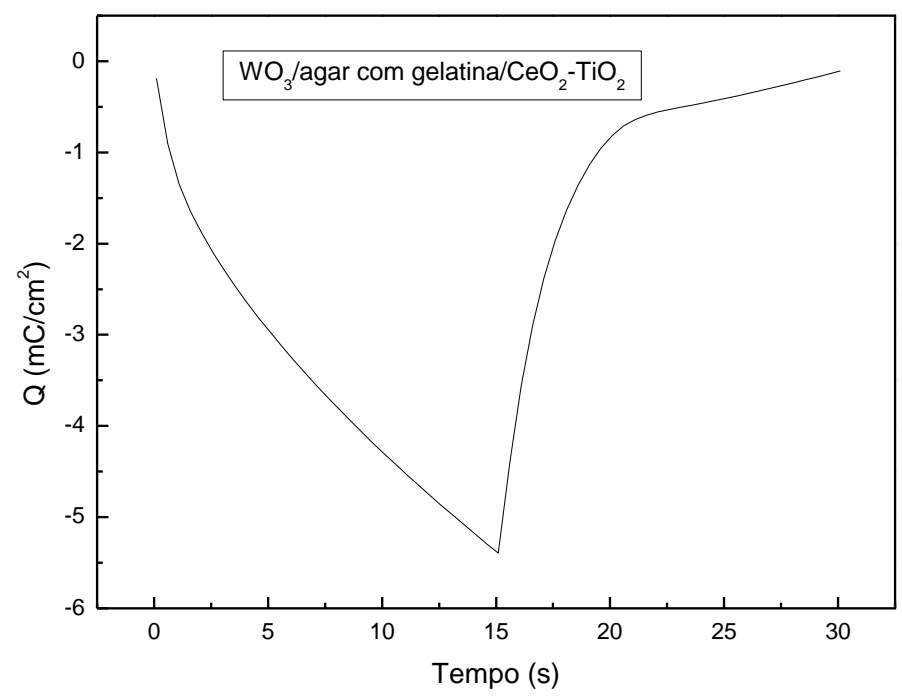

Figura 52: Densidade de carga para o DEC com eletrólito a base blenda de agar com gelatina.

A Figura 53 apresenta o voltamograma da janela constituída de filme de $\mathrm{WO}_{3}$, eletrólito à base de blenda de agar com gelatina e filme de $\mathrm{CeO}_{2}-\mathrm{TiO}_{2}$ a uma velocidade de varredura de $50 \mathrm{mV} / \mathrm{s}$, com potenciais aplicados entre $-3,5 \mathrm{~V}$ e $3,0 \mathrm{~V}$, para 10 ciclos, onde é possível observar um pico catódico a $-1,6 \mathrm{~V}$ que corresponde a inserção de prótons e elétrons no filme de $\mathrm{WO}_{3}$.e consequentemente sua coloração. A posterior diminuição da corrente elétrica vista nesse voltamograma é provavelmente devido aos outros processos, como inserção de cargas no filme de ITO ou evolução de hidrogênio da água do eletrólito. O voltamograma apresenta também um pico anódico, a 0,3V correspondendo à extração de prótons e elétrons 
do filme de $\mathrm{WO}_{3}$, e consequente descoloração do dispositivo. Além disso, também é observado um ombro a 1,5 $\mathrm{V}$ relativo, provavelmente aos processos de oxidação e/ou extração de cargas do filme de ITO.

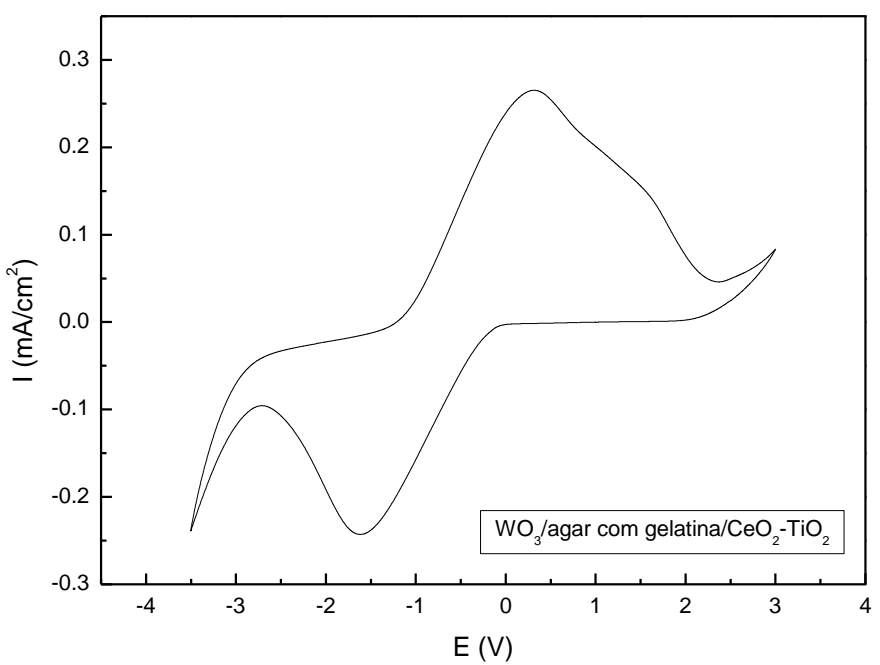

Figura 53: Voltamograma para o DEC com eletrólito a base de blenda de agar com quitosana contendo $\mathrm{CH}_{3} \mathrm{COOH}$.

Os resultados das janelas eletrocrômicas com eletrólitos a base de blendas de agar com quitosana ou com gelatina demonstraram-se promissores, onde $18 \mathrm{e}$ $25 \%$ de mudança de coloração é um valor próximo aos obtidos com outros dispositivos a base de gelatina ${ }^{2}$ que apresentaram mudanças de coloração de 15$20 \%$.

\section{8 - Conclusões do Capítulo}

Foram preparados novos eletrólitos poliméricos a base de blendas de agar com quitosana e agar com gelatina. As membranas obtidas apresentaram transparência de 73 a $86 \%$, na região do visível, valores estes muito bons para os eletrólitos serem aplicados em dispositivos eletrocrômicos. Isso se refere principalmente ao eletrólito a base de blenda de agar com gelatina que mostrou-se praticamente transparente na região do visível. Foi verificado que a amostra a base 
de blenda de agar com quitosana apresentou um valor de condutividade muito superior ao obtido para o eletrólito só a base do agar, enquanto que a amostra a base de blenda de agar com gelatina praticamente não apresentou alteração de condutividade iônica quando comparada ao eletrólito a base de agar. O melhor resultado de condutividade iônica foi de $7,9 \times 10^{-5} \mathrm{~S} / \mathrm{cm}$ à temperatura ambiente e $2,4 \times 10^{-3} \mathrm{~S} / \mathrm{cm}$ a $80^{\circ} \mathrm{C}$, para o eletrólito a base de blenda de agar com quitosana e os resultados de condutividade iônica em função da temperatura apresentaram comportamento do tipo Arrhenius para ambas amostras. As medidas de difração de raios- $\mathrm{X}$ confirmaram que as amostras são predominantemente amorfas. As micrografias mostram que os filmes preparados possuem uma superfície homogênea e uniforme, indicando que ocorreu boa compatibilização entre os diferentes macromoléculas utilizadas no preparo das blendas. Os estudos preliminares para aplicação destes eletrólitos em dispositivos eletrocrômicos resultaram em boa reversibilidade do dispositivo, e densidade de carga de $8 \mathrm{mC} / \mathrm{cm}^{2}$ (blenda: agar-quitosana) e $5,4 \mathrm{mC} / \mathrm{cm}^{2}$ (blenda: agar-gelatina). Todos esses resultados sugerem que eletrólitos poliméricos protônicos a base de blendas de agar são muito atrativos para serem utilizados em dispositivos eletrocrômicos.

\section{Referências Bibliográficas}

[1] DRAGUNSKI, D. C. Preparação de eletrólitos sólidos poliméricos a partir do amido. 2003. 163f. Tese (Doutorado) - Instituto de Química de São Carlos, Universidade de São Paulo, São Carlos, 2003.

[2] - AVELLANEDA, C. O.; VIEIRA, D. F.; AL-KAHLOUT, A.; HEUSING, S.; LEITE, E. R.; PAWLICKA, A.; AEGERTER, M. A. All solid-state electrochromic devices with gelatin-based electrolyte. Solar Energy Materials \& Solar Cells, v. 92, p. $228-233$, 2008 
[3] - DRAGUNSKI, D. C.; PAWLICKA, A. Starch based solid polymeric electrolytes. Molecular Crystals and Liquid Crystals Science and Technology. Section A. Molecular Crystals and Liquid Crystals, v. 374, p. 561 - 568, 2002.

[4] VIEIRA, D.; AVELLANEDA, C.; PAWLICKA, A. Conductivity study of a gelatinbased polymer electrolyte. Electrochimica Acta, v. 53, n. 4, p. 1404 -1408, 2007.

[5] PAWLICKA, A.; DANCZUK, M.; WIECZOREK, W.; ZYGADLO-MONIKOWSKA, E. influence of plasticizer type on the properties of polymer electrolytes based on chitosan. Journal of Physical Chemistry. A, Molecules, Spectroscopy, Kinetics, Environment, \& General Theory, v. 112, p. 8888 - 8895, 2008.

[6] RAPHAEL, E.; AVELLANEDA, C. O.; MANZOLLI, B.; PAWLICKA, A. Agar-based films for application as polymer electrolytes. Electrochimica Acta, v. 55, p. 1455 1459, 2009.

[7] MARCONDES, R. F. M. S.; D'AGOSTINIA, P. S.; FERREIRA, J.; GIROTTO, E. M.; PAWLICKA, A.; DRAGUNSKI, D.C. Amylopectin-rich starch plasticized with glycerol for polymer electrolyte application. Solid State lonics, v. 181, p. 586 - 591, 2010.

[8] MATTOS, R. I.; TAMBELLI, C. E.; DONOSO, J. P.; PAWLICKA, A. NMR study of starch based polymer gel electrolytes: Humidity effects. Electrochemica Acta, v. 53, p. $1461,2007$.

[9] MACHADO, G.; FERREIRA, H.; PAWLICKA, A. Influence of plasticizer contents on the properties of HEC-based solid polymeric electrolytes. Electrochimica Acta, v. 50, p. $3827-3831,2005$.

[10] REGIANI, A.; TAMBELLI, C.E.; PAWLICKA, A.; CURVELO, A. A. S.; GANDINI, A.; LENEST, J. F.; DONOSO, J. P. DSC and solid state NMR.characterization of hydroxyethylcellulose/polyether films. Polymer International, v. 49, p. 960 - 964, 2000.

[11] OLIVEIRA, S. C.; TORRESI, R. M. Uma visão das tendências e perspectivas em eletrocromismo: a busca de novo materiais e desenhos mais simples. Química Nova, v. .23, n. 1, p. $79-87,2000$. 
[12] COLONNA, P.; BULEON, A.; MERCIER, C. Physically modified starches. In: STARCH: Properties and Potencial. Great Brintain: Society of Chemical Industry, 1987, p. 49.

[13] VEERAPUR, R. S.; GUDASI, K. B.; SAIRAM, M.; SHENOY, R. V.; NETAJI, M.; RAJU, K.; SREEDHAR, B.; AMINABHAVI, T. M. Novel sodium alginate composite membranes prepared by incorporating cobalt(III) complex particles used in pervaporation separation of water-acetic acid mixtures at different temperatures. Journal of Material Science, v. 42 p. 4406-4417, 2007.

[14] OKAMOTO, Y. I. Eletrólitos poliméricos a base de alginato de sódio. São Carlos, 2010. 88f. Dissertação (Mestrado) - Programa de Pós-Graduação em Ciências e Engenharia de Materiais - Universidade de São Paulo, São Carlos, 2010.

[15] MORITA, M.; ARAKI, F.; KASHIWAMURA, K.; YOSHIMOTO, N.; ISHIKAWA, M. lonic structure and conductance behavior of plasticized polymeric electrolytes containing multivalent cations. Electrochimica Acta, v. 45, n. 8-9, p. $1335-1340$, 2000.

[16] KIM, Y. T.; SMOTKIN, E. S. The effect of plasticizers on transport and electrochemical properties of PEO-based electrolytes for lithium rechargeable batteries. Solid State Ionics, v. 149, p. 29 - 37, 2002.

[17] BASKARAM, R.; SELVASEKARAPANDIAN, S.; KUWATA, N.; KAWAMURA, J.; HATTORI, T.; AC impedance, DSC and FT-IR investigations on (x)PVAc- $(1-x)$ PVdF blends with LiClO4. Material Chemical Physics, v. 98, p.155, 2004.

[18] HIRANKUMAR, G.; SELVASEKARAPANDIAN, S.; BHUVANESWARI, M. S.; BASKARAN, R.; VIJAYAKUMAR, M. Ag+ ion transport studies in a polyvinyl alcoholbased polymer electrolyte system. Journal of Solid State Electrochemistry, v. 10, n. 4, p. 193-197, 2006.

[19] TSUTSUMI, H.; MATSUO, A.; ONIMURA, K.; OISHI, T. Conductivity enhancement of a polyacrylonitrile-based polymer electrolyte containing cascade nitrile as a plasticizer. Electrochemical Solid-State Letters, v. 1, p. 244, 1998.

[20] RATNER, M. A.; NITZAN, A. Conductivity in polymer ionics - dynamic disorder and correlation. Faraday Discussions. v. 88, p. 19, 1989. 
[21] REDDY, J. M.; SREEKANTH, T.; SUBBA RAO, U. V. Study of the plasticizer effect on a (PEO+NaYF4) polymer electrolyte and its use in an electrochemical cell. Solid State Ionics, v. 126, p. 55, 1999.

[22] SUBBA REDDY, Ch.V.; SHARMA, A.; NARASIMHA K.; RAO, V. V. R. Dielectric spectroscopy studies on (PVP + PVA) polyblend film. Journal of Power Sources, v. 114, p. 338, 2003.

[23] BASKARAM, R.; SELVASEKARAPANDIAN, S.; HIRANKUMAR, G.;

BHUVANESWARI, M. S. Ionics, v. 10, p. 129, 2004.

[24] KOPITZKE, R. W.; LINKOUS, C. A,; ANDERSON, H. R.; NELSON G.L.

Conductivity and Water Uptake of Aromatic-Based Proton Exchange Membrane

Electrolytes. Journal of Electrochemical Society, v. 106, p. 1677, 2000.

[25] DANCZUK, M. Eletrólitos sólidos poliméricos a partir de quitosana. 2007. 116f, Dissertação (Mestrado) - Instituto de Química de São Carlos, Universidade de São Paulo, São Carlos, 2007.

[26] PAWLICKA, A.; DANCZUK, M.; WIECZOREK, W.; ZYGADLO-MONIKOWSKA, $E$. Influence of plasticizer type on the properties of polymer electrolytes based on chitosan. Journal of Physical Chemistry A, v. 112, p. 8888-8895, 2008.

[27] WIECZOREK, W.; ZUKOWSKA, G.; OSTROVSKII, D.; FLORJANCZYK, Z. The application of mesoionic compounds into proton-conducting polymer gels. Journal of Physical Chemistry B, v. 105 p. 9686, 2001. 


\section{CAPÍTULO 8 - CARACTERIZAÇÃO DOS ELETRÓLITOS DE ÁGAR COM PEDOT:PSS - REŞULTADOS E DISCUSSÕES.}

Nesta parte do trabalho foi feito um estudo da adição de poli(3,4-etileno dioxitiofeno)/poli(estireno sulfonato) (PEDOT:PSS - Aldrich) aos eletrólitos a base de agar. O sistema foi escolhido devido à vários fatores. O primeiro foi a elevada condutividade eletrónica do próprio PEDOT devido a presença de ligações duplas conjugadas (é um polímero condutor eletrónico). O segundo fato é que o próprio PEDOT é também um polímero com propriedades eletrocrômicas. Contudo, este polímero é insolúvel em água, mas quandoele é misturado com PSS, que é solúvel em água obtêm-se um sistema solúvel em água, com alta condutividade elétrica, de baixo custo e de fácil manuseio (Figura 54$)^{1}$. Além disso, é um sistema de polímero condutor orgânico com possibilidade de diversas aplicações práticas como, sensores e mostradores entre outras aplicações que envolvam suas propriedades condutoras $^{1-4}$. O sistema PEDOT:PSS também apresenta algumas propriedades plastificantes para outros polímeros, ou seja atua também estabilizando o sistema onde é inserido, conduzindo a um mínimo de energia, e por suas cadeias serem linearizadas e tendo ligações duplas conjugadas, implica numa facilitação na condução de corrente elétrica ${ }^{1,4}$. Desta forma, foi feito inicialmente um estudo da melhor composição de eletrólito, em função da quantidade adicionada de glicerol e PEDOT:PSS, além do estudo das quantidades de $\mathrm{LiClO}_{4}$ ou ácido acético adicionados aos eletrólitos. A tabela 5 abaixo apresenta a composição dos diferentes filmes preparados. Todos eletrólitos foram preparados com quantidades fixas de agar $(0,5 \mathrm{~g})$ e formaldeído $(0,5 \mathrm{~g})$; foi variada a quantidade de $\mathrm{LiClO}_{4}$ ou ácido acético, glicerol adicionados ao sistema PEDOT:PSS. 


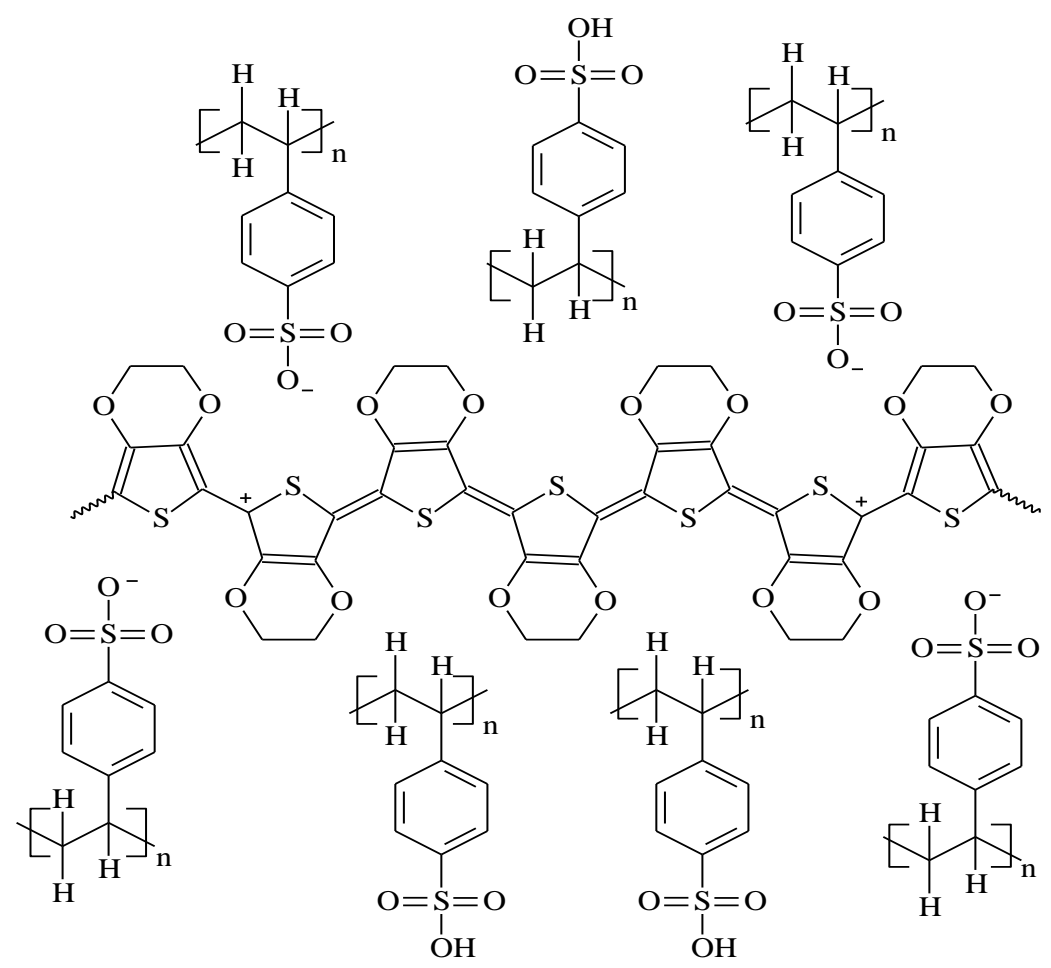

Figura 54 - Representação química do sistema PEDOT:PSS.

Tabela 5: Composição dos diferentes eletrólitos a base de agar com PEDOT:PSS preparados

\begin{tabular}{|c|c|c|c|c|}
\hline Eletrólito & $\begin{array}{c}\text { Ácido } \\
\text { acético }(\mathrm{g})\end{array}$ & $\begin{array}{c}\mathrm{LiClO}_{4} \\
(\mathrm{~g})\end{array}$ & Glicerol (g) & $\begin{array}{c}\text { PEDOT:PSS } \\
(\mathrm{g})\end{array}$ \\
\hline A & & 0,1 & 0,3 & 0,3 \\
\hline B & - & 0,2 & 0 & 0,5 \\
\hline C & - & 0,2 & 0,2 & 0,5 \\
\hline D & - & 0,2 & 0,3 & 0,4 \\
\hline E & - & 0,2 & 0,3 & 0,3 \\
\hline F & - & 0,3 & 0,3 & 0,3 \\
\hline G & - & 0,4 & 0,3 & 0,3 \\
\hline H & - & 0,5 & 0,3 & 0,3 \\
\hline I & 1,0 & - & 0,3 & 0,3 \\
\hline J & 1,0 & - & 0,5 & 0,5 \\
\hline K & 1,5 & - & 0,3 & 0,3 \\
\hline L & 1,5 & - & 0,5 & 0,5 \\
\hline
\end{tabular}




\section{1 - Espectroscopia de Impedância Eletroquímica (EIE)}

Como já foi discutido anteriormente, foram preparados filmes a base de agar com diferentes composições (Tabela 5), as amostras foram submetidas à medidas de condutividade iônica à temperatura ambiente, para estudar qual a melhor composição para obtenção de eletrólitos poliméricos. As Figuras 55 e 56 apresentam os valores de log da condutividade para os filmes em que foi adicionado $\mathrm{LiClO}_{4}$ como fonte de íons, e a Figura 57 apresenta os valores de log da condutividade para os filmes em que foi adicionado ácido acético como fonte de prótons.

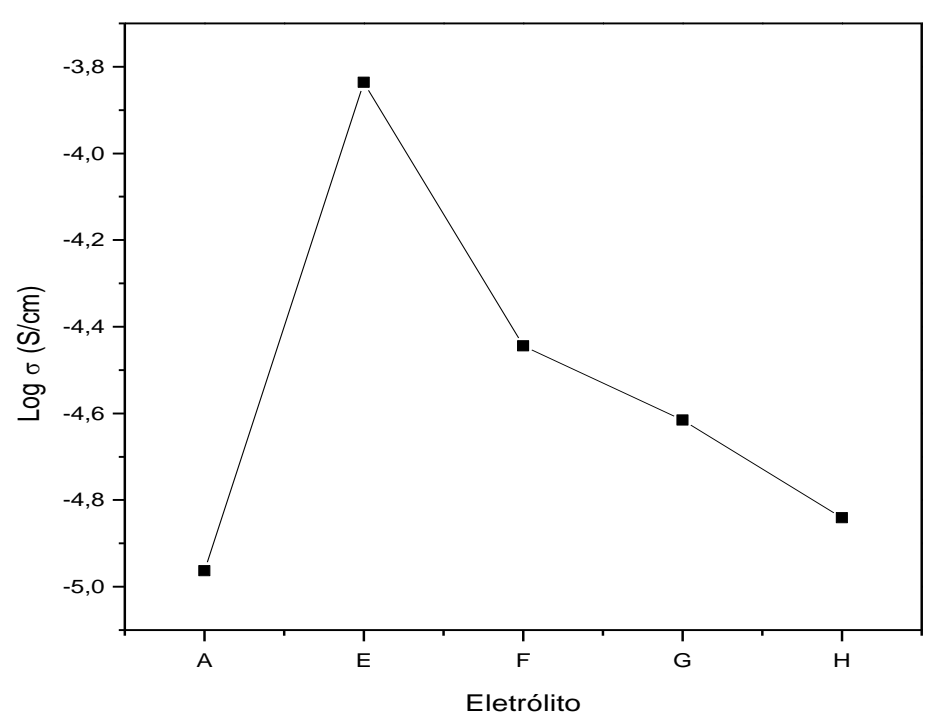

Figura 55 - Log $\sigma$ para os eletrólitos a base de agar com PEDOT:PSS com diferentes quantidades de $\mathrm{LiClO}_{4}$.

Os resultados da Figura 55 revelam que o eletrólito E (Tabela 5), onde foi adicionado 0,2 $\mathrm{g}$ de $\mathrm{LiClO}_{4}$ ao sistema, apresentou o melhor valor de condutividade iônica. Com base nesse resultado, em sequência ao trabalho, fez-se o estudo da condutividade iônica, variando-se as quantidades de glicerol e de PEDOT:PSS nos diferentes eletrólitos (Tabela 5) e mantendo-se fixa a quantidade de $\mathrm{LiClO}_{4}$ (Figura $56)$. 


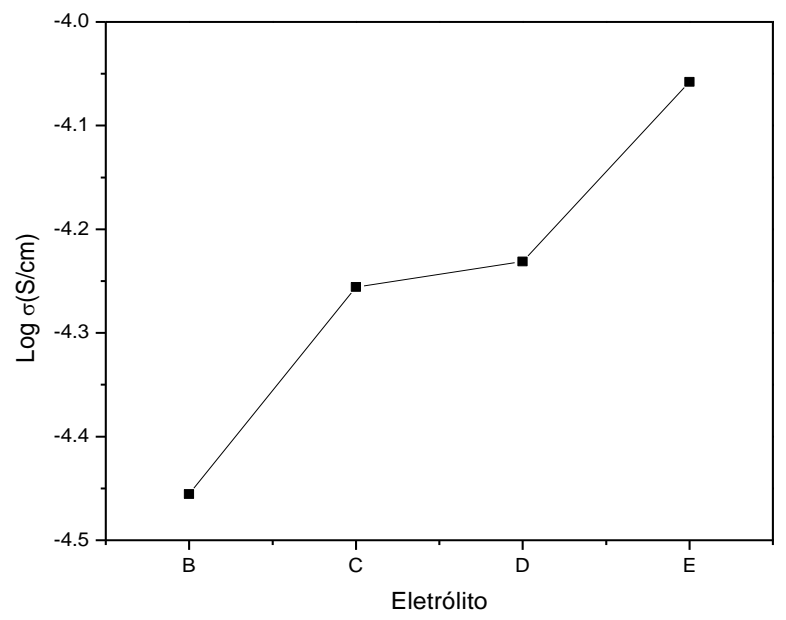

Figura 56 - Log $\sigma$ para os eletrólitos a base de agar com PEDOT:PSS e com quantidade fixa de $\mathrm{LiClO}_{4}$.

Através da Figura 56 pode-se verificar que a amostra que apresentou melhor condutividade iônica foi o eletrólito E (Tabela 5), o qual contem 0,3 g de glicerol e 0,3 g de PEDOT:PSS.

Também foi feito um estudo da condutividade iônica para sistemas utilizandose ácido acético como condutor protônico. Esses resultados podem ser observados na Figura 57 abaixo.

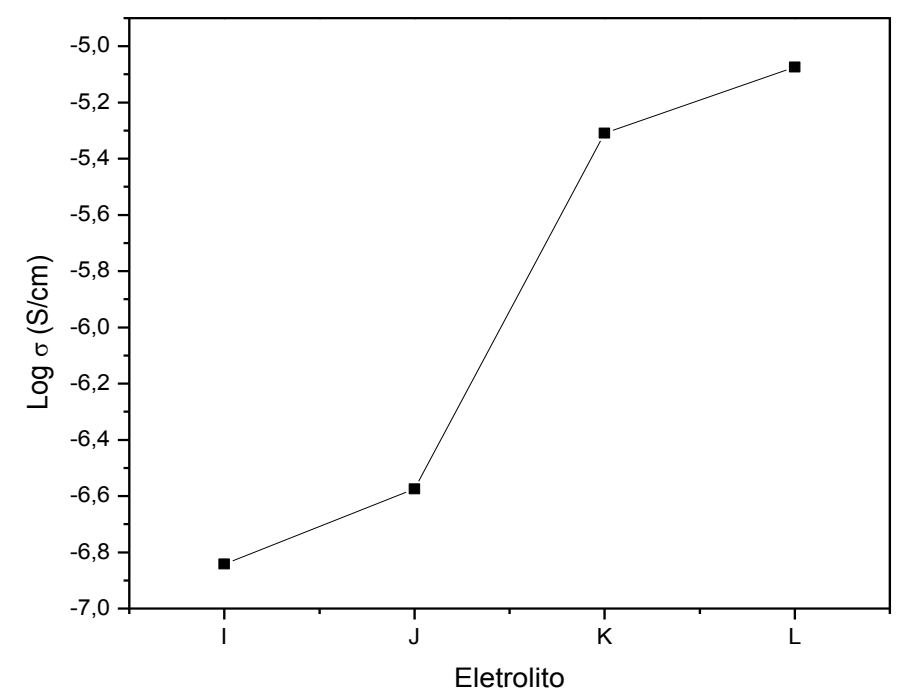

Figura 57 - Log $\sigma$ para os eletrólitos a base de agar com PEDOT:PSS e ácido acético.

As medidas de condutividade iônica para as diferentes amostras preparadas indicaram que a adição de PEDOT:PSS aos eletrólitos à base de agar melhora a condutividade no caso dos eletrólitos com $\mathrm{LiClO}_{4}$ em relação aos eletrólitos somente 
a base de agar. Entretanto, no caso dos eletrólitos com ácido acético a adição de PEDOT:PSS não favoreceu aumento de condutividade, pelo contrário, ocorreu diminuição na ordem de uma casa de grandeza.

A Figura 58 apresenta os resultados de condutividade iônica em função da temperatura para o eletrólito a base de agar com $\mathrm{LiClO}_{4}$ comparada ao eletrólito a base agar com $\mathrm{LiClO}_{4}$ e com adição de PEDOT:PSS. Pode se verificar que ocorreu aumento de quase uma ordem de grandeza da condutividade iônica sendo obtido os valores de $2,4 \times 10^{-5} \mathrm{~S} / \mathrm{cm}$ e $8,8 \times 10^{-5} \mathrm{~S} / \mathrm{cm}$, respectivamente, à temperatura ambiente.

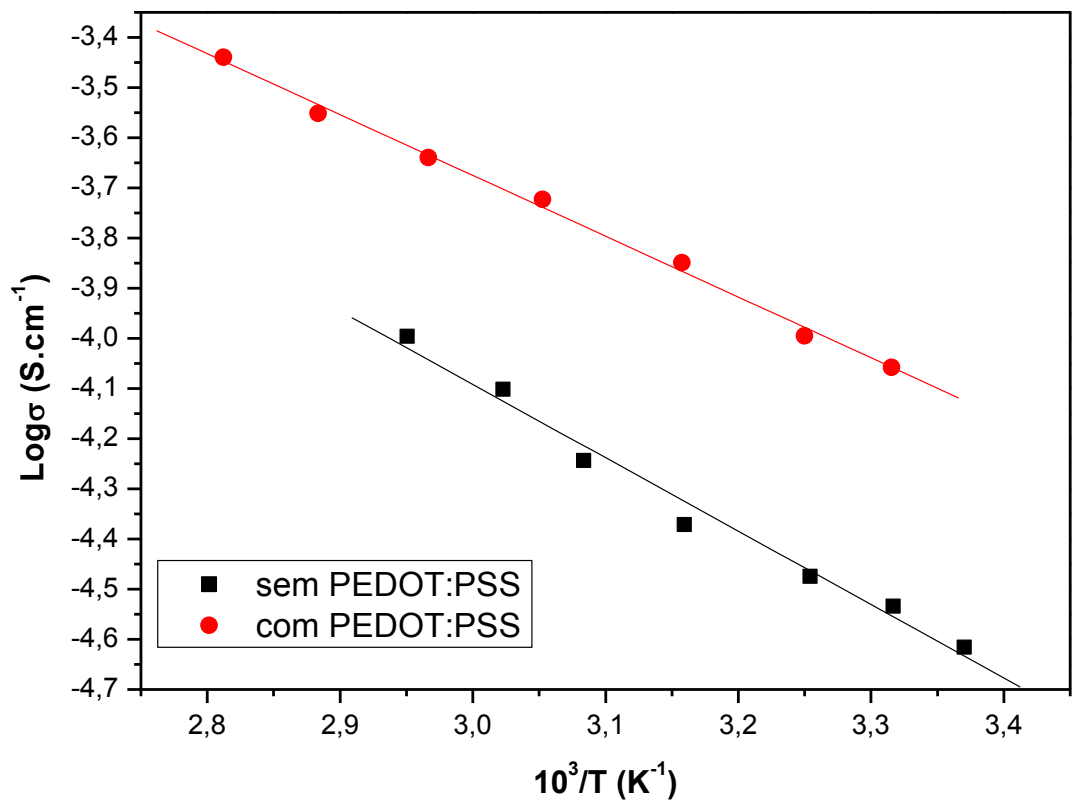

Figura 58 - Log da condutividade em função da temperatura para o eletrólito a base de agar, com e sem adição de PEDOT:PSS, ambos contendo $0,2 \mathrm{~g}$ de $\mathrm{LiClO}_{4}$.

A Figura 58 revela um mecanismo de condução do tipo Arrhenius para as amostras analisadas, onde não há participação de movimentos da cadeia polimérica no transporte de cargas. Nesse caso, apenas ocorre o movimento dos cátions por saltos entre os sítios de complexação, sendo denominado como mecanismo veicular ${ }^{8,9}$. Os dados da Figura 58 estão em concordância com a equação de Arrhenius (1). 
$\sigma=\mathrm{A} \exp (-\mathrm{Ea} / \mathrm{RT})$

Obtendo-se o coeficiente angular das retas apresentadas nos gráficos de condutividade (Figura 58), determinou-se a energia de ativação para cada amostra, cujos valores estão apresentados na Tabela 6, abaixo. Os valores encontrados para a energia de ativação estão relacionados diretamente com a condutividade iônica, nesse caso pode-se constatar que a adição de PEDOT:PSS contribuiu para o aumento da condutividade, e a conseqüente diminuição nas barreiras de energia para condução nessas amostras.

Tabela 6: Valores de condutividades e energia de ativação para os eletrólitos a base de agar e a base de agar com PEDOT:PSS, ambos contendo 2,0g de $\mathrm{LiClO}_{4}$

\begin{tabular}{|c|c|c|c|}
\hline $\begin{array}{c}\text { Eletrólito (contendo } \\
\left.0,2 \mathrm{LiClO}_{4}\right)\end{array}$ & $\begin{array}{c}\text { Condutividade iônica a } \\
\text { temperatura ambiente }(\mathrm{S} / \mathrm{cm})\end{array}$ & $\begin{array}{c}\text { Condutividade iônica } \\
\text { a } 65^{\circ} \mathrm{C}(\mathrm{S} / \mathrm{cm})\end{array}$ & $\begin{array}{c}\text { Energia de } \\
\text { Ativação }(\mathrm{kJ} / \mathrm{mol})\end{array}$ \\
\hline Agar & $2,4 \times 10^{-5}$ & $1,0 \times 10^{-4}$ & 23,3 \\
\hline Agar com & $8,8 \times 10^{-5}$ & $2,3 \times 10^{-4}$ & 28,2 \\
PEDOT:PSS & & & \\
\hline
\end{tabular}

A Figura 59 apresenta os resultados de condutividade iônica em função da temperatura para o eletrólito a base de agar com ácido acético comparada ao eletrólito a base agar com ácido acético e com adição de PEDOT:PSS. Pode se verificar que ocorreu diminuição da condutividade iônica em mais de uma ordem de grandeza sendo obtido os valores de $1,1 \times 10^{-4} \mathrm{~S} / \mathrm{cm}$ e $4,9 \times 10^{-6} \mathrm{~S} / \mathrm{cm}$, respectivamente, à temperatura ambiente. 


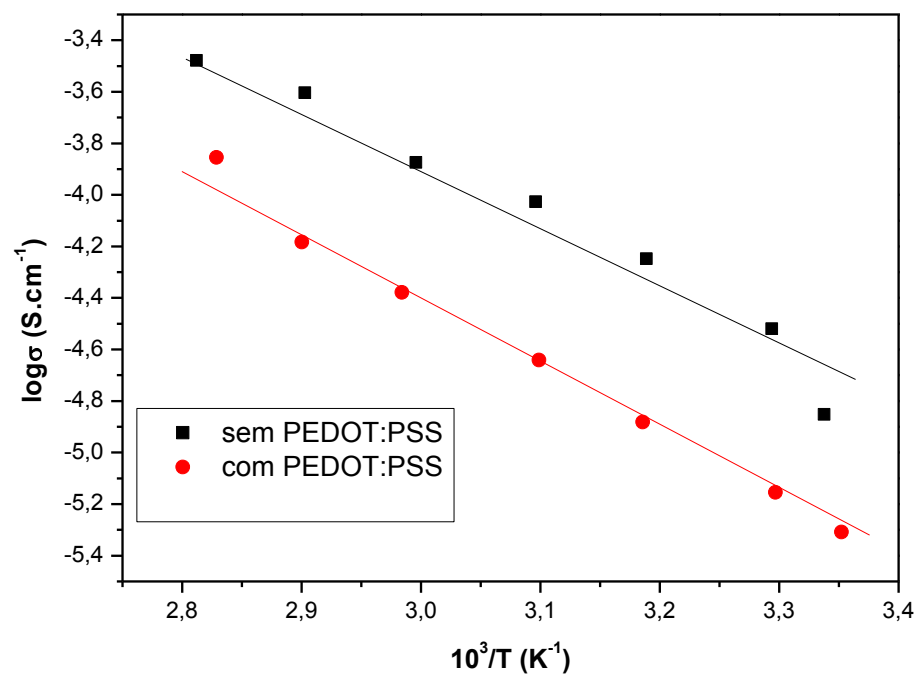

Figura 59 - Log da condutividade em função da temperatura para o eletrólito a base de agar, com e sem adição de PEDOT:PSS, ambos contendo 1,5g de ácido acetico.

A Figura 59 também revela um mecanismo de condução do tipo Arrhenius para as amostras analisadas, onde, obtendo-se o coeficiente angular das retas determinou-se a energia de ativação para cada amostra, cujos valores estão apresentados na Tabela 7, abaixo. Os valores encontrados para a energia de ativação estão relacionados diretamente com a condutividade iônica. Nesse caso pode-se constatar que a adição de PEDOT:PSS não contribuiu para o aumento da condutividade, ao contrário do esperado. Observou-se diminuição da condutividade iônica com a adição de PEDOT:PSS aos eletrólitos a base de agar plastificados com glicerol e contendo ácido acético, ocorrendo também, conseqüente aumento nas barreiras de energia para condução nessas amostras.

Tabela 7: Valores de condutividades e energia de ativação para os eletrólitos a base de agar e a base de agar com PEDOT:PSS, ambos contendo 1,5g de ácido acético

\begin{tabular}{|c|c|c|c|}
\hline $\begin{array}{c}\text { Eletrólito (contendo } \\
1,5 \mathrm{~g} \text { ácido acético) }\end{array}$ & $\begin{array}{c}\text { Condutividade iônica a } \\
\text { temperatura ambiente }(\mathrm{S} / \mathrm{cm})\end{array}$ & $\begin{array}{c}\text { Condutividade iônica } \\
\mathrm{a} 65^{\circ} \mathrm{C}(\mathrm{S} / \mathrm{cm})\end{array}$ & $\begin{array}{c}\text { Energia de } \\
\text { Ativação }(\mathrm{kJ} / \mathrm{mol})\end{array}$ \\
\hline Agar & $1,1 \times 10^{-4}$ & $9,6 \times 10^{-4}$ & 46,88 \\
\hline $\begin{array}{c}\text { Agar com } \\
\text { PEDOT:PSS }\end{array}$ & $4,9 \times 10^{-6}$ & $1,4 \times 10^{-4}$ & 50,62 \\
\hline
\end{tabular}




\section{2 - Análise Termogravimétrica (TG)}

Os filmes preparados a base do agar, com adição de $\mathrm{LiClO}_{4}$ ou ácido acético e com a adição de PEDOT:PSS foram submetidos às análises termogravimétricas, cujos, resultados são mostrados nas Figuras 60 e 61 . Através da termogravimetria pode-se verificar a estabilidade térmica das amostras.

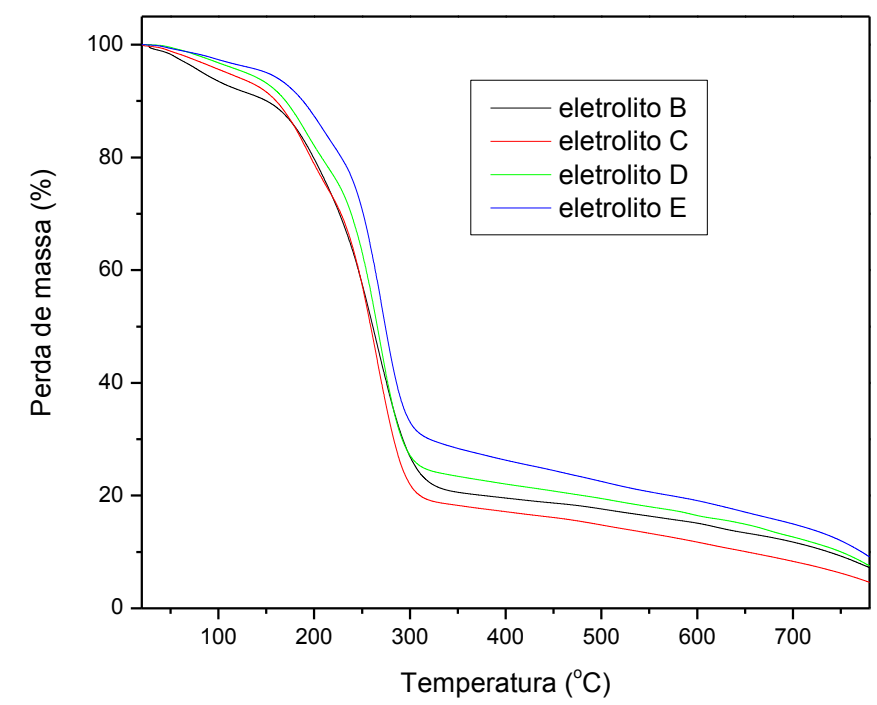

Figura 60 - Curvas de TG dos filmes contendo $\mathrm{LiClO}_{4}$ e diferentes quantidades de glicerol e PEDOT:PSS.

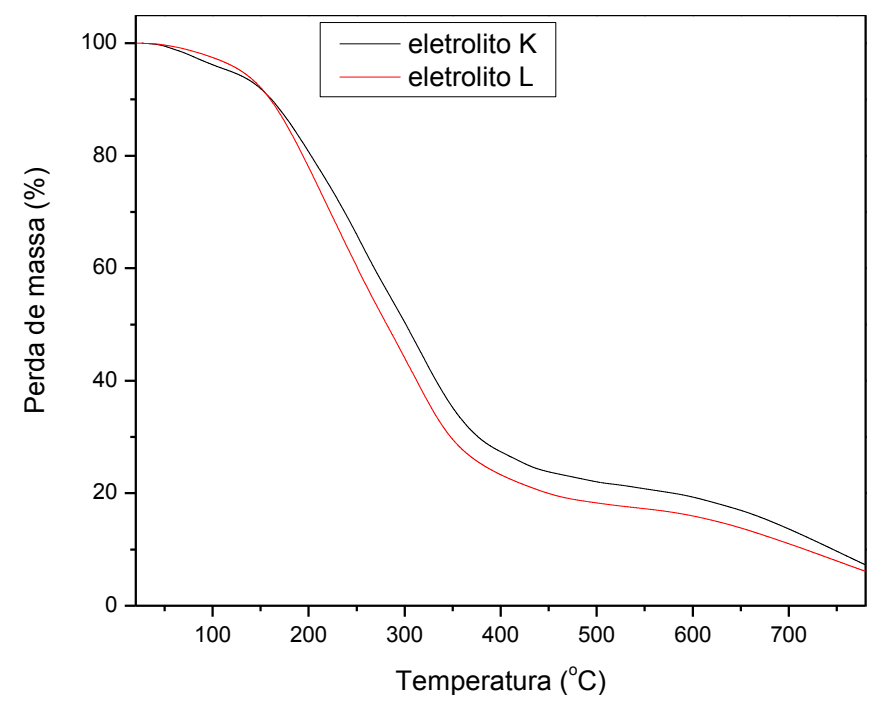

Figura 61 - Curvas de TG dos filmes contendo ácido acético e diferentes quantidades de glicerol e PEDOT:PSS. 
Ao analisar as curvas de TG das diferentes amostras percebe-se inicialmente, que todas apresentam uma perda de massa inicial entre 5 e $8 \%$ até a temperatura de $100^{\circ} \mathrm{C}$, perda essa atribuída à presença de umidade residual. Também, esse resultado é similar aos resultados encontrados para as blendas, tanto contendo somente agar, quanto contendo agar e outras macromoléculas, apresentadas e discutidas anteriormente. Em temperaturas maiores, na faixa de 190 a $230^{\circ} \mathrm{C}$ a perda de massa que ocorre nesta etapa pode ser atribuída ao início da decomposição do eletrólito. A região de temperatura superior a $230^{\circ} \mathrm{C}$ até a formação do resíduo a $400^{\circ} \mathrm{C}$ corresponde à etapa principal da decomposição. Nesse intervalo ocorre grande perda de massa, da ordem de $70 \%$, em uma única etapa. Do ponto de vista molecular, durante esse estágio ocorre a ruptura aleatória das cadeias, provocando liberação de componentes de baixa massa molar que se vaporizam, levando à perda de massa observada via $\mathrm{TG}^{5}$. Com base nesses resultados, pode-se dizer que todos os eletrólitos preparados são muito estáveis térmicamente, e que a adição de PEDOT:PSS não influenciou na temperatura de degradação das amostras.

\section{3 - Difração de Raios-X}

Com já foi discutido anteriormente, o agar é um polímero semicristalino constituído de grânulos e que o processo de plastificação resulta em filmes de agar com predominância do estado amorfo ${ }^{5-7}$. As fases amorfa e cristalinas podem ser observadas nos difratogramas de raios-X, apresentados nas Figuras 62 e 63, e obtidos para os eletrólitos a base de agar contendo diferentes quantidades de PEDOT:PSS (Tabela 5) com $\mathrm{LiClO}_{4}$ (Figura 62) ou ácido acético (Figura 63). 


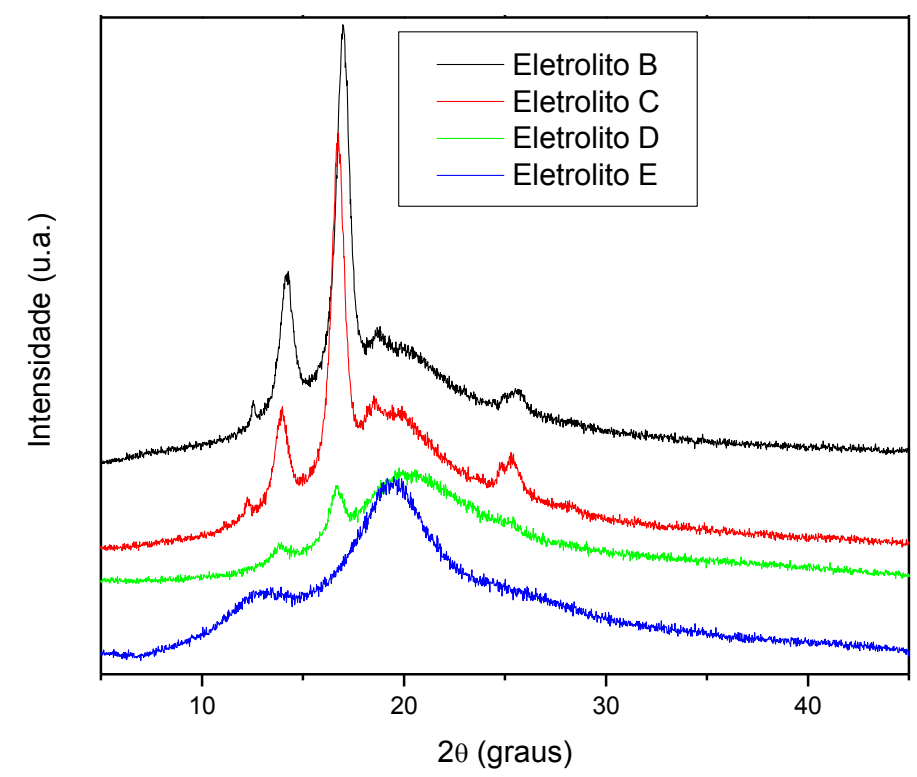

Figura 62- Difração de raios-X de filmes contendo diferentes quantidades de $\mathrm{LiClO}_{4}$.

Foi verificado nos capítulos anteriores que os eletrólitos com $\mathrm{LiClO}_{4}$ e plastificados com glicerol apresentam bandas difusas, largas e centradas em aproximadamente $2 \theta=22^{\circ}$ com um pequeno ombro em $2 \theta=13^{\circ}$. A adição de plastificantes assegura o caráter amorfo das amostras, no entanto para as amostras com adição de PEDOT:PSS pode-se verificar, em alguns casos, que o pequeno ombro em $2 \theta=13^{\circ}$ aparece como um pico com intensidade elevada e mais estreito, indicando a presença das regiões cristalinas (Figura 62). Outra mudança observada é o aparecimento de um pico em $2 \theta=16^{\circ}$ que decresce com a diminuição da concentração de PEDOT:PSS nas amostras. Isso indica que a adição de PEDOT:PSS em eletrólitos a base de agar contendo $\mathrm{LiClO}_{4}$ prejudica o processo de sua plastificação pelo glicerol, favorecendo, na consequencia, a sua cristalização ${ }^{1}$. Embora com a adição do PEDOT:PSS ocorre o rearranjo das cadeias lineares para diminuir a energia livre do sistema, ocasionando formação de regiões com mais cristalinidade, o sistema como todo ainda apresenta bons resultados de condutividade. Entretanto, os heteroátomos provenientes dos dois polímeros (PEDOT e PSS) e presentes em maior número nessas amostras, podem atuar como 
complexadores dos íons de lítio levando ao aumento de rearranjos macromoleculares. Ao diminuir a concentração de PEDOT:PSS, observa-se a diminuição gradual desta cristalização até que na quantidade de $0,2 \mathrm{~g}$ de PEDOT:PSS o processo de plastificação pelo glicerol ocorre normalmente levando a obtenção de um filme predominantemente amorfo.

No caso de amostras contendo ácido acético (Figura 63), os resultados de difração de raios-X mostraram-se mais parecidos aos resultados obtidos com as amostras condutoras iônicas a base de polímeros e macromoléculas naturais, i.e., com uma banda larga e centrada em $2 \theta=21^{\circ}$. Esses resultados indicam a predominância do estado amorfo na amostra, e comprovam que ocorre interação mais forte do $\mathrm{LiClO}_{4}$ para com o sistema do que do $\mathrm{CH}_{3} \mathrm{COOH}$ nas amostras a base de agar e contendo PEDOT:PSS.

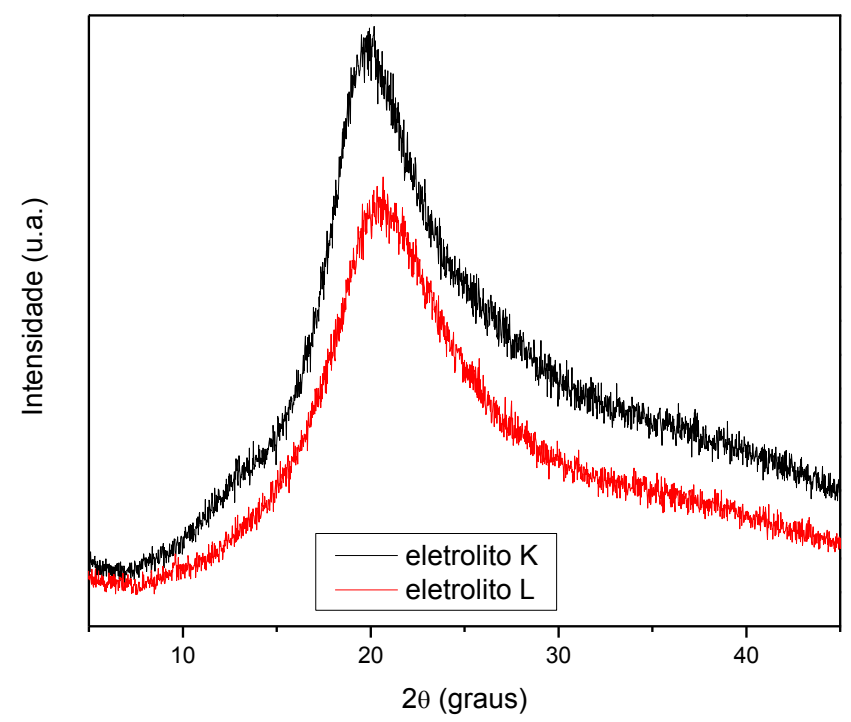

Figura 63 - Difração de raios-X de filmes contendo diferentes quantidades de ácido acético.

\section{4 - Calorimetria Diferencial de Varredura (DSC)}

Foi realizada análise térmica (DSC) para o eletrólito $E$ (Tabela 5), o qual apresentou a melhor condutividade iônica. O gráfico da Figura 64 mostra resultados 
dessa análise, onde se verifica uma mudança na linha de base, típica de transição vítrea $\left(\mathrm{T}_{\mathrm{g}}\right)$ em $-60^{\circ} \mathrm{C}$.

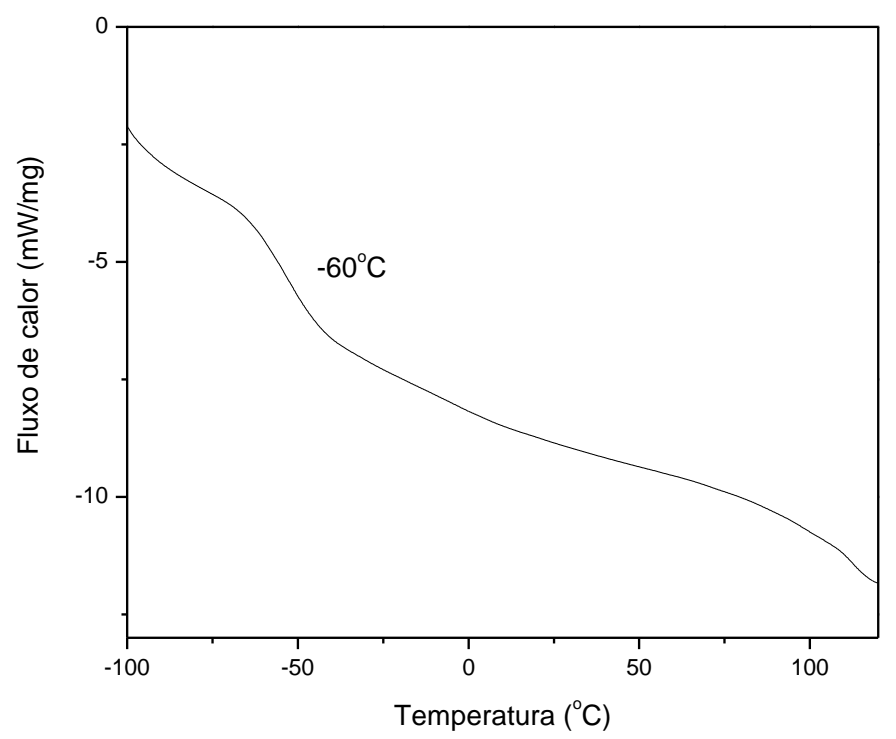

Figura 64 - Curva de DSC do eletrólito a base de agar com $\mathrm{LiClO}_{4}$ e PEDOT:PSS.

Como pode ser observado na Figura 64, ocorreu mudança na linha de base em torno de $-60^{\circ} \mathrm{C}$, mudança esta referente à movimentação das cadeias poliméricas e que influência os valores da condutividade iônica, desta forma a transição vítrea obtida em temperatura sub ambiente é similar a outros eletrólitos a base de polímeros naturais ${ }^{5-11}$. Também pode-se relacionar esse valor de baixa $T_{g}$ devido a esta composição de eletrólito ter apresentado difratograma de material predominantemente amorfo (Figura 62).

\section{5 - Microscopia Eletrônica de Varredura (MEV)}

Ao observar as micrografias dos filmes preparados (Figura 65) nota-se que nem todos os filmes apresentaram uma superfície homogênea. As imagens dos filmes com $\mathrm{LiClO}_{4}$ onde adicionou-se maior quantidade de PEDOT:PSS evidenciam pequenas rachaduras superficiais (Figura 65 a e b). Ao se fazer uma comparação 
com os resultados de difração de raios- $X$, nestes filmes é possível constatar que ocorreu cristalização parcial das amostras. Por causa disso, pode-se dizer que nos filmes com quantidade superiores a 0,4g de PEDOT:PSS não ocorre uma boa compatibilização com o agar e $\mathrm{LiClO}_{4}$. No caso dos filmes a base de agar e ácido acético (Figura 65 c), foi observada superfície homogênea para todas amostras, independente da quantidade de PEDOT:PSS adicionada.

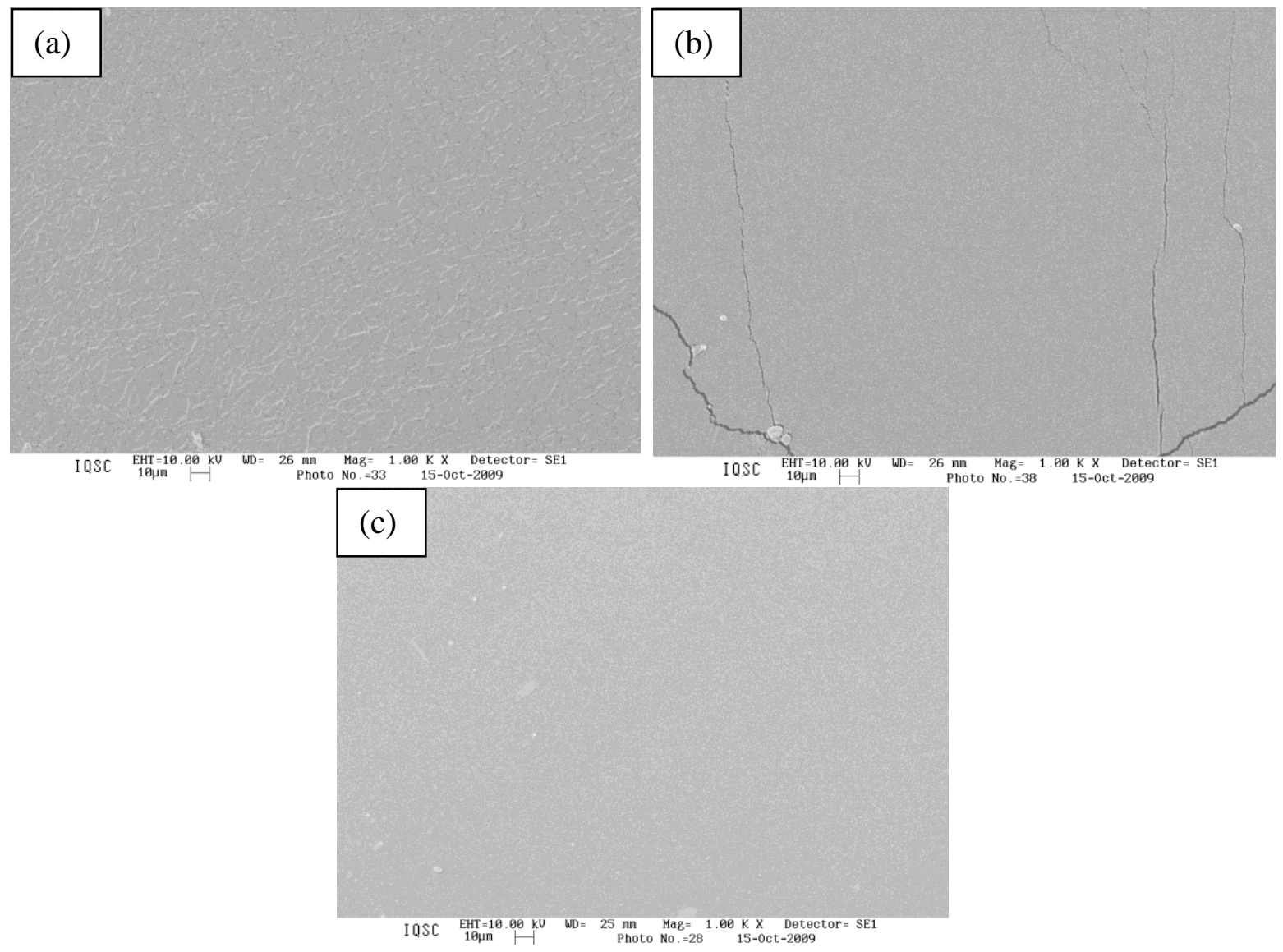

Figura 65 - Micrografias dos filmes de agar com diferentes quantidades de ácido acético, ou $\mathrm{LiClO}_{4}$, ampliadas 1000x: (a) eletrólito C , (b) eletrólito E, (c) eletrólito K.

\section{6 - Espectroscopia no Ultravioleta-Visível (UV-vis)}

Como pode ser observado na Figura 66, as amostras obtidas com a adição do sistema PEDOT:PSS não apresentaram boa transparência (17\% em 550 nm) na 
região do visível. Contudo, observa-se nessa figura uma pequena diferença entre no intervalo onde a transmitância começa aumentar. No caso da amostra a base de agar e contendo PEDOT:PSS e ácido acético a transmitância é zero até $240 \mathrm{~nm}$ onde começa subir até atingir seu valor máximo de $20 \%$ em $400 \mathrm{~nm}$. A amostra contendo perclorato de lítio apresenta um comportamento parecido, contudo a sua transmitância permanece zero até quase $300 \mathrm{~nm}$ e atinge seu máximo de 18\% em $450 \mathrm{~nm}$. Portanto, há um deslocamento de aproximadamente $50 \mathrm{~nm}$ nos valores de transmitância entre as duas amostras, o fato já observado no caso das blendas de agar com gelatina. Isso também indica que a adição de sal promove mudanças estruturais na amostra promovendo maior organização de suas cadeias e com isso mudança nas propriedades de transmissão na região UV. Os resultados obtidos nesse ensaio também corroboram com os resultados de difração de raios-X e de microscopia eletrônica de varredura.

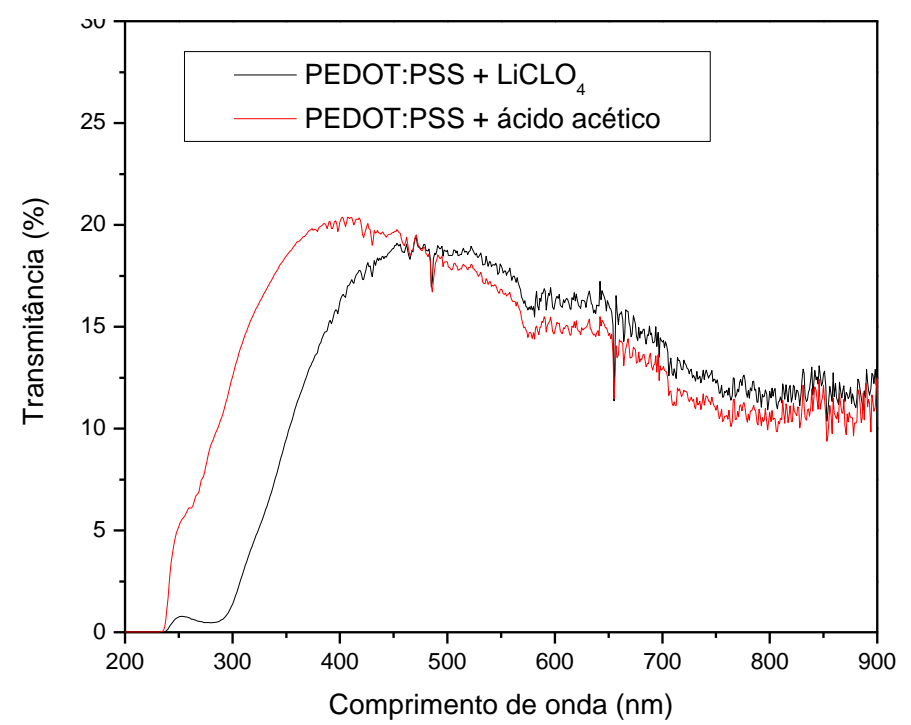

Figura 66 - Espectros de UV-vis para eletrólitos a base de agar com adição de PEDOT:PSS com ácido acético e com $\mathrm{LiClO}_{4}$.

Com esses resultados os filmes apresentados aqui não podem ser considerados transparentes na região visível (transmitância de aproximadamente 17\% na região do visível e IV próximo). A transparência dos filmes é de grande 
importância para a possível utilização destes eletrólitos em dispositivos eletrocrômicos, como janelas eletrocrômicas, por isso não é indicada a utilização deste tipo de eletrólito em janelas eletrocrômicas. No entanto, devido aos ótimos valores de condutividade apresentados, os mesmos podem ser estudados para outras aplicações, como por exemplo, em células solares, baterias, sensores, etc.

\section{7 - Conclusões do Capítulo}

Foram preparados e caracterizados novos eletrólitos poliméricos a base de blendas de agar com um sistema polimérico altamente condutor, PEDOT:PSS. Foi feito inicialmente um estudo da condutividade de diferentes composições de filmes preparados utilizando-se $\mathrm{LiClO}_{4}$ ou ácido acético como fonte de íons. Através das medidas de condutividade iônica pode-se constatar que a melhor composição de eletrólito é contendo $0,5 \mathrm{~g}$ de agar; $0,5 \mathrm{~g}$ de formaldeído, $0,2 \mathrm{~g}$ de $\mathrm{LiClO}_{4}, 0,3 \mathrm{~g}$ de glicerol e 0,3g de PEDOT:PSS, onde foi obtida condutividade iônica de $8,8 \times 10^{-5}$ S/cm à temperatura ambiente. Para comparação o mesmo eletrólito, mas, sem adição do sistema PEDOT:PSS foi de $2,42 \times 10^{-5} \mathrm{~S} / \mathrm{cm}$. Além do aumento dos valores de condutividade iônica, pode-se observar uma diminuição na energia de ativação do sistema, ou seja, foram diminuídas as barreiras energéticas de condução iônica para esse tipo de eletrólito polimérico, em relação ao eletrólito a base de agar com $\mathrm{LiClO}_{4}$. No caso de eletrólitos com adição de ácido acético como fonte de prótons, ocorreu o contrário do que se esperava, ou seja, houve uma diminuição de cerca de uma ordem de grandeza na condutividade iônica, para os sistemas onde foi adicionado PEDOT:PSS.

As amostras preparadas apresentaram ótima estabilidade térmica, que foi comprovada através de análise termogravimétrica. As medidas de difração de raios- 
$\mathrm{X}$ revelaram que a adição do sistema PEDOT:PSS aos eletrólitos interfere no processo de plastificação do agar pelo glicerol, formando um sistema mais ordenado de cadeias lineares, de forma que com aumento da concentração deste sistema polimérico nos eletrólitos, aumenta a cristalinidade das amostras. As análises confirmaram que as amostras são predominantemente amorfas quando se diminui consideravelmente a quantidade de PEDOT:PSS. As micrografias (MEV) mostram que os filmes preparados possuem uma superfície homogênea e uniforme, indicando que ocorreu boa compatibilização entre o sistema estudado, no entanto nas amostras onde foi observado aumento de cristalinidade ocorreram algumas pequenas rachaduras superficiais. As membranas obtidas apresentaram transparência de 17\%, indicando que não são transparentes na região do visível, ou seja não são adequadas para serem aplicadas em dispositivos eletrocrômicos. Desta forma é proposto que o material seja melhor estudado para utilização em outros sistemas eletrônicos, como, por exemplo, células solares ou baterias.

\section{Referências Bibliográficas}

[1] SILVA, F. A. R.; CESCHIN, A. M.; SALES, M. J. A.; SILVA, L. M.; VIANA, C.E.; KDP/PEDOT:KSS mixture as a new alternative in the fabrication of pressure sensing devices. Applied Surface Science, v. 255, p. 734 - 736, 2008.

[2] ZHANA, L.; SONGA, Z.; ZHANGA, J.; TANGA, J.; ZHANA, H.; ZHOUA, Y.; ZHAN, C. PEDOT: Cathode active material with high specific capacity in novel electrolyte system. Electrochimica Acta, v. 53, p. 8319 - 8323, 2008.

[3] XIE, F. X.; LIANG, C. J.; HE, Z. Q.; TAO, Y. L. Polymer Photovoltaic Cell Using TiO2/G-PEDOT Nanocomplex Film as Electrode International. Journal of

Photoenergy, v. 2008, p. 1 - 6, 2008. 
[4] KIM, J. Y.; JUNG, J. H.; LEE, D. E.; JOO, J. Enhancement of electrical conductivity of poly(3,4-ethylenedioxythiophene)/poly(4-styrenesulfonate) by a change of solvents. Synthetic Metals, v. 126, n. 2 - 3, p. $311-316,2002$.

[5] LAI, S. L.; CHAN, M. Y.; FUNG, M. K.; LEE C. S., LEE S. T., Concentration effect of glycerol on the conductivity of PEDOT film and the device performance. Materials Science and Engineering B, v. 104, n. 1 - 2, p. 26 -30, 2003.

[6] DRAGUNSKI, D. C. Preparação de eletrólitos sólidos poliméricos a partir do amido. 2003. 163f. Tese (Doutorado) - Instituto de Química de São Carlos, Universidade de São Paulo, São Carlos, 2003.

[7] VIEIRA, D.; AVELLANEDA, C.; PAWLICKA, A. Conductivity study of a gelatinbased polymer electrolyte. Electrochimica Acta, v. 53, n. 4, p. 1404 -1408, 2007.

[8] KREUER, K. D. Proton conductivity: Materials and applications. Chemical Materials, v. 8, p. $610-641,1996$.

[9] RAPHAEL, E.; AVELLANEDA, C. O.; MANZOLLI, B.; PAWLICKA, A. Agar-based films for application as polymer electrolytes. Electrochimica Acta, v. 55, p. 14551459, 2009.

[10] MACHADO, G.; FERREIRA, H.; PAWLICKA, A. Influence of plasticizer contents on the properties of HEC-based solid polymeric electrolytes. Electrochimica Acta, v. 50, p. 3827 - 3831, 2005.

[11] REGIANI, A.; TAMBELLI, C. E.; PAWLICKA, A.; CURVELO, A. A. S.; GANDINI, A.; LENEST, J. F.; DONOSO, J. P. DSC and solid state NMR.characterization of hydroxyethylcellulose/polyether films. Polymer International, v. 49, p. 960 - 964, 2000.

[12] OLIVEIRA, S. C; TORRESI, R. M. Uma visão das tendências e perspectivas em eletrocromismo: a busca de novo materiais e desenhos mais simples. Química Nova, v. 23, n. 1, p. 79-87, 2000.

[13] COLONNA, P.; BULEON, A.; MERCIER, C. Physically modified starches. In: STARCH: Properties and Potencial. Great Brintain: Society of Chemical Industry, 1987. p. 79. 
[14] MORITA, M.; ARAKI, F.; KASHIWAMURA, K.; YOSHIMOTO, N.; ISHIKAWA, M. lonic structure and conductance behavior of plasticized polymeric electrolytes containing multivalent cations. Electrochimica Acta, v. 45, n. 8 - 9, p. 1335 - 1340, 2000.

[15] KIM, Y. T.; SMOTKIN, E. S. The effect of plasticizers on transport and electrochemical properties of PEO-based electrolytes for lithium rechargeable batteries. Solid State Ionics, v. 149, p. 29 - 37, 2002.

[16] BASKARAM, R.; SELVASEKARAPANDIAN, S.; KUWATA, N.; KAWAMURA, J.; HATTORI, T. AC impedance, DSC and FT-IR investigations on (x)PVAc- $(1-x)$ PVdF blends with LiClO4. Material Chemical Physics, v. 98, p. 155, 2004.

[17] ] HIRANKUMAR, G.; SELVASEKARAPANDIAN, S.; BHUVANESWARI, M. S.; BASKARAN, R.; VIJAYAKUMAR, M. Ag+ ion transport studies in a polyvinyl alcoholbased polymer electrolyte system. Journal of Solid State Electrochemistry, v. 10, n. 4, p. 193-197, 2006.

[18] RATNER, M. A.; NITZAN, A. Conductivity in polymer ionics - Dynamic disorder and correlation. Faraday Discussions, v. 88, p. 19, 1989.

[19] REDDY, J. M.; SREEKANTH, T.; SUBBA RAO, U. V. Study of the plasticizer effect on a (PEO+NaYF4) polymer electrolyte and its use in an electrochemical cell. Solid State Ionics, v. 126, p. 55, 1999.

[20] SUBBA REDDY, Ch.V.; SHARMA, A.; NARASIMHA, K.; RAO, V.V.R. Dielectric spectroscopy studies on (PVP + PVA) polyblend film. Journal of Power Sources, v. 114, p. 338, 2003.

[21] HIRANKUMAR, G.; SELVASEKARAPANDIAN, S.; BHUVANESWARI, M. S.; BASKARAN, R.; VIJAYAKUMAR, M. Ag+ ion transport studies in a polyvinyl alcoholbased polymer electrolyte system. Journal of Solid State Electrochemistry, v. 10, n. 4, p. 193-197, 2006. 


\section{CAPÍTULO 9 - CONCLUSÕES FINAIS}

Foram preparados e caracterizados novos eletrólitos poliméricos a base de agar, contendo ácido acético ou $\mathrm{LiClO}_{4}$, blendas de agar com quitosana e com gelatina e também eletrólitos a base de agar com PEDOT:PSS. Modificações físicoquímicas foram efetuadas no agar através da adição de plastificantes, como o glicerol, bem como de formaldeído (para promover o entrecruzamento do material e a formação dos filmes).

Os resultados obtidos revelaram que as membranas apresentaram-se, em sua maioria, homogêneas, com estabilidade térmica até $200^{\circ} \mathrm{C}$ e com a estrutura predominantemente amorfa, com valores de temperatura de transição vítrea em torno de $-70{ }^{\circ} \mathrm{C}$ e transparência no visível de $90 \%$, exceto nas amostras com adição de PEDOT:PSS, onde a transmitância obtida foi na ordem de 17\%. O manuseio das amostras obtidas revelou boa maleabilidade e aderência ao vidro.

Os valores de condutividade iônica das membranas variaram entre $1.0 \times 10^{-6}$ $\mathrm{Scm}^{-1}$ e $1.1 \times 10^{-4} \mathrm{Scm}^{-1}$ dependendo da quantidade de ácido ou sal de lítio adicionado. Estes estudos revelaram que a concentração de ácido acético ou sal de lítio influencia a condutividade iônica do eletrólito e os melhores valores foram obtidos para adição de $50 \%$ em peso de ácido acético: $1,4 \times 10^{-5} \mathrm{~S} / \mathrm{cm}$ e de $17 \%$ em peso de $\mathrm{LiClO}_{4}: 1,6 \times 10^{-5} \mathrm{~S} / \mathrm{cm}$. Também foi verificado que o aumento da temperatura até $80^{\circ} \mathrm{C}$ promove o aumento da condutividade iônica para todas as amostras estudadas. Estes resultados mostram um comportamento VTF para os eletrólitos a base de agar com $\mathrm{LiClO}_{4}$ com uma energia de ativação de $\mathrm{Ea}=11$ $\mathrm{kJ} / \mathrm{mol}$, enquanto para todos os outros eletrólitos foi observado um comportamento 
do tipo Arrhenius, onde as energias de ativação obtidas foram: eletrólito a base de agar com ácido acético: $\mathrm{Ea}=49 \mathrm{~kJ} / \mathrm{mol}$, eletrólito de blenda de agar com gelatina: $\mathrm{Ea}=42 \mathrm{~kJ} / \mathrm{mol}$, eletrólito de blenda de agar com quitosana: $\mathrm{Ea}=62 \mathrm{~kJ} / \mathrm{mol}$, eletrólito a base de agar com PEDOT:PSS contendo 0,2g de $\mathrm{LiClO}_{4}$ : $\mathrm{Ea}=23,3 \mathrm{~kJ} / \mathrm{mol}$. No caso das amostras onde foi adicionado PEDOT:PSS, os resultados de condutividade obtidos foram de $8,8 \times 10^{-5} \mathrm{~S} / \mathrm{cm}$ à temperatura ambiente, melhorando a condutividade na ordem de uma casa de grandeza em relação à amostras sem PEDOT:PSS, no entanto devido às amostras não apresentarem a transparência desejada para serem aplicadas em dispositivos eletrocrômicos, elas podem ser estudadas para outras aplicações, como por exemplo: células solares, sensores, baterias, etc..

Foi feito também um estudo preliminar, de aplicação dos melhores eletrólitos em ECDs com configuração: $\mathrm{WO}_{3} /$ eletrólito-agar $/ \mathrm{CeO}_{2}-\mathrm{TiO}_{2}$, os quais revelaram boas mudança de coloração entre o estado colorido e transparente na ordem 15$25 \%$, densidades de carga variando desde $5,4 \mathrm{mC} / \mathrm{cm}^{2}$ para o eletrólito a base de blenda de gelatina com agar até $11,4 \mathrm{mC} / \mathrm{cm}^{2}$ para o eletrólito a base de agar com $\mathrm{LiClO}_{4}$, os dispositivos com todos os eletrólitos apresentaram tempo de coloração de 15 segundos e descoloração de ordem de $2 \mathrm{~s}$.

Com base nesses resultados pode-se concluir que o agar representa um material de grande interesse na obtenção de eletrólitos poliméricos, tanto para condutores protônicos quanto condutores iônicos, e que o preparo de blendas a partir do agar com gelatina ou com quitosana também se mostraram promissoras a serem aplicadas em dispositivos eletrocrômicos. Os eletrólitos a base de agar com PEDOT:PSS embora não sejam adequados para aplicações em DECs, apresentaram excelentes resultados de condutividade iônica, o que os tornam 
excelentes candidatos ao preparo de eletrólitos poliméricos para outras aplicações tecnológicas. 